$$
\begin{array}{cc}
10 \\
\end{array}
$$

JORGE MIRA PÉREZ

COORDINADOR

\title{
¿Es nuestro huso horario un problema?
}

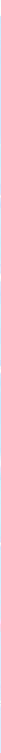




¿Es nuestro huso horario un problema? 
Edita

(c) CONSELLO DA CULTURA GALEGA, 2017

Pazo de Raxoi $\cdot 2^{0}$ andar - Praza do Obradoiro

15705 - Santiago de Compostela

T $981957202 \cdot F 981957205$

corre0@consellodacultura.gal

www.consellodacultura.gal

\section{Maquetación}

Mabel Aquayo, CB

Doi: 10.17075/enhhp.2017 


\section{JORGE MIRA PÉREZ COORDINADOR \\ ¿Es nuestro huso horario un problema?}


Presentación 


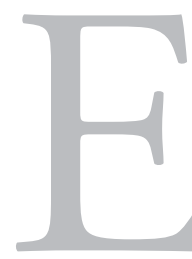

1 Consello da Cultura Galega es una institución autonómica de alto asesoramiento en los temas de interés cultural. Está compuesta por representantes de las principales organizaciones culturales de Galicia así como por personalidades destacadas en ese ámbito. Con más de treinta años de existencia, tiene ya una amplia experiencia en asesorar a través de informes solicitados o elaborados por propia iniciativa, así como a partir de congresos, simposios o estudios, sobre los asuntos del mayor interés cultural para la Comunidad Autónoma Gallega.

El debate público suscitado en los últimos tiempos sobre la conveniencia o no del cambio del huso horario en Galicia, en particular, y en España, en general, y su resolución en uno u otro sentido afecta a todos los niveles de la población, así como a sus hábitos y costumbres. No es, por lo tanto, un tema menor y sus consecuencias tienen un componente cultural indudable. Es por ello que el Consello consideró pertinente realizar a partir de su Sección de Ciencia, Natureza e Sociedade, en octubre del pasado año 2016, un debate, con defensores de una u otra postura, en relación con los cambios en el huso horario.

Conscientes del interés de este encuentro, tomó la decisión de publicar (en formato digital, en gallego y castellano) el presente libro basado en las ponencias presentadas en el mismo, deseando que su lectura y difusión contribuyan a favorecer un diálogo sereno y asentado, sobre todo, en el mejor conocimiento del que se dispone en la actualidad. Solo así se podrá caminar hacia fórmulas de convivencia que sean constructivas y de futuro.

\section{Francisco Díaz-Fierros Viqueira}

Coordinador de la Sección de Ciencia, Natureza e Sociedade

Consello da Cultura Galega 
Índice 


\section{PRESENTACIÓN}

Francisco Díaz-Fierros Viqueira

10 INTRODUCCIÓN

¿Arreglaría algo cambiar el huso horario oficial espańol?

Jorge Mira Pérez

13 NUESTRO HUSO HORARIO ES INOCENTE. INCONVENIENTES DE UN CAMBIO DE HUSO EN ESPAÑA

Jorge Mira Pérez

31 INNOVACIÓN SOCIAL: ANÁLISIS DE LOS BENEFICIOS DE LA RECUPERACIÓN DEL HUSO HORARIO QUE CORRESPONDE A ESPAÑA José María Fernández-Crehuet

57 HUSOS HORARIOS ESPAÑOLES: RACIONALIDAD FRENTE A LEYENDA José María Martín Olalla

85 HUSO HORARIO Y HÁBITOS SOCIALES

José Fernández-Albertos

103 CURRÍCULOS 


\section{Introducción \\ Jorge Mira Pérez}

Universidade de Santiago de Compostela 


\section{¿ARREGLARÍA ALGO CAMBIAR EL HUSO HORARIO OFICIAL ESPAÑOL?}

Un huso horario es cada una de las 24 franjas geográficas virtuales, orientadas de norte a sur, en las que se divide el planeta y que tienen una amplitud de 15 grados, que es el ángulo que rota la Tierra en una hora. Los relojes definidos por el mediodía de cada uno de estos husos son comparables entre sí y cada uno de ellos se construye sumando o restando un número entero de horas respecto del llamado Tiempo Universal Coordinado (UTC), que es el mantenido por relojes atómicos.

En la España peninsular, Baleares, Ceuta y Melilla la hora oficial es UTC+1, correspondiente al huso de Europa Central, como en casi toda Europa continental.

Una zona horaria es una región que comparte una misma hora oficial. Las zonas horarias no siguen fielmente los trazos meramente geográficos de los husos horarios, pues cada país ajusta su hora oficial libremente y, con frecuencia, no coinciden estrictamente con la convención geográfica. Así, lugares como Chile, Argentina, Francia, Bélgica, Holanda, Islandia, Alaska, Saskatchewan, Kazajistán, Georgia, Bielorrusia, Mauritania, Senegal, Gambia, Guinea-Bissau, Guinea, Sierra Leona, Liberia, Azerbaiyán o Armenia están en ese caso en diferente grado.

Hace algo más de una década, empezaron a moverse en España grupos que demandan un cambio de la hora oficial del país. Las primeras peticiones abogaban por retrasar los relojes 1 hora, abandonar la zona UTC+1 y pasar a la zona UTC+0; pero ahora, en fecha más reciente, los parlamentos de algunas comunidades autónomas mediterráneas han solicitado del Gobierno central la aplicación de medidas que van en el sentido opuesto: pasar a la zona UTC+2.

La coexistencia de estos dos extremos revela la facilidad con la que se producen interpretaciones diferentes en esta materia y, en principio, debería servir 
para hacer una llamada a la cautela y a la búsqueda de un criterio científico. Por si fuese poco, el debate se agudiza periódicamente en los momentos de ajuste estacional de la hora, que se realizan dos veces al año siguiendo una directiva europea, fundamentada en la gran variación solar que experimenta el continente europeo a lo largo del año (una variación que no tiene ninguna relación con las cuestiones relativas al huso).

Se trata de algo de más calado de lo que cabría pensar ya que la hora oficial afecta a todos y cada uno de los habitantes del país, sin excepción. Por eso cualquier reflexión sobre ella debe ser pausada por parte de los responsables del Gobierno, con el mejor asesoramiento posible, con un completo conocimiento de los factores en juego y, sobre todo, con unos datos solventes. En este punto, es digno de mención el valor que la estabilidad de la regulación horaria tiene en el funcionamiento de un país del mundo desarrollado. De hecho, desde la Segunda Guerra Mundial ningún país de ese ámbito (excepto Islandia) ha realizado cambios de zona horaria que hayan perdurado.

Frente a quienes solicitan el cambio de nuestra zona horaria actual, argumentando que eso beneficiaría los modos de vida de nuestra sociedad, se sitúan quienes advierten del peligro de tal medida: alertan del caos y coste de esa transición $y$, sobre todo, que dicho cambio no produciría ninguna mejora significativa en nuestros estilos de vida, que no dependen del huso.

En octubre de 2016 el Consello da Cultura Galega organizó la jornada ¿Es Nuestro Huso Horario un Problema?, con el fin de arrojar luz sobre este asunto con las aportaciones de expertos con diferentes posicionamientos. Este foro fue uno de los primeros realizados con posiciones enfrentadas sobre el tema en Espańa.

El eco público de la jornada y la riqueza de su contenido han motivado la publicación de este libro. Su aspiración final es ofrecer una obra de referencia, accesible, para que cualquier ciudadano pueda formar su opinión con fundamento.

Esperemos que así sea. 


\section{NUESTRO HUSO HORARIO ES INOCENTE. INCONVENIENTES DE UN CAMBIO DE HUSO EN ESPAÑA}

Jorge Mira Pérez

Universidade de Santiago de Compostela

Doi: 10.17075/enhhp.2017.001 



\section{INTRODUCCIÓN}

El debate sobre el huso horario español (y, por tanto, considerar al actual como un problema) apenas existía hasta principios del siglo xxi. A partir de ese momento, y sobre todo a lo largo de la última década, se ha colado con intensidad en nuestro país, movido principalmente por la Asociación para la Racionalización de los Horarios Españoles (Arhoe), que también se identifica como «Comisión Nacional para la Racionalización de los Horarios Españoles y su Normalización con los demás países de la UE» (constituida con anterioridad y que es el embrión de la asociación).

Esta asociación ha generado una serie de ideas-fuerza que, hábilmente difundidas, han llegado a instalarse en la mayoría de las redacciones de los medios de comunicación españoles, al punto de que muchas de las noticias sobre este tema han sido redactadas sobre la base de los recursos distribuidos por Arhoe.

El 10 de octubre de 2013, la Subcomisión de Racionalización de Horarios, Conciliación y Corresponsabilidad del Congreso de los Diputados publicó sus conclusiones. En medio de una prolija descripción de propuestas dedicadas a medidas de conciliación y organización empresarial, aparecía una alusión al cambio de nuestro huso horario, atribuyéndole unos supuestos efectos sobre la mejora de nuestras vidas que, según se intentará explicar en el presente capítulo, no tienen fundamento.

El informe de esa Subcomisión, junto con el momento de volatilidad política vivido poco después, conllevó que algún partido político lo empezase a incluir en su programa político, medida que pronto se extendió a otros del arco parlamentario.

Hoy se puede decir que, tras estos últimos años, se ha abierto la caja de Pandora del huso. Se constata sobre todo en las amplias discusiones que tienen lugar en los dos cambios horarios estacionales, en las que se confunden cuestiones que 
son diferentes (el huso por un lado y el cambio horario estacional por otro). Pero el peligro de esta dinámica se ha percibido de modo más agudo en fecha reciente, tras sendas declaraciones de los parlamentos balear y valenciano apoyando (por unanimidad de ambas cámaras) la permanencia del horario de verano todo el año, lo que en realidad implicaría situarse en el huso horario UTC+2 (UTC= tiempo universal coordinado, estándar de tiempo universal).

$\mathrm{Si}$ esto se considera digno de mención es porque UTC+0 corresponde a la zona horaria de Greenwich; es decir: lo propuesto por esos dos parlamentos regionales llevaría a esas dos comunidades a una zona horaria separada dos horas de la de Reino Unido y Portugal. El hecho de que varios de los partidos políticos que han contemplado la propuesta de pasar España al huso UTC+0 apoyen ahora, en esas comunidades, una medida diametralmente opuesta (el paso a UTC+2) demuestra a las claras el estado de confusión existente y el peligro que supondría tomar decisiones políticas de este calibre en dicho estado. También pone de manifiesto que nuestro huso actual, UTC+1 (el único que ha conocido el $95 \%$ de la población española y al cual se ha adaptado tras muchos años), es la opción centrada, frente a quienes quieren modificarlo, restando o sumando, con idénticas promesas mágicas (e incompatibles entre sí).

\section{CAMBIAR EL HUSO HORARIO NO SERVIRÍA PARA NADA}

Muchos de los defensores del cambio de huso horario en España piden que la hora oficial española pase a ser la UTC+0, como en el Reino Unido o Portugal. Para fijar con claridad este asunto a nivel práctico, esa medida implicaría que, si Ud. mira la hora ahora mismo, el cambio consistiría en darle para atrás una hora a su reloj.

Para un físico o un matemático ese acto corresponde a una operación habitual llamada «cambio de variable». Este nombre no esconde más que un rebautizo de los números usados para describir un fenómeno, pero teniendo claro que las propiedades medidas del fenómeno en sí no van a cambiar con esa operación estética.

Le pongo un ejemplo: si va la Puerta del Sol en Madrid, verá en una zona del suelo una placa en la que reza:

«Kilómetro 0. Origen de las carreteras radiales». 
Esas carreteras radiales de España marcan ahí su punto de partida. Con esa referencia, A Coruña está más o menos en el punto kilométrico 600 a partir de ese origen. Un cambio de variable, análogo al cambio de huso horario, consistiría en asignarle un número distinto al punto kilométrico de la Puerta del Sol.

Imaginemos que le asignamos a ese punto el valor «kilómetro 100». ¿Estaría A Coruna $100 \mathrm{~km}$ más cerca? No, porque al redefinir ese origen y asignarle un nuevo número, en el punto correspondiente de A Coruña pasaría a figurar el kilómetro $700(600+100)$. Se hace hincapié en este hecho para señalar que la distancia entre esos dos puntos es la resta de los valores nominales de los dos puntos kilométricos, de modo que, por mucho que se cambie el valor asignado al origen, la distancia no va a variar. El valor del punto kilométrico no tiene sentido en sí mismo, solo tiene sentido cuando es usado para ser restado a otro medido en el mismo sistema de referencia. Por supuesto, no cambiarían ni la distancia ni ninguna otra circunstancia relativa al tráfico (por ejemplo, el número de accidentes en el país no se alteraría por el mero hecho de desplazar ese valor de referencia de la Puerta del Sol).

Eso sí, si por alguna circunstancia se hiciere un cambio del «huso kilométrico» en la Puerta del Sol, esa operación arrastraría la renumeración de miles de puntos kilométricos, con un coste ya no solo material, sino derivado del despiste para la población, que no asimilaría esos nuevos puntos kilométricos de modo instantáneo (imagine el caso de aquellos profesionales que pactan citas indicando como referencia tal o cual punto kilométrico).

Pues algo similar ocurriría con un cambio de huso horario español. ¿Cómo visualizar el efecto de esa medida? Indiquemos cómo afectaría a un ciudadano de a pie.

Supongamos que ese ciudadano tiene un pequeño comercio, que abre de 9:00 a 14:00 y de 16:00 a 19:00 horas. Como todo el mundo, quiere mejorar su calidad de vida. Ha oído algo del huso horario, que según parece es culpable en parte de sus males: «Espańa cae en la zona de Greenwich del mapa horario y estamos malditos por no tener la hora británica», «Portugal tiene el huso británico, y nosotros no: algo no encaja», «los españoles vivimos de noche», «somos víctimas de los juegos de Hitler y Franco con el reloj», etc.

El mensaje que le llega de casi todas partes es el mismo: "pongámonos en el huso del Reino Unido y curaremos la anomalía horaria española», y para colmo los principales partidos políticos han comprado la idea. 
Ante ese estado de opinión, parece claro que ese ciudadano recibirá con los brazos abiertos el cambio de huso.

Ilustremos la situación con un día en el que el Sol se pone a las 19:00 (véase figura 1). Eso quiere decir que, cuando nuestro ciudadano baja la persiana de su comercio, ve ponerse el Sol. Supongamos ahora que al día siguiente el Gobierno ejecutase el cambio al huso británico.

¿Qué ocurriría ese día? Cuando nuestro amigo fuese a cerrar la persiana se encontraría que ya es de noche. El Sol se habría puesto hace una hora, a las 18:00. En eso consiste el cambio: en asignar a los hechos naturales una hora menos de la que tenían antes...

... Y esto nos lleva a la primera consecuencia tangible de ese cambio de huso: al igual que le ocurriría a ese ciudadano, toda la vida del país se desplazaría una hora hacia la noche.

Es paradójico que quienes defienden la medida argumenten que la toman para curar la supuesta anomalía horaria española, que hace que «los españoles vivamos de noche». Es obvio que el resultado, a pelo, va en el sentido diametralmente opuesto. Con todo, estos grupos intentan vender como supuesta ventaja otra medida que proponen adoptar al mismo tiempo: adelantar los horarios de cierre una hora.

Dicho así («salir antes del trabajo»), la medida parece un regalo, pero en realidad esconde un juego propio de trileros.

Veamos qué ocurre.

Al ciudadano se le adelantaría el momento de cierre una hora. Es decir, en vez de cerrar a las 19:00 cerraría a las 18:00. Así, cuando llegasen las 18:00 de la nueva hora oficial, bajaría la persiana de su negocio; pero... miraría al horizonte y vería... el Sol poniéndose, ¡tal y como sucedía antes de todas estas medidas!

Su reloj marcaría una hora distinta, sí, pero nada habría cambiado. De hecho, pronto se percataría del nulo efecto en la configuración de su jornada laboral. Si antes era de 9:00 a 14:00 y de 16:00 a 19:00, ahora tendría que abrir de 8:00 a 13:00 y de 15:00 a 18:00. Trabajaría las mismas horas, en las mismas condiciones y la evolución de su jornada con el recorrido del Sol sería exactamente la misma de antes. 


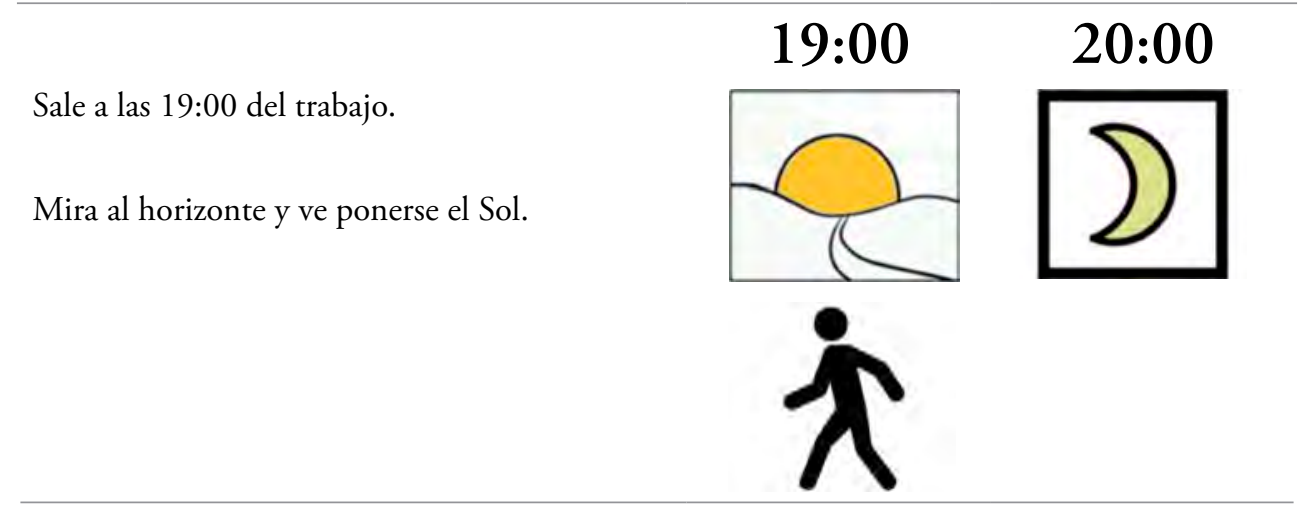
Al día siguiente, el Gobierno decreta el retraso al huso horario británico.
El Sol, que antes se ponía a las 19:00, ahora lo hace a las 18:00.

Sale del trabajo como siempre a las 19:00 y descubre que ya es de noche.

PRIMERA CONSECUENCIA DEL CAMBIO DE HUSO: LA VIDA DEL PAÍS SE DESPLAZA AUTOMÁTICAMENTE UNA HORA HACIA LA NOCHE.

\section{8:00 \\ 19:00}
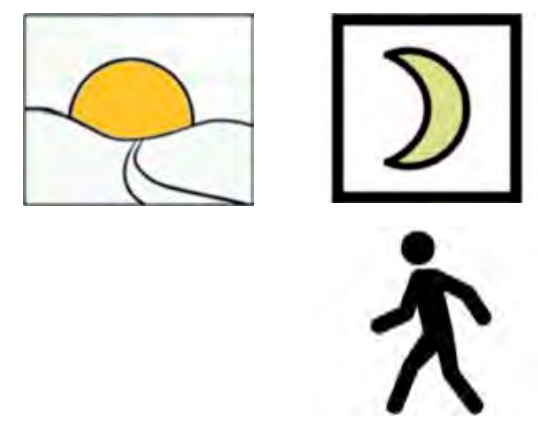

HORA HACIA LA NOCHE.

Para compensarle, se le adelanta una hora la salida del trabajo. Saldrá a las 18:00

Resultado: sale del trabajo, mira el horizonte y ve ponerse el Sol, exactamente como ocurría al principio.

NO HA CAMBIADO SU VIDA: RETRASAR EL HUSO $1 \mathrm{~h}$ Y ADELANTAR EL HORARIO 1 h ES UN JUEGO DE SUMA CERO. ESTÁ COMO ANTES.

\section{8:00}

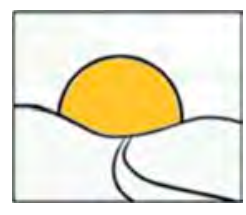

19:00
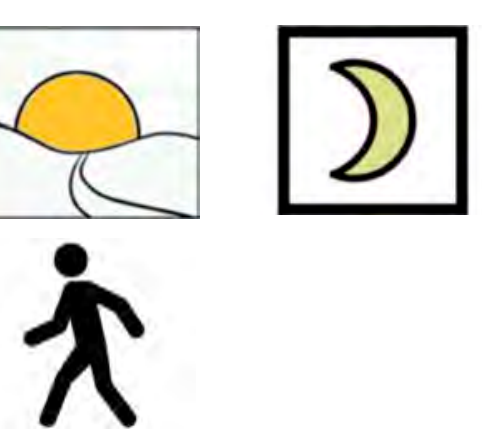

Figura 1: La inutilidad del cambio de huso. Al pasar a UTC+0, las actividades tienen lugar 1 hora más tarde respecto al Sol. Al compensar con el adelanto de horario, la actividad vuelve al mismo punto del que partía. Todo seguiría como antes, la situación no cambiaría. 
La operación es ridícula: retrasar una hora el punto de referencia horaria (huso) y adelantar una hora los horarios... para quedarnos exactamente en el mismo sitio. El único cambio: el número que marcaría el reloj para cada fase del día sería una unidad menor.

En la experiencia del autor de este artículo, ese es el principal obstáculo pedagógico a la hora de explicar la inutilidad del cambio de huso: la falta de percepción de que la combinación de ese cambio estético de la hora marcada por el reloj y el adelanto de los horarios no tendría ningún efecto en la vida de los españoles.

Además el eslogan dicho a pelo es seductor: «horarios hasta las 18:00 y huso de Portugal», se llegó a decir en campaña electoral. Cuando escuche eso, tenga claro que es lo mismo que «horarios hasta las 19:00 con nuestro huso horario actual».

En este punto cabría plantearse: «si con ese juego de suma cero nos quedamos igual, tampoco habría mucho riesgo por probar».

Sí que lo habría, ya que ese planteamiento está olvidando el coste de la transición, de modo análogo a lo que ocurría en el ejemplo de los puntos kilométricos. El cambio de huso se haría de golpe, pero la sociedad no iría ajustando (adelantando) sus horarios automáticamente, configurando un caótico viaje de vuelta a nuestro ritmo solar natural. Posiblemente empezasen adelantando horarios las grandes empresas y algunos organismos oficiales, pero el proceso se iría escalonando durante meses o incluso años, hasta converger a la misma situación en la que estamos actualmente.

Como variación en este juego de suma cero, Arhoe le propone a nuestro ciudadano «acortar una hora el período de descanso entre comidas», es decir, marcar para nuestro amigo un horario de 9:00 a 14:00 y de 15:00 a 18:00 horas (reducir el descanso para comer en una hora). Pero a esto hay una objeción evidente: esa medida no tiene nada que ver con el cambio de huso ni lo necesita, ya que se puede aplicar sin necesidad de cambiarlo. Lo mismo rige, por supuesto, para aquellos horarios que necesiten algún tipo de corrección: de ser así, cámbiense simplemente los horarios. Una cosa son los horarios y otra distinta el huso. Modificar los horarios es una operación que nada tiene que ver con el huso. 


\section{LAS FALACIAS USADAS PARA JUSTIFICAR UN CAMBIO DE HUSO}

Por si fuese poca la dificultad de explicación de los argumentos anteriores, se añaden usualmente al debate argumentos falaces. De entre ellos se destacan los siguientes:

\section{1. ¿El Sol es Greenwich y no Alemania?}

Este argumento, oído en campaña electoral, es el principal argumento de los defensores del cambio de huso. Se ilustra con un mapa plano del mundo, dividido en dos mitades por el meridiano de Greenwich, que enseñan a España, Portugal y Reino Unido con una aparente y absoluta sincronía bajo la luz del Sol y al resto de Europa bajo la oscuridad.

Ocurre, sin embargo, que la Tierra no tiene su eje de rotación alineado con respecto al Sol (ese eje sobre el que la Tierra gira sobre sí misma está desviado $23.5^{\circ}$ con respecto al eje de traslación alrededor del Sol). Esto implica que la manera en la cual el planeta es iluminado cambia a lo largo del ańo, o lo que es lo mismo, las duraciones del día y de la noche varían constantemente.

El momento de menor exposición solar, el día más corto del año, ocurre en el invierno. Dado que nuestro período de actividad está centrado en el día, esos días de invierno son los que establecen la pauta de nuestros horarios. Y dado que los horarios naturales del ser humano arrancan con el amanecer, se concluye pues que los amaneceres invernales son el punto natural de referencia mínima para establecer el inicio de la jornada.

¿Y cómo amanece en Europa en invierno? Si pudiésemos ver Europa desde el espacio en uno de esos amaneceres, la imagen sería la de la figura 2. La sorpresa surge al ver que la línea que separa la noche del día no se alinea con el Meridiano de Greenwich. Es más, sucede que esa línea sigue la inclinación del eje troncal que define el continente europeo.

El resultado: los europeos de la franja España-Francia-Alemania tenemos nuestros amaneceres sincronizados, o lo que es lo mismo, nuestros períodos de activación natural en invierno son más o menos los mismos. Es, por lo tanto, de lo más razonable que la Europa de esa franja España-Francia-Alemania (donde recae la mayor parte del peso europeo) tenga el mismo huso horario. Por ese mo- 
tivo, la referencia horaria actual es de lo más natural para un continente con la disposición geográfica europea. El Sol invernal, el que marca la referencia para el inicio de la actividad europea, es más Alemania que Greenwich.

\section{2. ¿Anochece muy tarde en España en verano?}

En el argumentario de los proponentes del cambio de huso suelen escucharse frases como «es imposible acostar a los niños en verano» o "estamos en un huso aberrante, no hay más que ver lo tarde que se pone el sol en verano».

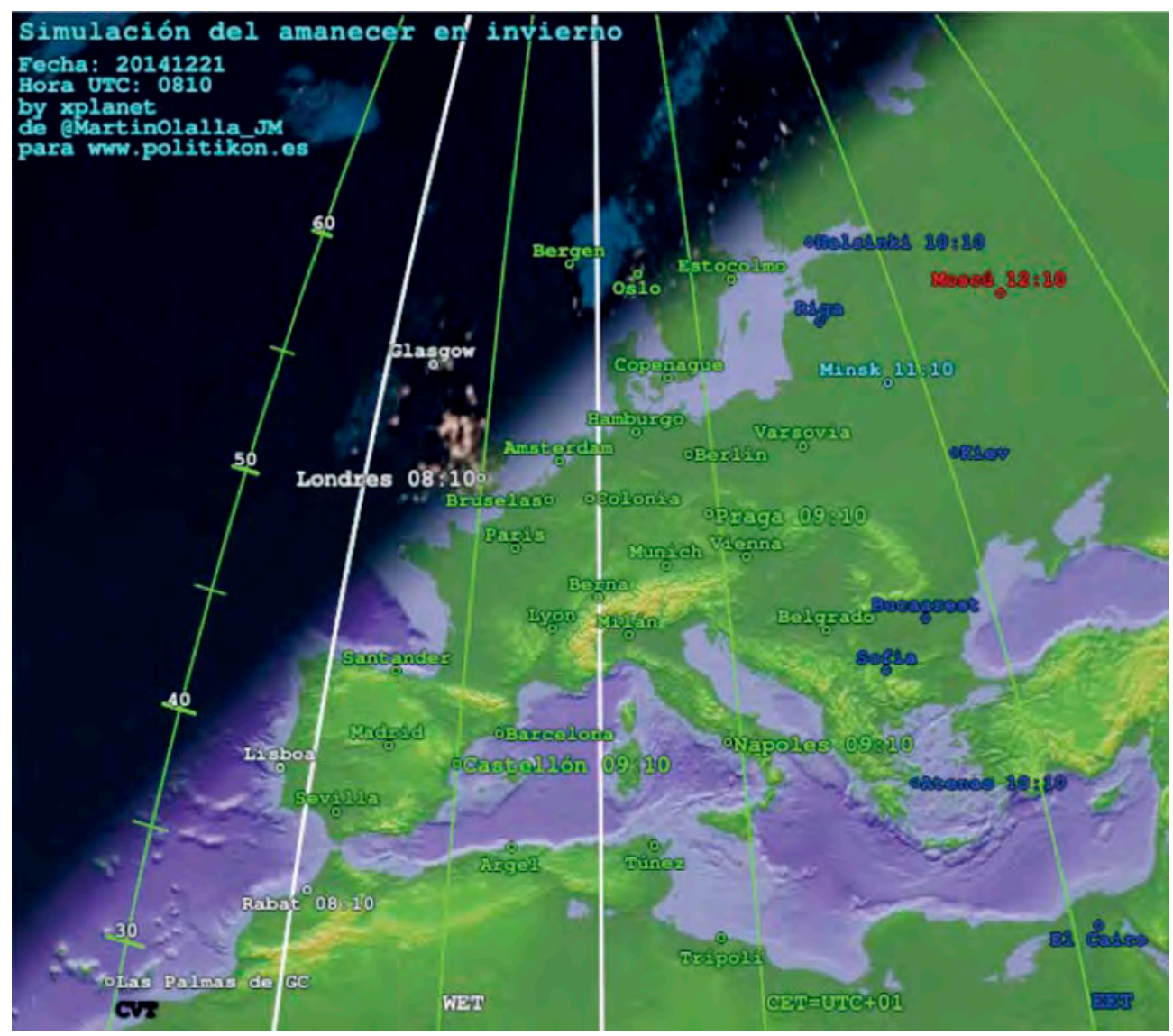

Figura 2: Aspecto del continente europeo en un amanecer invernal. La línea que separa el día de la noche sigue la inclinación natural del continente (figura cortesía de J. M. Martín Olalla). 
El anochecer del planeta Tierra es regulado por su rotación y posición respecto al Sol. Es por lo tanto de lo más obvio que se trata de un proceso natural, que en absoluto se va a ver modificado por el Boletín Oficial del Estado. Ocurre además que en el atardecer veraniego se produce la situación inversa al amanecer invernal: si pudiésemos ver Europa desde el espacio en uno de esos atardeceres, la imagen sería la de la figura 2 con los colores intercambiados (la zona oscura estaría iluminada y viceversa). En consecuencia, se concluye que el atardecer estival de los europeos está también sincronizado con el bloque central del continente, con el que compartimos el huso.

Esta circunstancia es, además, fácilmente constatable sin más que consultar horas de puesta de Sol en varias de las principales capitales europeas. Así, por ejemplo, el 1 de julio el Sol se pone a las 22:00 en París y Bruselas, a las 22:10 en Ámsterdam...

¿Y en Madrid? ¡A las 21:49!

Sí: en pleno verano el Sol se pone más tarde en las capitales de Francia, Bélgica y Países Bajos que en la capital de España. Lo de los supuestamente anómalos atardeceres españoles no es más que otra falacia.

Nuevamente, se recuerda que el cambio estético constituido por el pack «retraso de 1 hora de reloj + adelanto de 1 hora en la salida del trabajo» no haría más que dejarnos en la misma situación y, por lo tanto, España seguiría teniendo su misma relación con su atardecer.

\section{3. ¿No tenemos horarios europeos?}

Un mantra que, a base de ser repetido por los grupos que piden el retraso de nuestro huso horario, ha calado en la sociedad española, explotando nuestra secular tendencia a la autoflagelación. Nuevamente incurre en el gravísimo error de razonar sobre un mapa plano cuestiones que se deben explicar sobre una esfera. Tal y como se indicó en la sección 3.1, el hecho de tener la Tierra su eje de rotación desviado respecto al de traslación implica que la manera en la que el Sol ilumina Europa a lo largo del año cambia muchísimo. Entre otras consecuencias, la duración del día invernal decrece de manera acusada al movernos hacia el norte. Así, mientras que en el solsticio de invierno la duración del día en Madrid es de 9 h 17 min, en Londres es de 7 h 49 min (casi hora y media menos), en 
Berlín es de 7 h 39 min o en Estocolmo de 6 h 05 min (casi 3 horas y cuarto de diferencia con Madrid).

El 15 de diciembre anochece a las 14:45 en Estocolmo. Cuando un habitante de esa ciudad enciende la televisión en esa época para ver un partido de la Champions League (programado a las 20:45), llevará ya 6 horas de noche a sus espaldas, mucho más que cualquier español. A la vista está que no son situaciones comparables: el ritmo de un europeo del norte tiene unas limitaciones bastante distintas de las de un europeo del sur. La latitud, por su efecto determinante en la duración del día solar, es la que marca los ritmos de vida de los pueblos, no su huso horario, que es un convenio estético para asignar un número a cada momento del día.

Los pueblos se adaptan a su huso: una vez marcada la referencia horaria, elaboran sus horarios a partir de él en función de la situación solar correspondiente a su latitud. En las encuestas de uso del tiempo (aquellas que miden cuándo la población de un país realiza sus actividades diarias) se observa que las sociedades tienden a sentarse a comer $x$ horas antes del anochecer invernal [1] (véase figura 3). En el caso de la sociedad espańola, la hora promedio de la comida es 3-4 horas antes del anochecer y no presenta ninguna anomalía al compararla con la de otros países (figura 3), y eso no va a variar por cambiar el huso.

Tras el cambio de huso, esa hora de comida se acercaría 1 hora al anochecer y la sociedad española acabaría compensándolo adelantándola, convergiendo a la misma situación en la que estamos ahora (un proceso análogo al indicado en la figura 1), guiada por la secuencia día-noche propia de nuestra zona. Lo mismo se aplica para la hora de cena, que en las diferentes sociedades tiene lugar un determinado número de horas tras el anochecer.

Si en Santiago de Compostela el día de Navidad una familia se sienta a comer en torno a las 14:00 horas, eso supone hacerlo 4 horas antes del anochecer de ese día. Lo mismo ocurre para la cena, que sería en torno a unas 3 horas después del anochecer. Si se cambiase al huso horario británico, esa familia (viendo el acercamiento de la comida al anochecer) acabaría comiendo a las 13:00 horas, nuevamente 4 horas antes del anochecer de ese día (que tras el cambio de huso estaría produciéndose a las 17:00); es decir, la misma situación de antes (vuelve a producirse el proceso análogo al indicado en la figura 1). Lo mismo para la cena, que pasaría a comenzar en torno a las 20:00 h, 3 horas después del anochecer; es decir, una situación idéntica a la de antes. 


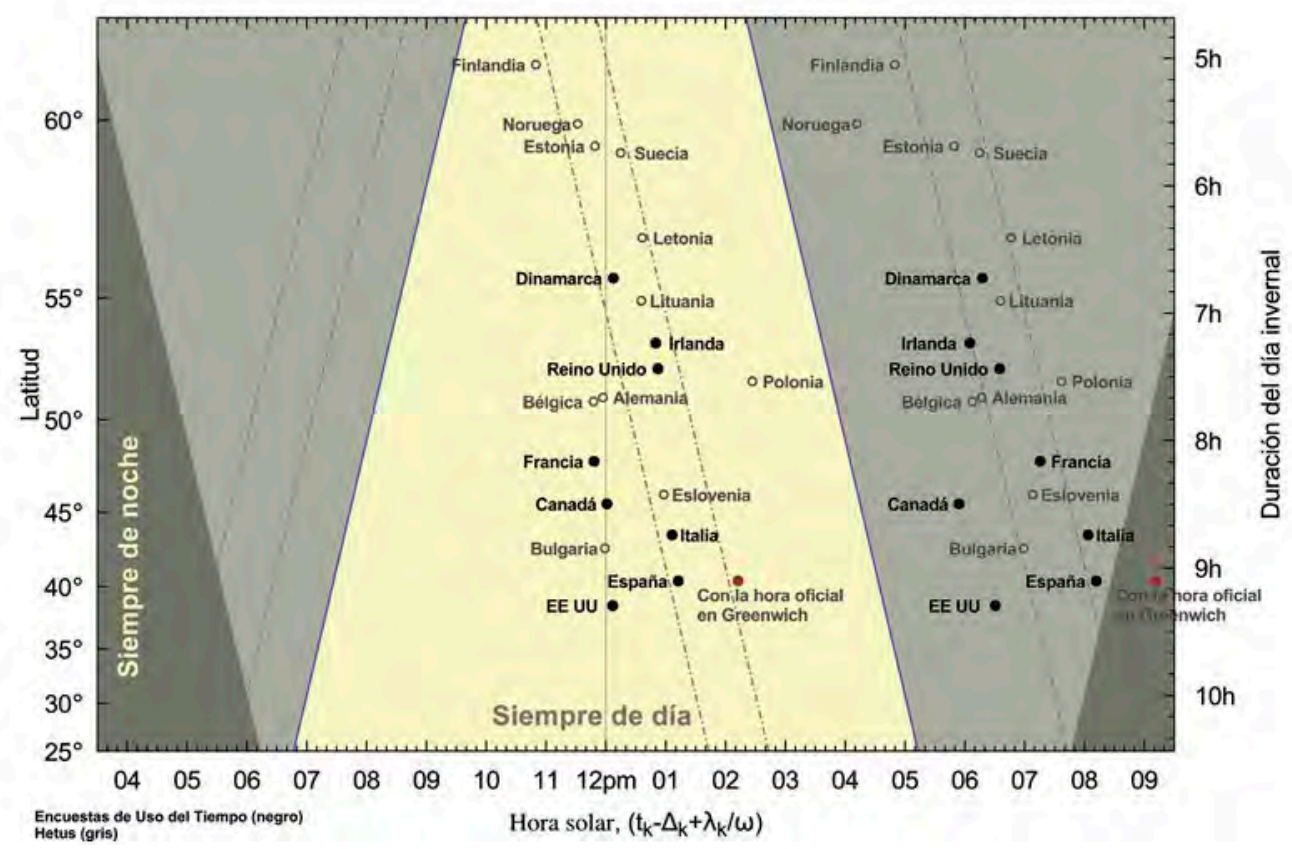

Figura 3: Horas promedio de comida y cena en diferentes países, en un diagrama que muestra su situación con respecto a los momentos de amanecer y anochecer mínimo y máximo. Tal y como se observa, España está en una situación normal. Nótese la disposición de los momentos de comida y cena con respecto a la línea del anochecer mínimo. Se indica dónde quedaría el momento de comida y cena tras un paso al horario de Greenwich (figura cortesía de J. M. Martín Olalla, véanse los datos en el cuadro I de la página 62).

Lo mismo se aplica a todas las demás facetas, como el prime time televisivo, que empieza en Italia y en España prácticamente en el mismo momento con respecto al anochecer.

Lo mismo se aplica a todas las demás facetas, como el prime time televisivo, que empieza en Italia y en España prácticamente en el mismo momento con respecto al anochecer.

En las jornadas realizadas en el Consello da Cultura Galega en octubre de 2016, que son el origen de este libro, José María Martín Olalla dejó bien patente esta circunstancia, con datos que demuestran cómo el discurrir de la vida de italianos y españoles sigue la misma curva a lo largo del día, al ser países de latitud parecida (véase [1]) y, por lo tanto, ritmo solar parecido. 
La mitad norte de Europa no tiene la suerte de disfrutar de la mayor homogeneidad de la iluminación solar a lo largo del año que tiene la mitad sur. La duración mínima de su día solar cae por debajo de las 8 horas, lo cual les hace imposible programar jornadas laborales realizables en período diurno.

No, su situación no es la nuestra. No cabe pues hablar de un «horario europeo».

\section{4. ¿Somos víctimas de un capricho de Franco y Hitler?}

Esta es, posiblemente, la falacia más sorprendente vertida en las discusiones sobre el huso horario; además con notable éxito, porque ha conseguido insertarse por defecto en muchas de las piezas que la mayoría de los medios de comunicación elaboran sobre el asunto.

Se desconoce quién es el introductor de este bulo, pero, dado que no se encuentra antes de 2008 ninguna referencia a él en internet, posiblemente fuese puesto en circulación ese año. Investigar y descubrir su origen es aún una tarea pendiente.

He aquí el contenido del bulo: supuestamente nuestro huso horario sería fruto de un gesto de pleitesía de Franco hacia Hitler en el curso de la II Guerra Mundial; una imagen de lo más potente, acompañada del mensaje de que la supuesta miseria horaria española es culpa de algo tan execrable como el nazismo.

La realidad es bien distinta: España sufrió casi una decena de cambios de hora oficiales (a veces de modo casi caótico) a cargo tanto del bando republicano como del nacional [2]. La hora de Berlín fue tan republicana como franquista. La II República desapareció, de hecho, bajo el huso horario de Berlín. Por si fuese poco, en contradicción con el relato construido, cuando Franco entró en Madrid, Barcelona y Valencia, suprimió en ellas el horario de Berlín y pasó al de Londres.

En marzo de 1940 se realizó un cambio al horario de verano que, simplemente, no tuvo vuelta atrás. Tal y como seńala Pere Planesas en [2] «[...] en la práctica, supuso un cambio permanente de la hora oficial de España adoptando, sin decirlo y, posiblemente, sin planearlo, la del huso horario $+1 »$. Ninguna pleitesía a Hitler. Ese supuesto vínculo nazi de nuestro huso simplemente no existe.

A partir de ese momento, España comenzó la adaptación a esa referencia horaria de modo natural. En una España atrasada (que desde luego no vivía bajo el signo de un reloj con la misma intensidad que ahora) el trauma no debió ser 
demasiado. Si se cambiase el huso horario en nuestros días, el coste del cambio sería muchísimo mayor. Además, tal y como se ha argumentado anteriormente, el modo de vida de los españoles acabaría convergiendo a la misma situación que tenemos ahora (y que es función de la latitud en la que vivimos).

En esa época Europa ya estaba inmersa en la II Guerra Mundial, un período que vivió múltiples cambios de horas oficiales de los contendientes (sin ir más lejos, el Reino Unido llegó a estar instalado en UTC+2, 1 hora más que España). $\mathrm{Al}$ acabar la guerra, varios de los países que habían adoptado el horario de Berlín se mantuvieron en él. Uno de ellos fue la Francia de Charles de Gaulle. Cinco años después De Gaulle impulsaría la CECA, el germen de lo que hoy es la UE, y posiblemente le pareciese una buena medida empezar esa unidad por el huso horario. En aquel momento Hitler y el régimen nazi ya no existían, así que se hace difícil sostener un alineamiento con ellos. España solo siguió la medida de su vecino más poderoso. Si alguien quiere poner apellidos al actual huso horario español, que diga que es gaullista y europeo.

¿Y Portugal? «O Portugal está malo España está mal». ¿Qué hay de esa típica frase? Portugal quedó anclado en la hora británica, así que sus marcas de referencia horaria no evolucionaron como las de España. Hoy, cada país está adaptado a su huso: la frontera horaria es virtual. Si cuando en España empieza el Telediario de las 21:00 h Vd. llama a un amigo portugués, oirá de fondo la sintonía del Telejornal de las 20:00. Si cuando viaja a Portugal deja Vd. la hora del reloj sin cambiar, y sigue más o menos la misma rutina horaria que en España, observará que no hay tanto cambio. Y, desde luego, las diferencias que perciba no serán debidas al huso horario.

\section{CONCLUSIÓN}

No existe la supuesta anomalía horaria española. Es un mito que se ha difundido sin el debido contraste con datos reales y se ha instalado como un mantra en nuestra sociedad. Es de la máxima urgencia para este debate aclarar las fuentes de dichas informaciones y la veracidad de los datos empleados. La objetividad científica ha brillado bastante por su ausencia. Es aún más grave, si cabe, la constatación de que en este debate se han introducido argumentos falaces. Sería interesante emprender alguna investigación sobre su origen. 
Tal y como se demuestra con los datos de uso del tiempo (encuestas generales que dibujan el ritmo del país), España tiene un ritmo de actividad similar al de otros países con latitud parecida (aunque tengan huso distinto). Latitudes diferentes implican ritmos de luz solar diferentes. Dado que las sociedades humanas reparten su actividad en función de la disponibilidad de luz solar, se debe ser cauteloso al comparar los ritmos de la Europa del norte con los del sur. El reparto de la actividad diaria de una sociedad depende de la duración de su exposición solar, no del huso que adopten como referencia.

Es de una evidencia palmaria que un retraso al huso británico desplazaría automáticamente toda la vida de España 1 hora hacia la noche (figura 1). No deja de ser asombroso que los defensores de esa medida afirmen querer «evitar que vivamos de noche», puesto que, paradójicamente, dicha medida no hace más que empeorar la situación. Se borda ya lo absurdo cuando se propone que, para compensar el efecto, "se adelantarían los horarios de salida del trabajo 1 hora»: la combinación del retraso de huso con el adelanto del horario hace que ambos movimientos se cancelen, dejando el ritmo diario de España tal y como está actualmente.

Es este un juego de trileros que confunde a la población y debe ser aclarado; la pedagogía es esencial en este debate. Es hasta cierto punto normal que una sociedad que vive bajo el reloj sacralice los dígitos que marcan sus agujas y por lo tanto pueda ser confundida por ciertos discursos. A la vista está que el típico mapa plano que representa las diferentes zonas horarias del planeta ha llegado a ser considerado erróneamente como un imperativo de igualdad de referencia horaria, so pena de graves consecuencias. Por esta razón, antes de cualquier debate, es necesario que la ciudadanía tenga meridianamente claro que las 19:00 de Madrid marcan exactamente el mismo momento que las 18:00 de Londres y Lisboa. Un acto a las 19:00 en España estará ocurriendo al mismo tiempo que un acto a las 18:00 de Londres o Lisboa. Una persona que sale del trabajo a las 19:00 horas en Madrid está saliendo al mismo tiempo que una que sale del trabajo a las 18:00 en Londres o Lisboa. Un programa de televisión que empiece en España a las 19:00 estará empezando al mismo tiempo que uno a las 18:00 del Reino Unido. Da lo mismo decir «19:00 de Madrid» que «18:00 de Londres», y no hay nada catastrófico en ello. Por muy ridículo que uno se sienta al repetir estas obviedades, la experiencia demuestra que es necesario.

Se debe advertir también del peligro de confusión de las operaciones de cambio de huso con las de cambio de hora estacional, realizadas dos veces al año en 
virtud de una Directiva Europea. El cambio estacional es debido a la gran fluctuación de horas de exposición solar en las zonas no tropicales (fluctuación que crece con la latitud) y busca centrar nuestra vida con el ritmo solar.

Una vez argumentado que un retraso de huso y adelanto de horario es una operación con resultado nulo, y también que el huso usado como valor de referencia no marca el ritmo de un estado, podría pensarse que nada malo habría en que un país cambiase a capricho su huso horario a las primeras de cambio.

La razón que lo desaconseja es el coste del cambio: el cambio de huso se ejecuta de golpe, pero la adaptación de un país de 46 millones de habitantes a esa nueva referencia no sería en absoluto directa. Hay ejemplos fallidos de este tipo de aventuras. El más destacable es el del Reino Unido, que de 1968 a 1971 adoptó el huso horario de España. El resultado fue un contundente fracaso, ya que la sociedad británica había fijado su referencia tras muchos años de vida con reloj, y no resistió la readaptación de dicha referencia.

Instalar a España en el huso horario del Reino Unido crearía un desbarajuste que tendría su coste y, lo que es peor, tras ese período de catarsis la sociedad espańola acabaría convergiendo a su ritmo natural, que viene marcado por su latitud y no por su huso. El huso horario no regula nuestras vidas.

\section{REFERENCIAS BIBLIOGRÁFICAS}

[1] Martín Olalla, José María (http://personal.us.es/olalla/time/santiago.pdf).

[2] Planesas Bigas, Pere: «La hora oficial de España y sus cambios», Anuario del Observatorio Astronómico de Madrid, 1 (2013), 373-402. 



\section{INNOVACIÓN SOCIAL: ANÁLISIS DE LOS BENEFICIOS DE LA RECUPERACIÓN DEL HUSO HORARIO QUE CORRESPONDE A ESPANA}

José María Fernández-Crehuet Universidad Politécnica de Madrid

Doi: 10.17075/enhhp.2017.002 

Las causas y consecuencias de que en Espańa la hora oficial no coincida con la hora solar se han convertido en un tema de candente actualidad. De hecho, en enero de 2017, la agencia de noticias Europa Press difundía en varios de los principales periódicos de Espańa una noticia con declaraciones de dos físicos y un politólogo contrarios al cambio del huso horario. Ya que no tuve opción de participar en esa entrevista, aprovecho estas líneas para poner por escrito mis argumentos y los de muchos de los lectores-comentaristas de uno de los periódicos en donde apareció (he seleccionado El País 8/01/2017) que quisieron dejar por escrito en sus comentarios sus razones a favor del cambio del huso horario (serán entrecomilladas y con cuerpo menor en la página para diferenciarlo).

Esta cuestión también ha entrado de lleno en la agenda política. De hecho, la ministra de Empleo, Fátima Báñez, planteó en el mes de diciembre de 2016, ante la Comisión de Empleo del Congreso, un pacto político y social para que la jornada laboral acabe a las seis de la tarde (medida que contemplaba el programa electoral del PP para las elecciones del pasado junio de 2016), para lo que propuso «un pacto nacional por la conciliación y la racionalización de los horarios». En la propuesta también se incluía la posibilidad de estudiar el cambio del huso horario en Espańa, ya anunciada en abril de 2016 en un mitin electoral por el entonces presidente en funciones Mariano Rajoy, quien afirmaba que había que «impulsar el cambio del huso horario» para adecuarlo a las «necesidades» del país y facilitar la conclusión de la jornada laboral a las 18.00 horas.

Dicha medida estaba también contemplada en el pacto firmado por el PSOE y Ciudadanos para la consecución del fallido Gobierno en el mes de febrero de 2016. Sus firmantes, Pedro Sánchez y Albert Rivera, apostaban en su página 39 por la «recuperación del huso horario GMT (hora en el meridiano de Greenwich) que sirva de catalizador para el resto de medidas propuestas», para favorecer «una campaña de concienciación sobre las ventajas económicas y sociales de racionalizar los horarios y flexibilizar la jornada laboral». Mi tesis también apoya 
las pretensiones de dichos partidos políticos y sostiene que debemos volver al huso horario que nos corresponde. La conciliación de la vida profesional, familiar y personal se beneficiaría de este hecho.

En enero de 2017 se cumplieron 190 años del nacimiento del ingeniero canadiense que inventó los husos horarios. En geografía, huso horario es cada una de las 24 áreas en que se divide la Tierra, siguiendo la misma definición de tiempo cronométrico.

Todos los husos horarios se definen en relación con el denominado tiempo universal coordinado (UTC), huso horario centrado sobre el meridiano de Greenwich (también conocido como meridiano cero), que recibe ese nombre por pasar por el Real Observatorio de Greenwich, en el Gran Londres.

Puesto que la Tierra gira de oeste a este, al pasar de un huso horario a otro en dirección este, hay que sumar una hora. Por el contrario, al pasar de este a oeste hay que restar una hora. El meridiano de $180^{\circ}$, conocido como línea internacional de cambio de fecha, marca el cambio de día.

En España, la referencia era el meridiano de Madrid, con excepción de la Armada, cuya base era el de San Fernando. En 1901, el Gobierno de la reina regente, María Cristina, aprueba el cambio al tiempo solar medio que geográficamente nos corresponde, el del meridiano de Greenwich.

Reunida la Conferencia Internacional de la Hora en París en 1912, se acepta el sistema de husos horarios comenzado en 1884, y pasa a denominarse hora legal la que correspondía al huso horario.

En 1922, en un decreto firmado por Alfonso XIII, motivado en parte por una demanda de Inglaterra a causa del gran comercio con las islas Canarias, se les aplicó a estas el huso 23, uno menos que el resto de España, justificado por su situación distinta con respecto al meridiano de Greenwich. Por lo tanto, desde esa fecha, la hora legal del territorio nacional, tanto peninsular como el de las islas, fue la que le correspondía a su situación geográfica, exceptuando la parte occidental de Galicia, del meridiano de Mondońedo hasta el mar, pues se encuentra en el huso 23, el mismo que el archipiélago canario, pero mantuvo la misma hora que el resto de la Península.

Se ha hablado y escrito mucho sobre el origen histórico del cambio de hora legal de España con respecto a la oficial y de sus modificaciones. Por resumir, podemos indicar que, por razones históricas, en 1940, después del armisticio con Francia, cuando Alemania llega hasta los Pirineos, la hora de la Europa central 
es impuesta a la Europa occidental ocupada. Ese mismo horario ya había sido anteriormente adoptado en Espańa al inicio de la II Guerra Mundial en concreto por Orden de 7 de marzo de 1940, de Presidencia del Gobierno, donde se dice:

Hora legal. Se adelanta en sesenta minutos. Considerando la conveniencia de que el horario nacional marche de acuerdo con los de otros países europeos y las ventajas de diversos órdenes que el adelanto temporal de la hora trae consigo, dispongo:

Artículo $1^{\circ}$. El sábado 16 de marzo, a las veintitrés horas, será adelantada la hora legal en sesenta minutos.

[...]

Artículo $5^{\circ}$. Oportunamente se señalará la fecha en que haya de restablecerse la hora normal.

Tal restablecimiento no ha tenido lugar desde entonces hasta la actualidad. En la práctica supuso un cambio permanente de la hora oficial de España, que adoptó, sin decirlo, y posiblemente sin plantearlo, la del huso horario +1 para la península y las islas Baleares y la del huso horario 0 para las islas Canarias ${ }^{1}$.

Parece ser también que para evitar confusiones con los horarios - y evitar desfases durante los bombardeos y demás acciones de guerra programadas—, los países del meridiano optaron por ajustar sus horarios al huso central alemán. De esta manera, Gran Bretańa, Irlanda, Portugal y Espańa atrasaron el reloj una hora. Después de la guerra, algunos países volvieron a su horario habitual, cosa que no hizo España.

La decisión de la hora oficial, al ser soberana, es muy distinta dependiendo del país. En EEUU hay diez zonas horarias: cuatro en el propio continente, dos en Alaska, Hawái y cuatro en las posesiones. En Rusia hay once. En cambio, en China, aunque le correspondería tener seis zonas horarias, solo existe una hora oficial ${ }^{2}$. Por su parte, la hora legal de cada país es la que corresponde a su situación geográfica, la del huso horario en que se encuentre, sin posibilidad de cambios.

Tal y como puede apreciarse en la imagen 1, a Espańa (salvo Canarias y parte del oeste de la Comunidad Autónoma de Galicia), le corresponde el huso horario $\mathrm{GMT}+0$.

1 Pere Planesas: «La hora oficial en España y sus cambios». http://astronomia.ign.es/rknowsys-theme/images/webAstro/paginas/documentos/Anuario/lahoraoficialenespana.pdf (19/01/17).

2 Para ver los husos horarios del mundo y cuándo anochece y amanece en tiempo real se puede consultar el siguiente enlace http://24timezones.com/reloj hora exacta.php (14/01/17). 


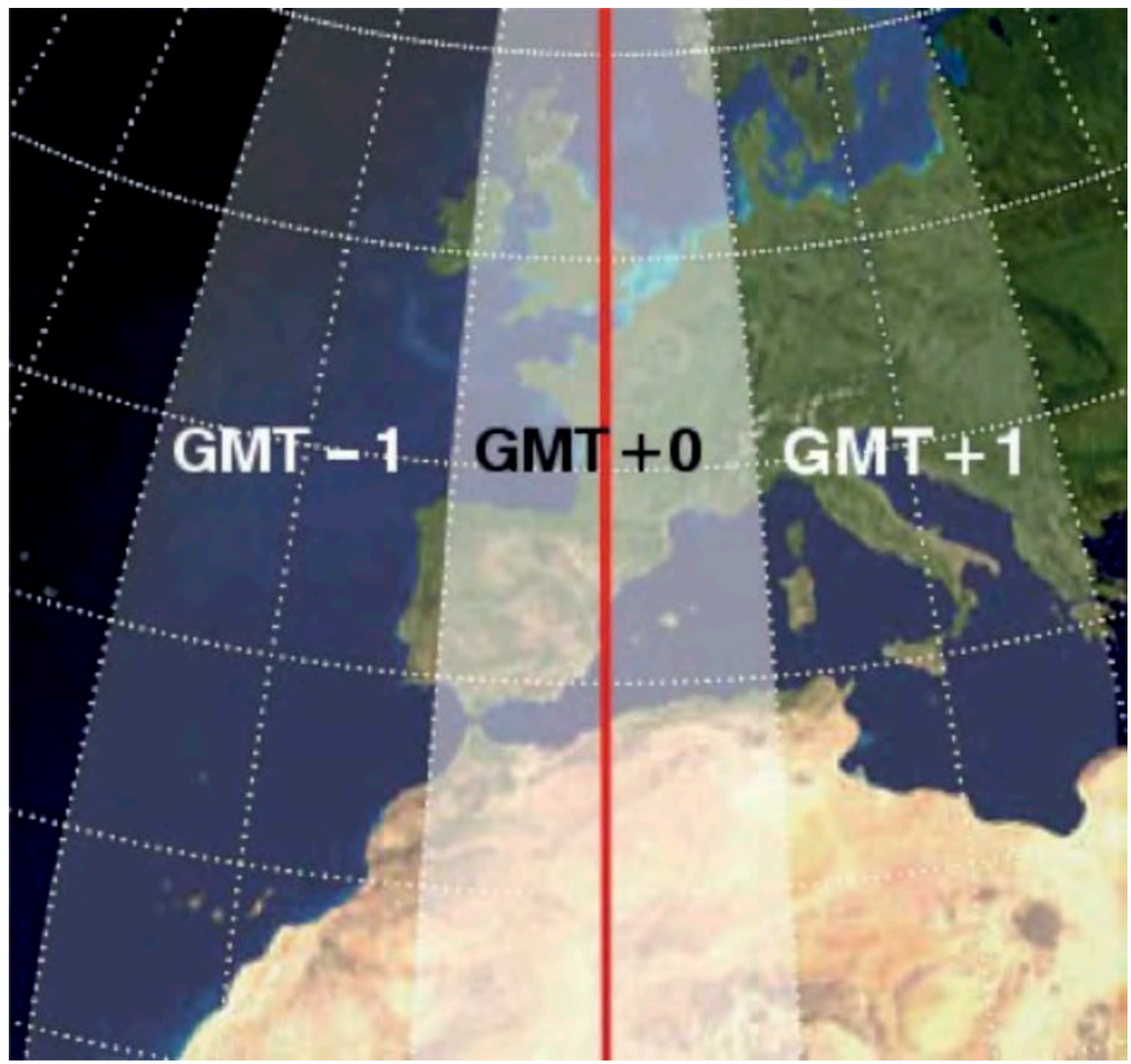

Imagen 1: El meridiano de Greenwich y su huso horario GMT+0.

Fuente: http://www.megaspora.net/es/gmt0-para-espana/ (19/01/17).

En la imagen 2 podemos observar un mapa de Europa. El color blanco indica una concordancia entre la hora oficial y la solar, el azul corresponde a un retraso de la hora oficial frente a la solar —o un adelanto de la solar sobre la oficial— y el rojo, justo a la situación contraria, con un color tanto más intenso cuanto mayor sea la diferencia entre ellas, tal y como nos sucede en Espańa. 


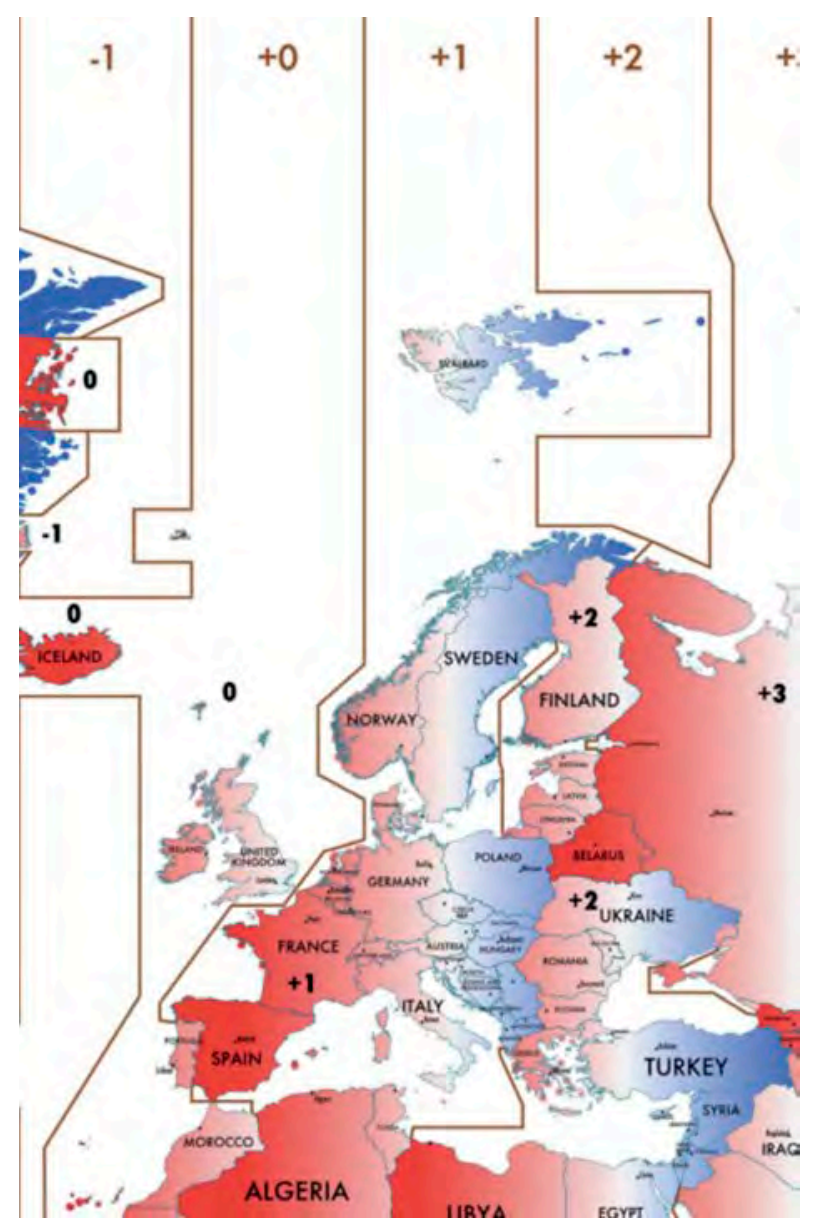

Imagen 2: Ajustes-desajustes hora oficial-hora solar.

Fuente: adaptado de (Stefano Maggiolo) http://blog.poormansmath.net/the-time-it-takesto-change-the-time/ $(19 / 1 / 2017)$.

Que en España la hora solar no coincide con la hora oficial (la que correspondería a nuestro huso horario) es un hecho aceptado por todos e indiscutible. En lo que se discrepa es en si ese hecho nos beneficia, nos perjudica o es indiferente. Desde mi punto de vista (y el de muchos de los lectores que comenté anteriormente, de los que quiero ser altavoz y a los que voy a dar un espacio generoso en este texto), el tener la hora de Alemania, en vez de la del Reino Unido, influye 
negativamente en nuestro día a día, puesto que el huso horario influye en nuestros usos y costumbres.

Una primera cuestión es preguntarnos lo siguiente: ¿Quién tiene razón? ¿Los que están a favor del cambio de huso horario o los que prefieren que permanezcamos? ¿Es una cuestión técnica e indiscutible u opinable? ¿Debe tratarse y resolverse desde un punto de vista matemático, físico, químico, o más bien del de las ciencias sociales? Demos paso a los lectores:

«Soy de ciencias, pero, lo siento, esto no es un tema de física, sino de costumbres humanas, y ese no es precisamente el punto fuerte de la ciencia»

«Pensando un poco superficialmente, entiendo el escepticismo de los físicos. El sano escepticismo es una característica de la ciencia. Y los argumentos parecen aceptables. Sin embargo, me permito señalar el detalle de que ni en los estudios de físicas, ni siquiera haciendo un doctorado, se estudia nada del comportamiento humano, ni respecto a los individuos ni respecto a los grupos. Si a un sociólogo o a un psicólogo le diera por fundamentar argumentos con la misma ligereza respecto a las disciplinas objeto de especialidad de estos expertos, serían tratados sin duda con desconfianza y se les demandaría un mejor fundamento en sus juicios»

«La formación científica no sirve para evaluar si cambiarían o no los usos (sin hache) si cambiara el huso (con hache). Eso entraría más bien en el campo de la sociología».

«Fuentes de la Real Academia de Ciencias Exactas, Físicas y Naturales han señalado que el debate sobre el cambio de huso es "político y económico. Desde el punto de vista de la ciencia no hay ninguna postura que tomar" "

«Los científicos que salen en este artículo son reputados físicos, lo cual no pongo en ninguna duda, pero cuando se dice: "Un cambio de huso no sólo no arreglaría nada sino que incluso traería problemas" y "Si se cambia, se va a generar un caos que implicaría un coste enorme”, me gustaría que me explicaran en qué se basan para saber de ese coste enorme, porque, que yo sepa, no son catedráticos en Economía para saber los enormes costes, ni en Sociología para saber el caos que crearía en la sociedad y si eso es bueno o malo para la conciliación familiar. En fin, me parece una opinión muy respetable de un gran físico hablando de física. Lo de hablar de economía y sociología debería dejárselo a los catedráticos en Economía y a los catedráticos en Sociología»

«Lo que sí que se puede debatir es sobre la hora oficial que es más conveniente adoptar en función de los beneficios económicos o sociales que se quieren obtener con el cam- 
bio. Y resulta que esos señores físicos son preguntados sobre estos aspectos que no son precisamente su especialidad. Por eso digo que su opinión no es relevante en este caso». «Todo lo más que podemos hacer los físicos es decir cuándo sale y se pone el Sol. Lo que se haga con esas horas de luz o cómo se aprovechen o distribuyan para actividades laborales y sociales ya no es cosa nuestra»

«Simplemente niego que la física sea la disciplina que deba opinar sobre lo oportuno de un cambio. Medicina, psicología, sociología, economía... están más cualificadas para ver el impacto de esta medida. Precisamente he escuchado a científicos de esos campos defender el cambio. Hasta la química tiene mucho más que decir que la física sobre nuestros biorritmos»

Después de profundizar en este tema desde bastantes años e investigarlo ya antes de tratarlo en mi tesis doctoral, vi que la respuesta a la pregunta de si el huso horario afecta a mi día a día es una cuestión cuya respuesta varía según los hábitos de vida, las circunstancias personales e incluso los gustos, y llegué a la conclusión de que hay que valorar el modo de vivir del conjunto de la población española y acomodarse a lo que favorezca a la mayoría. Demos paso, de nuevo, a los lectores:

«Vamos tarde a todos los sitios y alargamos la jornada de forma artificial. ¿Por qué abre el comercio a las 10 de la mañana? ¿Por qué entrando a trabajar a las 8 paramos para comer a las 14 , seis horas después?»

«La baja tasa de natalidad, desestructuraciones familiares y altos niveles de estrés y depresiones o bajas por el mismo motivo demuestran que hay algo que no está en su correcto funcionamiento, puesto que es absurdo tener a alguien trabajando desde las 9 de la mañana hasta las 8 de la tarde con tres y a veces más horas para comer. ¿Cómo demonios se hace alguien cargo de la crianza de sus hijos si llega a casa a las 10 de la noche...?»

«Lo que tienes son horarios laborales que se alargan hasta las 8 o 10 de la noche. ¿Resultado? dormimos menos horas»

«Los físicos dicen que con el cambio de huso horario sólo se beneficiaría a un porcentaje de la población que tiene una jornada laboral muy concreta — la discontinua, con pausas para comer que se reducirían-, pero perjudicarían a los de jornada continua... ¡Debe ser que somos pocos los de la discontinua! Y... ahora que me fijo, todos los "científicos" que hablan son funcionarios» 
«Gasto más de luz y de calefacción que antes, voy más cansado y los horarios de mi trabajo se hacen más largos que antes, la gente va más nerviosa y más irascible y la natalidad ha bajado un montón»

El huso horario equivocado actual no debería ser un problema si fuéramos coherentes en nuestro horario. Si en España buena parte de la población come entre las 14.00-15.00 h y cena a las 21.00-22.00 h, lo lógico es que se empezara a trabajar a las 10.00-11.00 de la mañana y no a las 9.00, como ocurre actualmente. Este hecho provoca que madruguemos demasiado y que se alargue la jornada laboral por la mañana durante cinco horas seguidas hasta el parón a medio día, lo que no sucede en ningún país europeo.

El retraso en nuestros hábitos sociales para ajustarnos al huso horario alemán perjudica nuestra calidad de vida, sumado a un prime time televisivo - que ha sufrido un retraso de 72 minutos en los últimos 25 años (Contreras, 20163) cada vez más tardío desde la aparición de las cadenas de televisión privadas, que afecta al rendimiento y cansancio vital con el que nos levantamos por las mañanas y que arrastramos durante el día.

«En España lo que hay que cambiar son los horarios de los programas de TV. Lo que no es normal es que un programa o una peli acaben a las 12 de la noche o más tarde. Nos hemos acostumbrado a retrasar todo hasta el infinito. Eso hace que se duerman menos horas, por ejemplo... Esa mala costumbre de no comer antes de las 15 h o de no cenar antes de las 10 de la noche no sé cuándo empezó, pero creo que es bastante reciente. Porque en los 80 se comía a las 14 y se cenaba a las $21 . .$. , o sea, que seguramente se salía antes del trabajo». «Lo normal, a mi parecer, es cenar a la hora en que puedas acostarte dos horas después de cenar teniendo por delante ocho horas de sueño antes de tener que levantarte»

Con el cambio de huso horario, amanecería más temprano y anochecería también antes. En verano renunciaríamos a los anocheceres más tardíos, pero tendríamos unos amaneceres más tempranos. ¿Qué preferimos? ¿Depende de las circunstancias personales? ¿Del sector donde uno trabaje? ¿De la edad? ¿Debe primar la salud, la conciliación, lo que opine la mayoría de los españoles? ¿Ha de hacerse un cambio por ley, tipo ley anti-tabaco?

3 http://www.elmundo.es/television/2016/06/07/5755c5c0ca4741d8738b465a.html (19/01/2017). 
«El problema en invierno es que hay pocas horas de luz y ante eso poco podemos hacer. Me disgusta entrar de noche y me disgusta salir de noche. Pero, si tengo que elegir, prefiero lo primero y luego tener una horita de Sol al salir. Aunque entiendo que esto es una preferencia personal y que cada uno tendrá la suya»

"Completamente de acuerdo. Para estar en la oficina me da igual que fuera sea de día». «Lo que es de locos es que los niños se tengan que acostar en mayo y junio, que todavía tienen colegio, con la luz del día»

«Nuestro horario es terrible para los niños, los hace cansados desde pequeños, por alargar la actividad tras la puesta de Sol. En fin, que no hay por donde defenderlo si no es desde el turismo cutre o el pluriempleo (típico de la posguerra del 39)»

«En verano, cuando tengo que entrar a trabajar a las siete de la mańana, si tengo que dormir ocho horas, contando con una hora o con media hora para prepararme desde que me despierto, pues resulta que tendría que irme a acostar cuando todavía hace sol. Ese es un ejemplo del disparate de nuestro horario. Si tuviésemos nuestro huso horario natural, a las diez de la noche ya sería de noche, si no totalmente, casi, y mi cuerpo iría a dormir cumpliendo mucho mejor con nuestro horario interno. Ese es un ejemplo sencillo y habrá muchos más. Retrasar nuestro huso horario hace que el reloj biológico se sincronice mejor con el horario legal y todo son ventajas para nuestra salud»

«Al estar más al norte, oscurece a las cuatro de la tarde en Londres en invierno. Pero en verano hay sol y sale pronto por la mañana y te acompaña durante el día. Si salgo a cenar, puede ser a las 7 de la tarde, y estoy en casa no más tarde que la una (y por ley muchos lugares cierran a las once para no generar ruido). No entiendo la manía de pensar que Espańa es mejor porque estamos despiertos hasta las tantas»

La Tierra es una esfera y su eje de rotación está inclinado respecto al plano de traslación, eso implica que en países situados en el mismo huso horario no amanece simultáneamente. La línea de barrido día-noche está inclinada respecto a los meridianos. ¿Hay que partir de la base del invernal porque es el que marca el amanecer más tardío y el anochecer más temprano?

«En el sur de Europa los días en invierno son más largos que en el norte, mientras que en verano son más cortos en el sur. De Alemania para arriba los europeos se despiertan y se acuestan de noche durante el invierno. En verano, al contrario, se despiertan y se acuestan cuando es de día» 
«En Berlín y en Madrid en invierno amanece a la misma hora, con el huso actual, pero en Madrid disfrutan de una hora y media más de luz que en Berlín» «Y en junio, en Madrid es de noche cerrada a las 22.00, mientras que en Berlín no anochece hasta aproximadamente las 23.45»

«Lo que yo he dicho es que, con el huso horario, la hora de amanecer en Berlín es la misma que en Madrid en invierno, pero que oscurece una hora y media más tarde. Si cambias el huso, en Madrid amanece una hora más pronto, pero oscurece a la misma que en Berlín. Tú mismo dónde quieres las horas de sol. A las 7 de la mańana o a las 7 de la tarde. Es tan simple como eso»

«Todos los puntos de la tierra tienen un $50 \%$ de día y un $50 \%$ de noche visto un año entero. Los países del sur (si con ello se refieren a los más cercanos al ecuador) reciben más horas de luz que los del norte (en invierno), y menos en verano»

«En cualquier caso lo que es aberrante es que durante siete meses al año estamos en gmt +2 . No sé qué ventaja puede tener estar a las nueve de la tarde a cuarenta grados y con sol en el valle del Guadalquivir, o que el ocaso sea casi a las once en el oeste peninsular cuando tienes que levantarte a las seis o siete de la mañana para ir a trabajar. Dicen que en Portugal los hábitos son similares a los nuestros, parece que visitan poco el país vecino, donde se come a la una y se cena a las ocho y pico o nueve en verano a más tardar. Además, ¿̨no han tenido niños pequeños?» "¿Por qué tenemos que tener tres meses de oscuridad matutina (8.00 am) cuando cambiando el huso tendríamos solo uno?»

«El problema de España es que en realidad necesitaríamos estar en dos husos. En verano en Galicia se hace de noche casi a las once de la noche y en invierno a las nueve de la mañana no hay luz, lo cual es un disparate. Si se cambiase la hora, eso en Galicia se corregiría pero en Barcelona en invierno sería de noche casi a las cuatro de la tarde, lo cual sería un fiasco para esa zona»

«A ver, chico, ¿¿tú que prefieres, tener sol cuando estás en la oficina o cuando sales de ella? Pregunto, porque es tan simple como eso. El cambio de huso es lo que hace, te pone el Sol por la mañana y te lo quita por la tarde»

«Tienes que tomar la del solsticio de invierno, es cuando amanece más tarde y anochece más temprano. Y sigues en las mismas sea equinoccio o solsticio. Ganas sol por la mañana y lo pierdes por la tarde. Pero por lo visto a ti lo que te gusta es andar en la oficina con sol y que sea de noche cuando sales. $\mathrm{Al}$ resto, o al menos a algún resto, no» «Lo del horario es una cuestión social y de cultura. Personalmente, estoy a favor del cambio por una sencilla razón, difícilmente vas a educar a un chaval para que se acueste 
pronto y se levante pronto, si en verano permites que el Sol esté hasta las $21 \mathrm{~h}$ de la noche, eso sí que es antinatural. Y que en invierno se haga de noche a las $17 \mathrm{~h}$ de la tarde, sí, pero, mira, al menos se levantará con el Sol en el cielo y no de noche, para "que papá y mamá” puedan disfrutar del bar, único argumento que dan los que son contrarios al cambio de horario, "es que así podemos tener más fiesta"”

«En invierno se haría de noche a las 16, según tú claro; eso sí, a las 7 de la mañana tendrías luz. Solo tienes que echarle un vistazo a la hora a la que anochece y ha amanecido en Madrid hoy y quitarle una hora. Y en verano no es por nada, pero a mí me encantaba estar jugando en la calle libre como un pájaro hasta que se ponía el Sol, que era la hora fijada para volver a casa. Regla que he seguido con mi hijo...»

«Estás hablando de gustos personales»

«Pues ponemos el huso de Moscú y nos bañamos en julio a las 12 de la noche»

En mi opinión, el hecho de que en España tengamos más horas de luz en el invierno que en los países nórdicos no justifica que necesitemos una pausa de dos horas para comer y volvamos a nuestro puesto de trabajo para permanecer en él hasta que sea de noche.

«En España se toman dos platos, en Francia, Portugal, e Italia se toma uno. En los países no latinos ya ni un plato, es más un tentempié. Y creo que hasta tú podrás entender que se tarda más en tomar dos platos que uno, y uno más que un tentempié»

Tener más horas de luz no significa que las estemos disfrutando. La costumbre espańola de cenar cuando ya es de noche y antes de acostarnos (lo cual no es saludable) no se da en nuestros socios europeos, que lo hacen de día durante todos los meses estivales, beneficiándose de un tiempo libre que nosotros no disponemos.

«Lo sensato sería concentrar horarios, poderse levantar alrededor de las 7.30 (realmente solares, cuando sale el Sol), empezar a trabajar a las 8.30, un receso hacia las 13 de una hora para comer algo y salir del trabajo alrededor de las 5.30, de modo que quedase algo de tarde libre. La programación de televisión también debería adecuarse, de modo que los programas principales hubiesen acabado como mucho sobre las 23.30 y el personal no tenga la tentación de perder horas de sueño» 
«Lo que no es de recibo es lo que se ven obligados a hacer actualmente muchos trabajadores, sobre todo en las grandes ciudades: levantarse de noche, trabajar 10 horas, tener una pausa obligatoria de dos para comer, con lo que se levantan a las 7 para llegar al trabajo a las 8 (eso los que tienen suerte de que no les pille muy lejos y tengan que hacer trasbordos), parar de 1 a 3 y luego vuelta al trabajo de 3 a 6/7 (eso si no tienen que echar una "propina”), con lo que acaban llegando a casa a las entre las 7 y las 8 y terminan estando 12/13 horas pendientes de su ocupación, sin apenas tiempo libre»

«iEs que necesitamos un cambio de costumbre! Lo que no se puede hacer es levantarse mucho más tarde, la gran mayoría de los españoles, que los europeos, y comer y cenar a las horas que se come y cena en España. Además, en España se desayuna muy mal. Para empezar la jornada, necesitas un buen desayuno que te haga rendir bien a lo largo de la mañana. Cada uno puede pensar cómo quiera, pero creo que, si cambiáramos ciertas costumbres en España, nos iría mucho mejor»

«Está clarísimo que España está fuera de su horario natural y está clarísimo que nuestras costumbres de horarios son muy poco sanas. Dormimos una hora menos. Pero es que ni los países del sur con nuestro clima tienen horarios tan locos. Ni Portugal, ni Italia ni Grecia. Además, cambiar el horario a la hora de Canarias sería tan fácil como abstenerse de cambiar de hora en marzo este año y ya está»

«En el resto de Europa la jornada laboral para oficinas suele ser de 08.00 a 12.00 (30-60 minutos para comer, dependiendo del país) y hasta las 17.00-17.30. Si cambiásemos la hora podríamos tener horarios de 09.00 a 13.00 (una hora para comer) y luego hasta las 18.00 18:30. De esta forma, estaríamos perfectamente alineados con el resto de países vecinos y tendríamos también un mejor equilibrio trabajo-familia»

La Encuesta de Empleo del Tiempo ${ }^{4}$ es una investigación estadística no periódica realizada por el INE que facilita información sobre el porcentaje de personas que realizan una actividad en el transcurso del día, el promedio de tiempo diario (en horas y minutos) dedicado a una actividad por las personas que la realizan, la distribución de actividades en un día promedio por tipo de día (laborable o de fin de semana) y el porcentaje de personas que realizan la misma actividad en el mismo momento del día, denominado ritmos de actividad diaria.

4 La última Encuesta de Empleo del Tiempo se contempla en el Plan Estadístico Nacional 2009-2012, recogido en el Real Decreto 1663/2008, de 17 de octubre (BOE, 15 de noviembre de 2008). 
Con dicha encuesta, podemos obtener información primaria para saber en detalle aspectos como la dimensión del trabajo no remunerado realizado por los hogares, cómo y cuánto tiempo dedican los ciudadanos a la cultura, al ocio, a las responsabilidades familiares, etc. Así, es posible llegar a poder concretar el uso del empleo del tiempo de grupos sociales especiales como el de los ancianos, los que se encuentran desempleados o los jóvenes, para así concretar mejor políticas familiares, de conciliación e igualdad entre mujeres y hombres a la vez que estimar las cuentas satélites de la contabilidad nacional del sector hogares (considerado actualmente como trabajo no productivo, al no estar incluido en el PIB).

La metodología de la última Encuesta de Empleo del Tiempo realizada en España (2009-2010) parte de la anterior encuesta efectuada entre los ańos 2002-2003 y de las nuevas reglas de Encuestas Armonizadas Europeas de Empleo del Tiempo, de la Oficina Estadística de la Unión Europea, preparadas por expertos durante los ańos 2007 y 2008 para poder hacer más sencilla la normativa de este tipo de encuestas que se hizo en el año 2000.

Uno de los objetivos conseguidos en el proyecto de esta encuesta de Eurostat es la posibilidad de comparar los resultados obtenidos entre los diferentes países, ya que de esta manera se puede obtener más valor de las informaciones que se desprenden de los resultados. Es la conclusión más destacable a la que se llegó tras la equiparación pormenorizada de las encuestas que se utilizaron para los países de la Unión Europea y de la Asociación Europea de Libre Comercio (EFTA).

Tal y como he comentado, durante los años 2002-2003 el Instituto Nacional de Estadística llevó a cabo la primera edición de la Encuesta de Empleo del Tiempo siguiendo las recomendaciones de Eurostat, bajo las cuales 15 países de la Unión Europea han realizado operaciones similares en los últimos años. La encuesta entrevista a todos los individuos del hogar de 10 años o más, los cuales deben rellenar un cuestionario de datos sociodemográficos y un diario de actividades donde se recogen todas las actividades realizadas durante 24 horas en intervalos de $10 \mathrm{minu}$ tos. En la primera edición de la encuesta fueron entrevistadas 46.774 personas de 10 años o más pertenecientes a 20.603 hogares. La segunda edición de la encuesta se llevó a cabo en 2009-2010 y, por falta de presupuesto, en ella completaron el diario de actividades 19.295 personas (menos de la mitad que la anterior oleada) residentes en 9.541 hogares (nuevamente menos de la mitad). En la página web del INE se puede acceder a los datos completos de ambas encuestas. 
He solicitado formalmente al INE lo conveniente que sería realizar otra encuesta actualizada y con un número representativo de hogares, puesto que los nuevos datos nos ayudarían a que este debate pudiera estar más fundamentado empíricamente. Me han confirmado que la siguiente encuesta está prevista cuando se realice la próxima ola europea en el 2020. Pensemos que otros países realizan esta encuesta anualmente y no pocos investigadores me han comentado que los datos españoles son escasos y anticuados, por lo que se pierde fiabilidad. También debemos pensar que se trata de una encuesta (en este sentido podemos hablar de una estimación) y no una comprobación verificada real de hechos.

Una recopilación de datos de diferentes países europeos sobre el uso del tiempo de los ciudadanos ha sido elaborada por Eurostat a través del Harmonised European Time Survey en un proyecto denominado «Time use survey - collection round $»^{5}$. El Instituto Estadístico de Suecia y la Universidad de Oxford ${ }^{6}$ realizaron un estudio complementario con dichos datos.

Muchos países europeos más desarrollados que España tienen un horario distribuido de diferente manera que permite integrar mejor la vida familiar, profesional y personal. ¿Cómo lo consiguen? ¿Sería posible modificar poco a poco el horario español para acercarnos a su horario? ¿Influye el huso horario? Nos serviremos de las gráficas de los ritmos de tiempo, es decir, el porcentaje de personas que realizan la misma actividad principal en el mismo momento del día, al ser este el mejor de los indicadores obtenidos en las encuestas normalizadas para toda Europa en el uso del tiempo si el fin es hacer una comparativa. Para entender bien los gráficos que exponemos a continuación, hay que partir de que en el eje de ordenadas aparece el tanto por ciento de personas que realizan una acción y en el eje de abscisas las horas del día en las que la realiza. La intersección de ambas coordenadas en los diferentes puntos forma un área no regular pintada de diversos colores que nos indica los períodos en los que se destina ese tiempo para dicha actividad. Por otra parte, hay que tener en cuenta que siempre habrá ciudadanos que tienen unos horarios distintos al resto, pero, para poder hacer el

5 Harmonised European Time Use Survey [online database versión 2.0]. Creada en el 2005-2007 por el Instituto Sueco y Finés de Estadística [reference date 2007-10-01]. http://www.tus.scb.se (19/01/17).

6 La Universidad de Oxford cuenta con un Centro de Investigación Internacional sobre el Uso del Tiempo en el que he realizado una estancia invitado como investigador académico. Para la realización de mi tesis doctoral recibí orientación por parte de diferentes profesores del Departamento de Economía y Sociología de dicha Universidad, lo que, junto con los seminarios a los que he podido asistir y las publicaciones consultadas en el centro bibliográfico, enriquece y da un perfil más internacional a mi investigación. 
estudio, vamos a fijarnos en lo que realizan la mayoría de personas configurando un horario estándar.

Los países europeos analizados son:

-Alemania

-Bélgica

—Finlandia (cuyo horario oficial tiene una hora más que Alemania)

-Francia

- Noruega (escogido, a pesar de no ser miembro de la UE, como botón de muestra de país con facilidades para conciliar)

—Reino Unido (cuyo horario oficial tiene una hora menos que Alemania)

-Suecia

-Italia

No contamos con datos de la Harmonised European Time Survey para otros países como Austria, Holanda, Luxemburgo, etc., así que no podemos incluirlos en nuestro estudio.

Los colores que definen las diferentes áreas (intersección del tanto por ciento de personas que realizan una acción y las horas del día en las que la realizan) son:

- Rojo: trabajo y estudio

- Azul: dormir y cuidados personales

- Marrón: televisión, vídeo, internet

- Amarillo: desplazamientos

- Blanco: comidas

- Verde: trabajos del hogar

- Gris: tiempo libre

- Granate: tiempo no especificado (apenas existente)

España es un país muy peculiar en sus horarios, muy distintos a los del resto de Europa, tal y como podemos observar en los siguientes gráficos. 


\section{España}

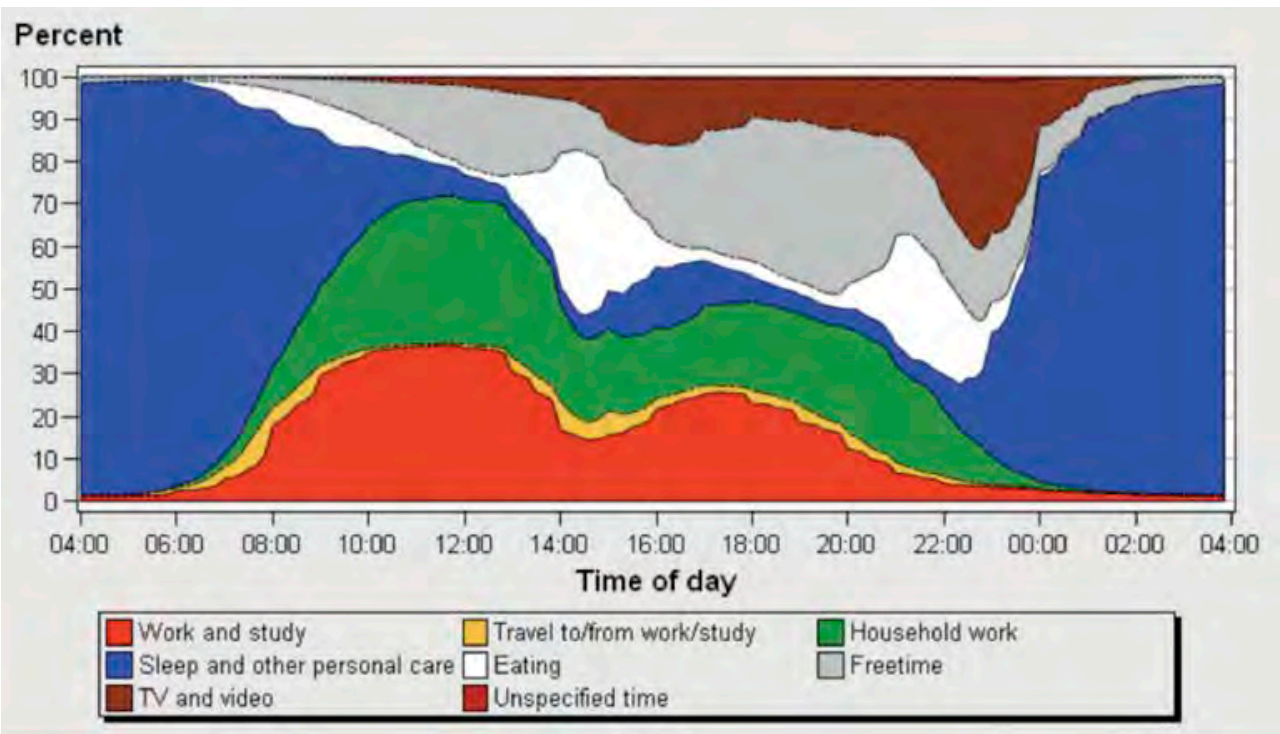

Italia

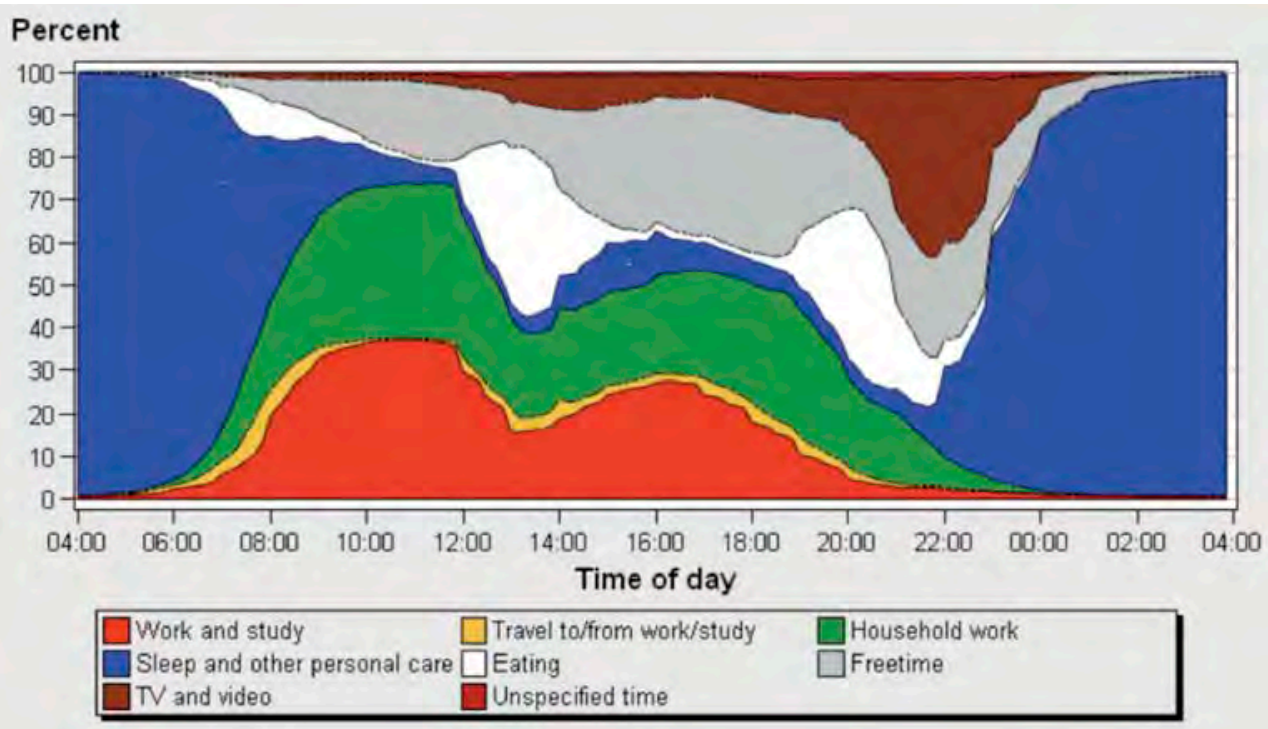




\section{Francia}

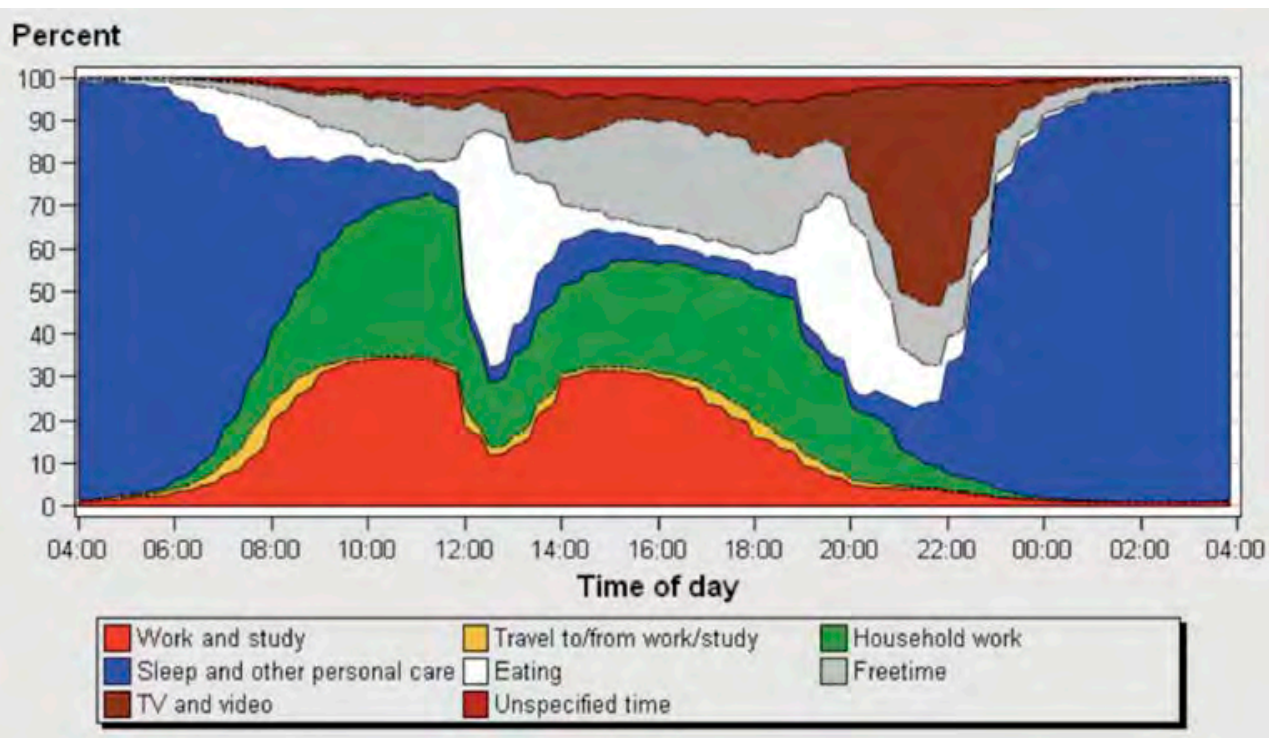

\section{Bélgica}

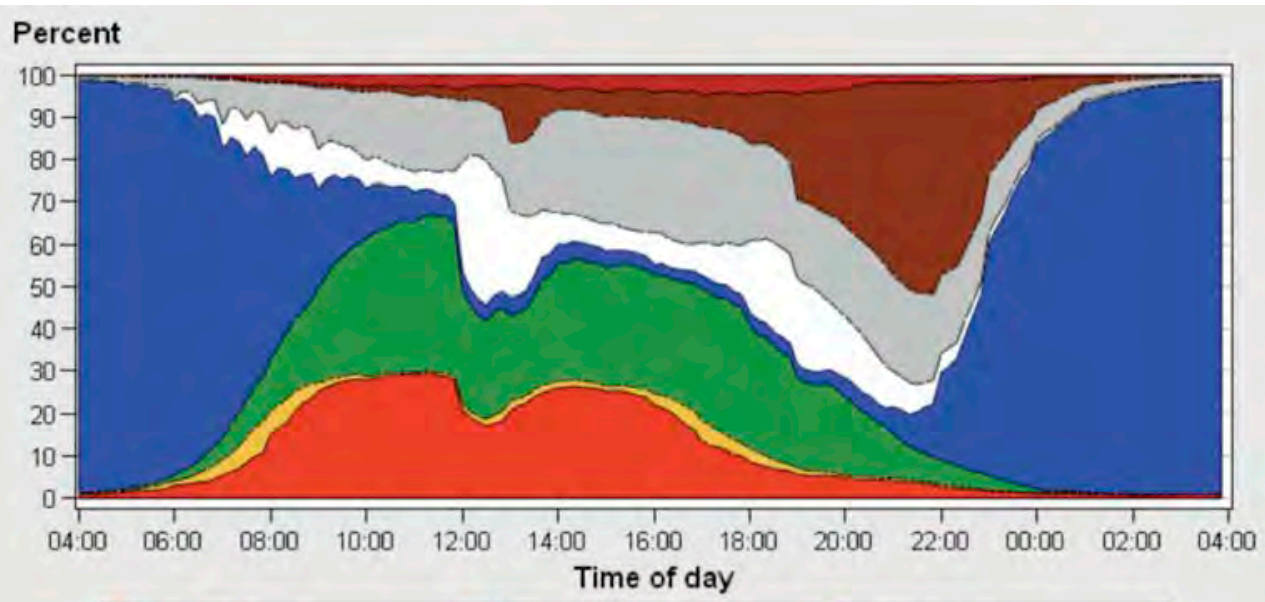

$\begin{array}{ll}\square \text { Work and study } & \square \text { Travel to/from work/study } \\ \text { Sleep and other personal care } & \square \text { Eating } \\ \text { TV and video } & \square \text { Unspecified time }\end{array}$




\section{Reino Unido}

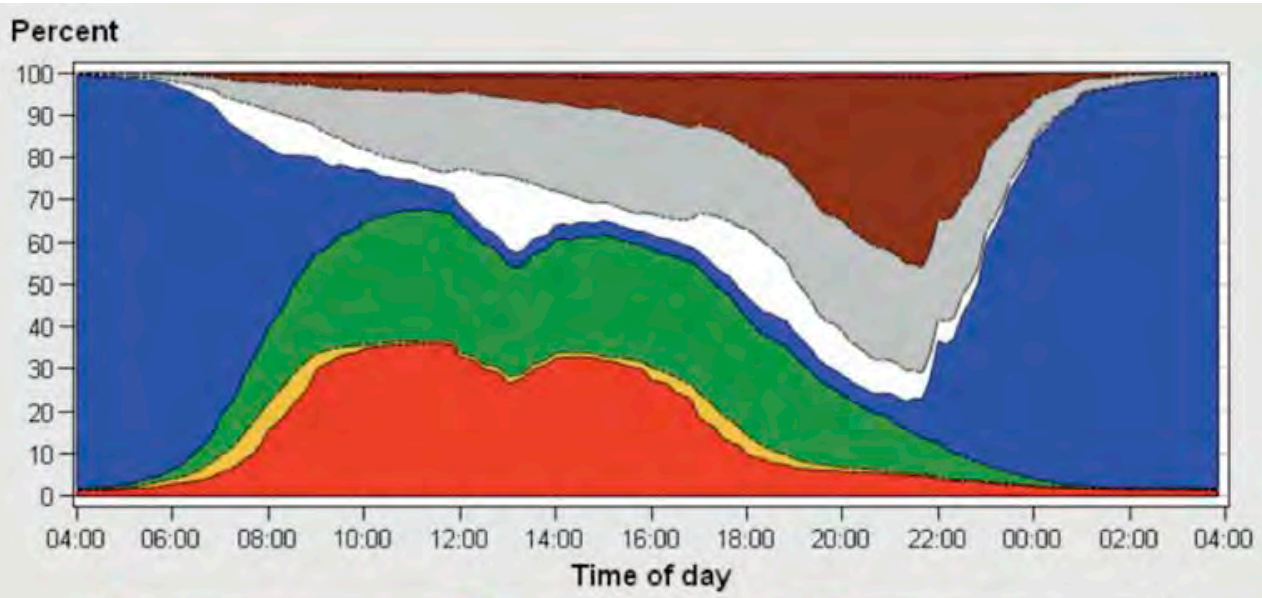

\begin{tabular}{|c|c|c|}
\hline Work and study & $\square$ Travel to/from work/study & Household work \\
\hline Sleep and other personal care & $\square$ Eating & Freetime \\
\hline TV and video & Unspecified time & \\
\hline
\end{tabular}

\section{Alemania}

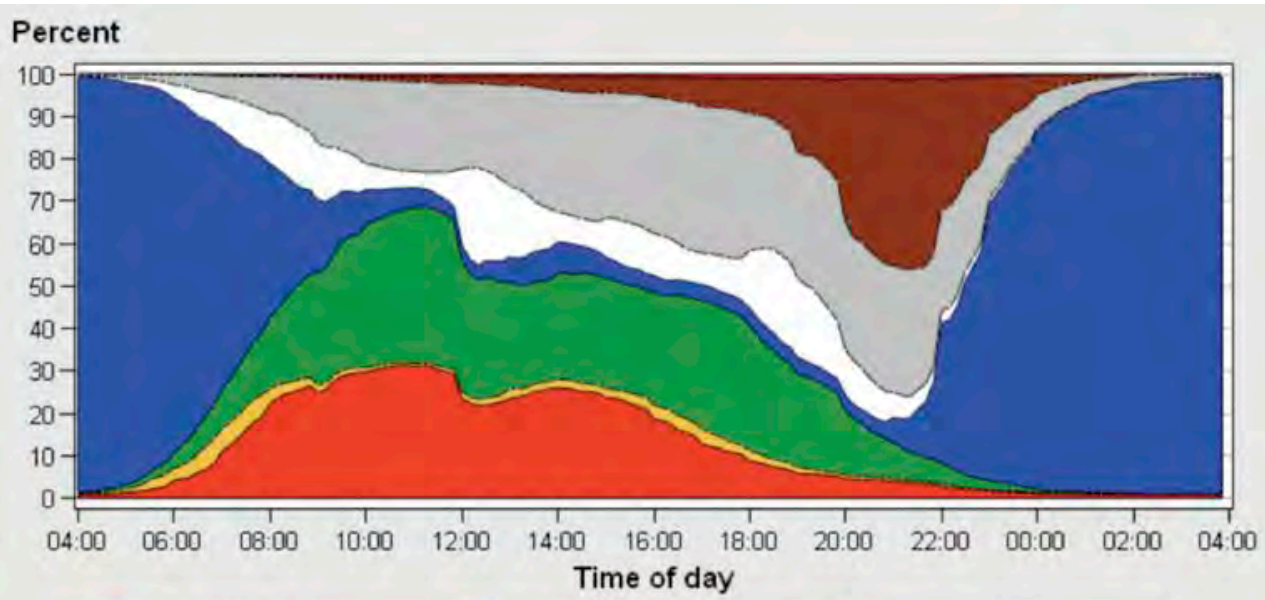

$\square$ Work and study $\quad \square$ Travel to/from work/study

Sleep and other personal care $\square$ Eating

Household work

TV and video

$\square$ Unspecified time

Freetime 


\section{Suecia}

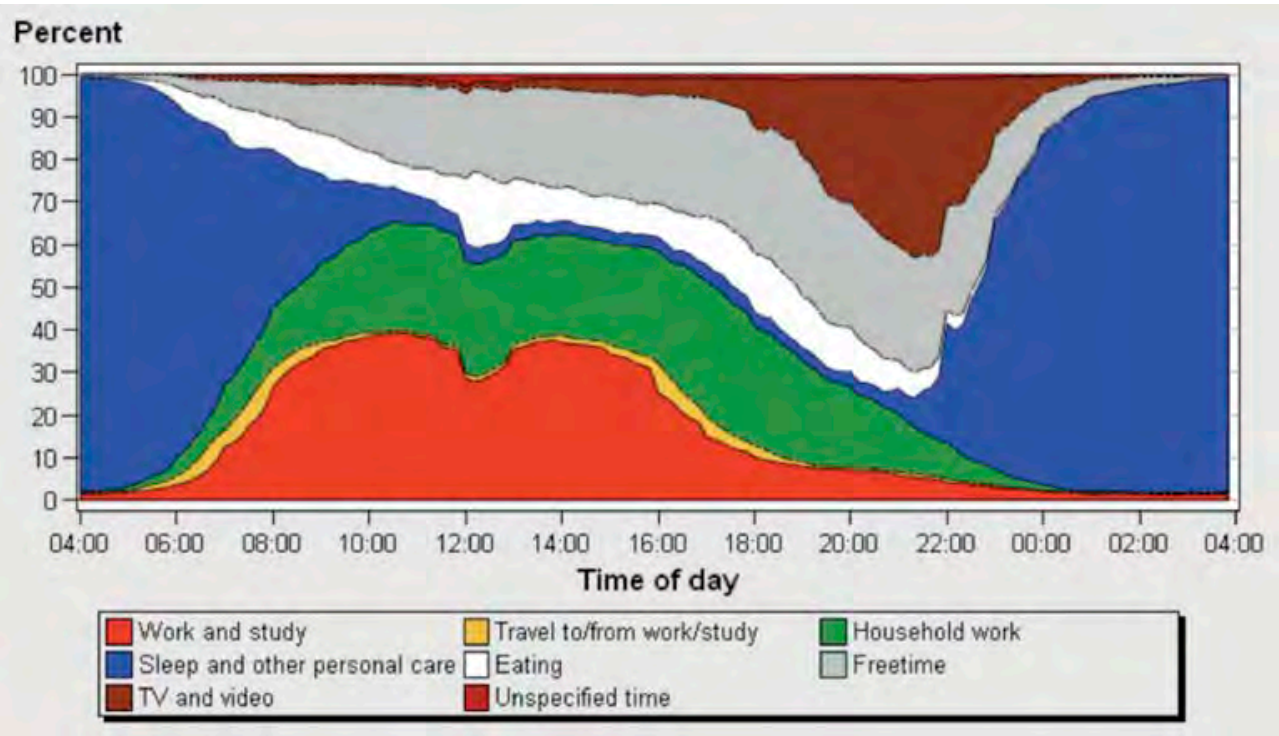

\section{Noruega}

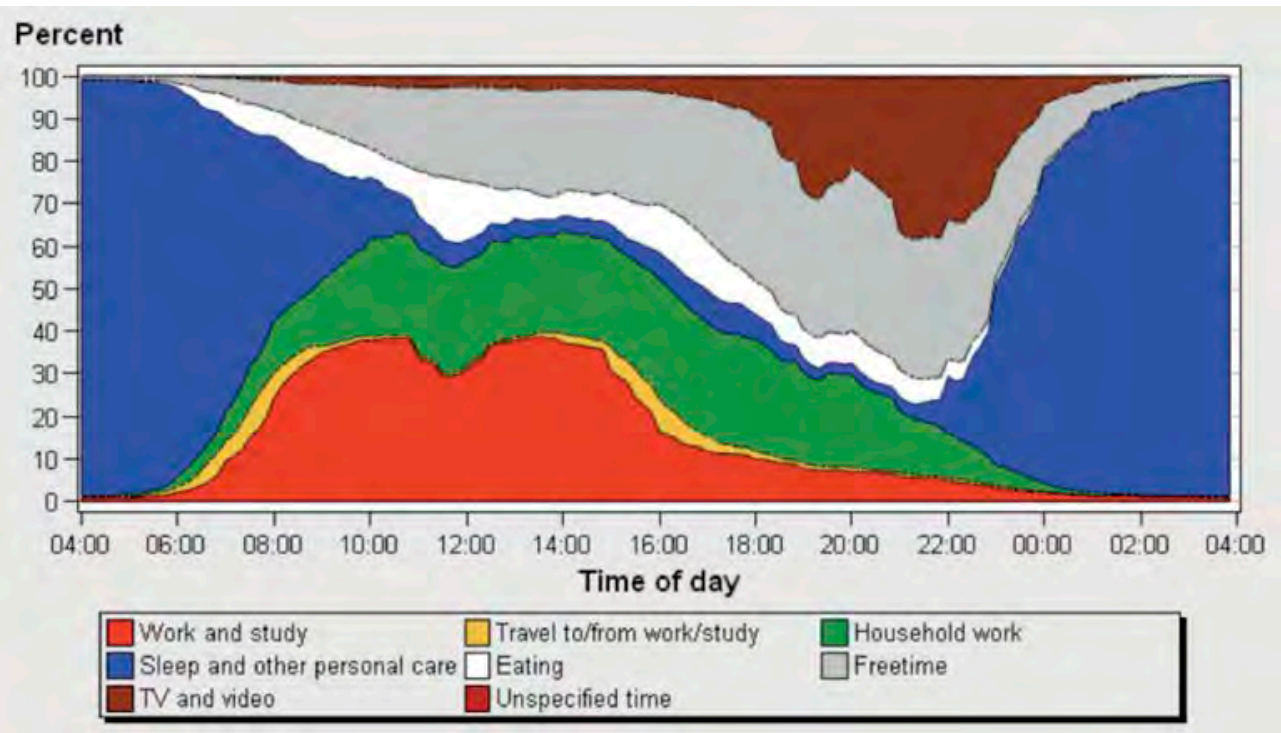




\section{Finlandia}

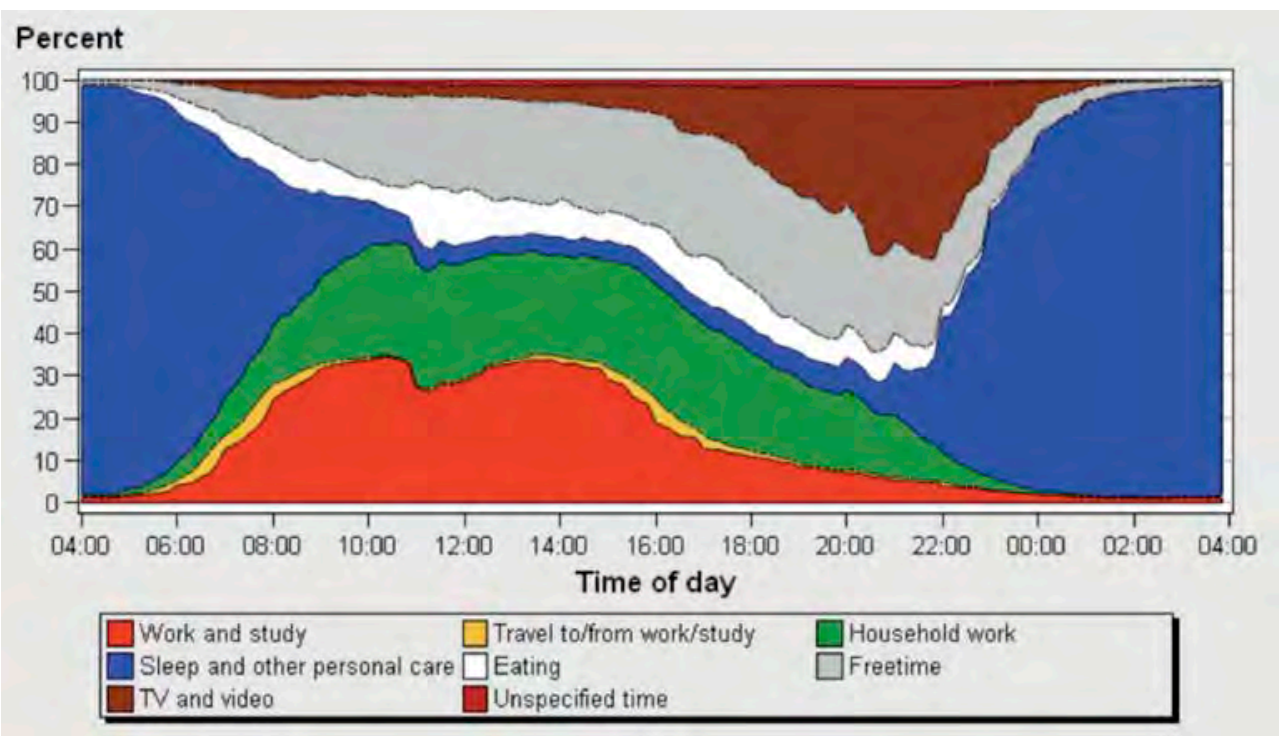

¿Solucionaría solamente el cambio de huso horario el problema de poder conciliar la vida profesional con la familiar y personal? En mi opinión, sería una ayuda, una palanca para poner en marcha otro tipo de medidas:

«[Los físicos] Se muestran escépticos sobre la posibilidad de que implique un cambio de costumbres. Pues claro que el cambio de huso horario no traería un cambio en las costumbres, porque no sería la única modificación necesaria para cambiar los hábitos de los españoles. Habría que introducir cambios paulatinamente y en menos de dos décadas nos habríamos adaptado a horarios europeos y más convenientes y productivos»

«Cambiar el horario no es la medida mágica para conciliar ni racionalizar, pero es el acicate necesario"

«Cambiar el horario no genera problemas, porque es tan fácil como esta primavera abstenerse de cambiarlo (si nos quejamos de que este cambio genera trastornos, nos ahorramos este y ya está)»

«Mi opinión es que cambiar de huso no influiría demasiado en nuestros hábitos si no va acompañado de más cambios que se podrían hacer igualmente. Por ello, no soy partidaria 
de ningún cambio, pero entiendo que personas que están a casi una hora solar de distancia puedan tener otra opinión»

"Que España tiene un huso horario incorrecto es un hecho, no una opinión. España va una hora adelantada con respecto al Sol. Si esto ha sido por Franco o por De Gaulle, es un intento de politizar... Pero está claro que España NO está en el huso horario propio. Si esto cambiaría costumbre es discutible y puede que no si es un hecho aislado, pero si se mete dentro de un paquete de propuestas, como adelantar la TV, reducir la pausa para comer, adelantar las horas de entrada y salida de los trabajos... Adelantar los horarios de los colegios... Pues es posible que España pueda dejar de ser el país donde todo ocurre tarde»

«Si amanece antes y comemos antes, podemos salir antes del trabajo y esto sería una palanca para otros cambios, además de lograr un beneficio para la salud»

«En mi opinión es un factor que ayudaría a la productividad, pero sólo sería uno entre los doce que yo considero fundamentales, como es el liderazgo, la cultura del trabajo, el respeto y la cooperación, los horarios laborales, la motivación, conciliación, el trabajo en equipo, la honestidad, la promoción, la remuneración y la humildad»

La cultura del presentismo laboral y el miedo a perder el puesto de trabajo en una sociedad (la española) con el doble de paro que la media comunitaria hace que muchos se vean obligados a estar presentes en el puesto de trabajo muchas más horas de las realmente contabilizadas y pagadas, lo que disminuye nuestra productividad por hora trabajada, con un sacrificio personal que sufre la conciliación con la vida personal y familiar. Además, y aquí está una parte importante de que nuestro huso horario impida que podamos conciliar más, cuando más tarde anochece, más se alarga la jornada laboral (no en la hora fijada como finalización de la jornada laboral en los contratos, sino en las horas extras que se realizan no pagadas y realizadas por estar mal visto ausentarse antes de que lo haga el mando superior, por ejemplo).

«Te cuento. Donde yo trabajaba antes había horario flexible, podías entrar entre las 8 y las 9.30; por tanto, según la hora de entrada, podías salir entre las 17 y las 18.30. Pero allí nadie salía por lo menos hasta las 7 , excepto los integrantes del comité de empresa, que sí entraban a las 8 y se iban a las 17 y nos decían a los demás que hiciéramos lo mismo, 
pero nadie se atrevía por miedo, no por la carga de trabajo. Si nos hicieran entrar a las 7 para salir teóricamente a las tres, seguiríamos saliendo a las 7 de la tarde, los jefes no entenderían el que alguien tenga toda la tarde la silla vacía y esté en su casa. Es muy triste». «Cambiar la zona horaria nos daría más horas de luz por la mañana sacrificándolas de noche. En Inglaterra, donde llevo unos diez años, se nota al despertarse que tiene más luz. Cuando voy a España me sorprende no ver el Sol hasta pasadas las 9 a veces. Otra cosa es que la vida en España no cambie y, aunque se haga de noche antes, la gente siga en la oficina hasta tarde. Pero eso es un estudio sociológico, ¡no físico!»

«La costumbre popular es que mientras haya Sol... es tiempo de trabajar ¿De qué nos sirven más horas de Sol si nos tienen encerrados en jornadas interminables entre cuatro paredes?»

«Cuando el Sol se pone antes en términos de hora legal, esto hace que la gente acelere la salida del trabajo»

«La realidad es que España tiene un grave problema de productividad a pesar de que se trabaja más horas que en el resto de países de Europa y el desacompasamiento del horario con respecto al horario solar es un elemento que influye en esta cuestión»

«El tema que no se quiere debatir es la conciliación laboral porque al empresariado no le interesa que la gente salga del trabajo a las 17-18 horas»

«Si una hora de desfase con la hora solar no creo que influya, en verano pasan a ser de dos horas, más de dos horas y media en Vigo, eso ya me parece excesivo. Al final, cuando son las 12 de la noche oficialmente en Vigo, en la hora real no son ni las nueve y media; sin embargo muchos trabajadores empiezan a las 6, que en horario real no son ni las tres y media, horario en el que una persona para su descanso óptimo a ser posible debería estar durmiendo todavía y no andar despierto desde hace una hora. Al final el desfase horario contribuye a querer aprovechar el día de forma engańosa, excesiva y a la larga contraproducente»

Por otra parte, con el correcto huso horario, se facilitaría una mayor apertura de las exportaciones espańolas a los mercados europeos (actualmente el 51,7 \% a la zona euro y el 66,5 \% a la Unión Europea), puesto que al coordinar los horarios de nuestras jornadas laborales con el resto de Europa, se mejorarían nuestras relaciones comerciales y esto beneficiaría al contacto entre países.

"Yo utilizo profesionalmente los horarios comerciales intereuropeos. En la situación actual, con los horarios españoles, NO EXISTE coincidencia de horarios. Yo estoy 
harto de que me llamen a mi hora de comer y me frustra no poder comunicarme con mis interlocutores continentales de 12.30 a 14.00 hora espańola. Hasta tal punto que he tenido que ir adelantando mi hora de almuerzo, pero ya le digo que eso no es tan fácil de poner en práctica en Espańa sin que te miren como a un batracio. Por tanto, ponernos en el horario de UK facilitaría las relaciones comerciales con Europa, no las empeoraría. No tiene más que ver el comercio que hay dentro de los USA, a pesar de sus cuatro husos horarios»

Aunque hay algunos que prefieren un gran parón a medio día con aperitivo y siesta incluida:

«La siesta y el aperitivo que no nos lo quiten»

Los turistas, que en España contribuyen al $11 \%$ del PIB y generan el $13 \%$ del empleo, agradecerían (nos referimos a un turismo sano) dicha modificación y se sentirían menos sorprendidos de nuestro desordenado estilo de vida, al que no acaban de adaptarse los días que disfrutan de nuestro país.

«Y si nos metieran el huso horario de verano para todo el año (el sueńo de los hosteleros), nos levantaríamos y viviríamos las primeras horas de la jornada entre tinieblas en invierno. Lo mejor es el huso horario del invierno para todo el ańo y a los hosteleros se les ve el plumero, ya que quieren turistas borrachos apurando las horas de luz de la tarde, más toda la noche, ya que por la mañana les importa una higa que el Sol salga pasadas las $9 \mathrm{~h}$ en invierno. Los turistas borrachos están durmiéndola mientras trabajadores y escolares van entre tinieblas a sus obligaciones»

El objetivo no es que todos tengamos el mismo horario (lo cual es imposible y generaría, por ejemplo, cantidad de problemas de tráfico y cuellos de botella en bares y restaurantes), sino acomodar nuestras vidas para poder integrar la vida profesional, personal y familiar. Pensemos que el uso del tiempo y la forma de conciliar tienen una influencia grande en muchos y diversos aspectos: la calidad de vida, la salud, el rendimiento escolar, la productividad, el sueńo, la siniestralidad, los accidentes de tráfico, la igualdad, etc. 
Es acertada la propuesta de las fuerzas políticas de adelantar la hora de la salida del trabajo a una hora razonable, realizando también un estudio, en el que esté representada la sociedad española en su conjunto, sobre el posible cambio de huso horario en España y analizar el resultado. En economía nos referimos a la teoría de juegos como una teoría de estrategias en la que las acciones de cada jugador son interdependientes, y eso es lo que ocurre con nuestros horarios, puesto que están interrelacionados.

«Yo estaría encantado de entrar a currar a las 8 am con el huso actual, a las 7 am con el de Greenwich. Pero resulta que, si mis clientes no cambian de horario, me toca adaptarme y seguir entrando a las 9 am»

Se trataría de llegar a la estrategia óptima maximizando la ganancia esperada por cada jugador y eso es lo que plantean hoy en día mayoritariamente las fuerzas políticas antes citadas. Seamos valientes para afrontar el artículo $5^{\circ}$ de la famosa Orden de 7 de marzo de 1940, de Presidencia del Gobierno, que supuso a la larga el abandono del huso horario de Greenwich, que indica: «Se señalará la fecha en que haya de restablecerse la hora normal». No podemos seguir aplicando más vale lo malo conocido que lo bueno por conocer. 
HUSOS HORARIOS

ESPANOLES: RACIONALIDAD

FRENTE A LEYENDA

José María Martín Olalla

Universidad de Sevilla

Doi: 10.17075/enhhp.2017.003 

La discusión sobre los horarios españoles ha hecho fortuna con dos lemas. El primero plantea el problema: «Vivimos con un jet-lag permanente» (Vidales 2013). El segundo da la solución: «Conciliar presupone regresar a Greenwich» (Chinchilla 2012). Este simple análisis y esta simple solución mejorarían un sinfín de problemas de la vida diaria cuyo origen está en otro sinfín de hechos marcados todos por el signo del mal: el nazismo, el franquismo, la guerra, el pluriempleo, el machismo, la ineficiencia y la secular irracionalidad española. Quienes han propagado estas ideas, Joseph Collin (véase p. 26 del Informe de la Subcomisión y Barbería 2014), Nuria Chinchilla (2012) y, en general, la Asociación para la Racionalización de los Horarios Españoles (Arhoe), actúan como una especie de policía moral con un éxito mediático tal que no extrañaría que algunas personas miren hoy al reloj mientras comen, cenan o ven la televisión tratando de discernir si hacen bien o hacen mal.

Esos dos eslóganes son científicamente incorrectos. El primero engaña al común ignorando la naturaleza cíclica del problema horario. No vivimos con ningún jet-lag permanente porque el mediodía sigue ocurriendo con la misma cadencia regular de siempre. Los gobiernos no pueden alterar la naturaleza manifestada en la duración del día, de la noche o de una revolución de la Tierra. Los gobiernos pueden alterar la hora oficial porque esta no es natural: es una construcción humana, social y política. Cuando alteran la hora oficial, las duraciones que moldean nuestro ritmo de vida (el día y la noche) no cambian.

La conciliación también se refiere a duraciones, en este caso de actividades humanas, y por eso también es independiente de la hora oficial, que es solo una referencia. Mejorar la conciliación no requiere alterar el huso, solo requiere mejorar la conciliación. Al ligar estos conceptos independientes, Chinchilla y Collin muestran su escaso conocimiento sobre la naturaleza real del problema. Dejen el huso en paz. 


\section{EL RELOJ CAMBIA, LA VIDA NO}

El Gobierno puede fijar el huso horario pero no tanto los hábitos horarios, que son determinados por las personas. Lo hacen tomando decisiones racionales basadas en la hora oficial establecida. Estas decisiones dejan de ser racionales si se altera la hora oficial. Por este papel primordial, y no por cuestiones ideológicas, la hora oficial nunca se ha modificado en los países desarrollados en tiempos de paz y mantienen hoy las decisiones que se tomaron tras el final de la Segunda Guerra Mundial. La estabilidad del sistema horario, y no el huso concreto, es el bien superior. Dejen el huso en paz.

Cuando se altera la hora oficial, y siempre se hace hacia adelante, la sociedad reacciona de forma diferente según las circunstancias. En tiempos de paz es relativamente frecuente que la sociedad rechace la nueva hora y la medida se revierta pronto. Ni Portugal ni Reino Unido pudieron mantener la hora de Berlín en la segunda mitad del siglo pasado; tampoco en Rusia tuvo éxito con la reforma de principios de esta década, ni en Chile con la de 2015.

En otros casos la sociedad opta por no alterar nominalmente sus horarios y acepta adelantar sus costumbres. Un ejemplo es la provincia canadiense de Saskatchewan, la única de ese país con un huso horario adelantado y que mantiene los mismos horarios nominales. El reloj no cambia aparentemente y la vida simplemente se desplaza: aceptan entrar a trabajar de madrugada a cambio de salir antes de anochecer. Ni siquiera en este caso extremo podemos hablar de un jet-lag permanente porque los habitantes siguen viviendo con la cadencia debida.

Un comportamiento colectivo olvidado, fascinante y racional es que la sociedad responda con una reacción igual y de sentido contrario que anule la medida gubernamental. Si el Gobierno adelanta la hora legal, la sociedad retrasa racionalmente todos sus horarios (Martín Olalla 2016a: 14 y ss.). Con este comportamiento la sociedad sigue realizando sus quehaceres diarios exactamente igual que antes: el reloj cambia, la vida no.

Esta fue la respuesta racional que los españoles dieron al adelanto del huso horario: retrasar sus horarios. Sí, parece increíble, pero se puede construir una oración afirmativa simple con las palabras españoles, huso horario y racional. Y es increíble porque setenta años después este comportamiento racional es malinterpretado y vilipendiado irracionalmente desde Arhoe. Esta asociación cree, incorrectamente, que cambió el reloj y cambió la vida. 


\section{LA LEYENDA HORARIA ESPAÑOLA}

El mito horario español proviene, en última instancia, de no entender este proceso y, operativamente, se debe a la inercia de comparar los hábitos horarios en base a las horas nominales del reloj. Hay dos problemas con este protocolo: primero, que los relojes modernos desconocen todo lo relativo al amanecer y el anochecer, cuya influencia desarrollaré más tarde. En segundo lugar, que en la Tierra se usan dos relojes diferentes: el estándar, que fija el mediodía solar arbitrariamente a las $12 \mathrm{pm}$, y el reloj adelantado, que fija el mediodía solar arbitrariamente a la $1 \mathrm{pm}$, usado no solo en España, sino en una veintena de países, como Francia o Argentina.

Ninguno de estos relojes es mejor que el otro. Son simplemente diferentes y no se pueden comparar directamente, como hace Fernández-Crehuet (Fernández-Crehuet 2016; Sánchez 2016): hay que referir los valores del reloj adelantado al reloj estándar correspondiente o referir los valores del reloj estándar a su correspondiente adelantado. No es complicado: se trata de restar o sumar la unidad.

El proceso se entiende mejor con un ejemplo: cuando un reloj marca en Madrid las 2pm hora de Berlín (adelantada), también está marcando la 1 pm hora de Londres (estándar), porque ambos son exactamente el mismo instante de tiempo. El primer valor (el que aparece en el reloj) es el que usamos día a día sin problemas. El segundo valor es el que debe usarse para comparar con otros lugares donde rija un reloj estándar: las 2pm en Madrid hoy no son lo mismo que las $2 \mathrm{pm}$ en Berlín ni que las 2pm en Londres, ni siquiera lo mismo que las 2pm en Madrid en el año 1930. Las actuales 2pm en Madrid son lo mismo que la $1 \mathrm{pm}$ en cualquiera de esas circunstancias: es decir, una hora después del mediodía.

Cuando se analizan de esta forma nuestros hábitos, se observa que nuestra hora de comer (1 pm hora de Londres), de cenar ( $8 \mathrm{pm})$, del prime-time televisivo $(10 \mathrm{pm})$ son similares a las de otros países (véase el cuadro I y Martín-Olalla 2016b: 20-26). Este sencillo argumento, conocido desde hace décadas, explica racionalmente la leyenda de los horarios españoles y las coincidencias muestran que seguimos haciendo las cosas igual que en 1930: el reloj cambió, la vida no. 


\begin{tabular}{|c|c|c|c|c|c|c|}
\hline \multirow[t]{4}{*}{ País } & \multicolumn{3}{|c|}{ Comida } & \multicolumn{3}{|c|}{ Cena } \\
\hline & Hora & Hora & Distancia al & Hora & Hora & Distancia al \\
\hline & oficial & estándar & anochecer & oficial & estándar & anochecer \\
\hline & $\mathrm{t}$ & $\mathrm{t}^{*}$ & $\Delta \mathrm{t}$ & $\mathrm{t}$ & $t^{*}$ & $\Delta \mathrm{t}$ \\
\hline Alemania* & $12: 20$ & $12: 20$ & $-04 \mathrm{~h} 00 \mathrm{~m}$ & $18: 40$ & $18: 40$ & $+02 \mathrm{~h} 20 \mathrm{~m}$ \\
\hline Bulgaria* & $12: 20$ & $12: 20$ & $-04 \mathrm{~h} 30 \mathrm{~m}$ & $19: 20$ & $19: 20$ & $+02 \mathrm{~h} 30 \mathrm{~m}$ \\
\hline Bélgica* & $12: 30$ & $11: 30$ & $-04 \mathrm{~h} 10 \mathrm{~m}$ & $18: 50$ & $17: 50$ & $+02 \mathrm{~h} 10 \mathrm{~m}$ \\
\hline Canadá & $12: 20$ & $12: 20$ & $-04 \mathrm{~h} 20 \mathrm{~m}$ & $18: 10$ & $18: 10$ & $+01 \mathrm{~h} 30 \mathrm{~m}$ \\
\hline Dinamarca & $12: 20$ & $12: 20$ & $-03 \mathrm{~h} 20 \mathrm{~m}$ & $18: 30$ & $18: 30$ & $+02 \mathrm{~h} 50 \mathrm{~m}$ \\
\hline Eslovenia* & $13: 00$ & $13: 00$ & $-03 \mathrm{~h} 20 \mathrm{~m}$ & $19: 10$ & $19: 10$ & $+02 \mathrm{~h} 50 \mathrm{~m}$ \\
\hline España & $14: 30$ & $13: 30$ & $-03 \mathrm{~h} 30 \mathrm{~m}$ & $21: 30$ & $20: 30$ & $+03 \mathrm{~h} 30 \mathrm{~m}$ \\
\hline Estados Unidos & $12: 10$ & $12: 10$ & $-04 \mathrm{~h} 40 \mathrm{~m}$ & $18: 40$ & $18: 40$ & $+01 \mathrm{~h} 50 \mathrm{~m}$ \\
\hline Estonia* & $12: 10$ & $12: 10$ & $-03 \mathrm{~h} 10 \mathrm{~m}$ & $18: 10$ & $18: 10$ & $+02 \mathrm{~h} 50 \mathrm{~m}$ \\
\hline Finlandia* & $11: 10$ & $11: 10$ & $-03 \mathrm{~h} 50 \mathrm{~m}$ & $17: 10$ & $17: 10$ & $+02 \mathrm{~h} 10 \mathrm{~m}$ \\
\hline Francia & $12: 40$ & $11: 40$ & $-04 \mathrm{~h} 20 \mathrm{~m}$ & $20: 10$ & $19: 10$ & $+03 \mathrm{~h} 00 \mathrm{~m}$ \\
\hline Irlanda & $13: 15$ & $13: 15$ & $-03 \mathrm{~h} 00 \mathrm{~m}$ & $18: 30$ & $18: 30$ & $+02 \mathrm{~h} 15 \mathrm{~m}$ \\
\hline Italia & $13: 20$ & $13: 20$ & $-03 \mathrm{~h} 20 \mathrm{~m}$ & $20: 10$ & $20: 10$ & $+03 \mathrm{~h} 40 \mathrm{~m}$ \\
\hline Letonia* & $13: 00$ & $13: 00$ & $-02 \mathrm{~h} 40 \mathrm{~m}$ & $19: 10$ & $19: 10$ & $+03 \mathrm{~h} 30 \mathrm{~m}$ \\
\hline Lituania* & $13: 00$ & $13: 00$ & $-03 \mathrm{~h} 00 \mathrm{~m}$ & $19: 00$ & $19: 00$ & $+03 \mathrm{~h} 00 \mathrm{~m}$ \\
\hline Noruega* & $11: 50$ & $11: 50$ & $-03 \mathrm{~h} 20 \mathrm{~m}$ & $16: 30$ & $16: 30$ & $+01 \mathrm{~h} 20 \mathrm{~m}$ \\
\hline Polonia* & $14: 10$ & $14: 10$ & $-01 \mathrm{~h} 30 \mathrm{~m}$ & $19: 20$ & $19: 20$ & $+03 \mathrm{~h} 40 \mathrm{~m}$ \\
\hline Reino Unido & $13: 00$ & $13: 00$ & $-03 \mathrm{~h} 00 \mathrm{~m}$ & $18: 40$ & $18: 40$ & $+02 \mathrm{~h} 40 \mathrm{~m}$ \\
\hline Suecia* & $12: 10$ & $12: 10$ & $-02 \mathrm{~h} 50 \mathrm{~m}$ & $18: 10$ & $18: 10$ & $+03 \mathrm{~h} 10 \mathrm{~m}$ \\
\hline
\end{tabular}

Cuadro I: Si medimos la hora de la comida y la hora de la cena como el instante cuando más personas comen cerca del mediodía y por la tarde-noche, el cuadro expresa de tres formas diferentes esos instantes: $\mathrm{t}$ es la hora oficial, $\mathrm{t}^{*}$ es la hora estándar válida para comparar unos con otros (en el caso de Francia, Bélgica y España se corresponde a la hora del meridiano de Londres) y la columna $\Delta \mathrm{t}$ es la distancia al anochecer invernal. Los datos están redondeados a la decena del minuto más cercano, excepto el irlandés, que lo está al cuarto de hora. Los datos de los países señalados con una estrella se obtuvieron de la Encuesta de Uso del Tiempo Armonizada en Europa (Hetus 2005).

Los datos están representados en la figura 3 del artículo «Nuestro huso horario es inocente. Inconvenientes de un cambio de huso en España» de Jorge Mira Pérez, en esta publicación, página 25. 
Por eso no hace falta que nos hagan regresar a Greenwich. Nunca nos fuimos de allí. Dejen el huso en paz.

\section{LA LEYENDA DEL PAÍS INSOMNE}

Arhoe ha cimentado parte de su discurso en torno a la idea de que los españoles duermen significativamente poco: Collin afirma que «casi una hora menos» que los europeos (véase p. 26 del Informe de la Subcomisión), Chinchilla (2012: 12) dice que "50 minutos menos de lo recomendado por la OMS» [Organización Mundial de la Salud] y el anterior presidente de la asociación, Ignacio Buqueras, lo fija en "53 minutos menos» que los europeos (véase p. 62 del Informe de la Subcomisión). Este número de minutos puede encontrarse en numerosas referencias en Internet en un rango temporal que se extiende desde 2010 (Posilio 2010b) hasta el pasado mes de febrero (Kelley 2017).

Hay que acoger con escepticismo estos valores. No parece razonable que los españoles duerman casi una hora menos que el resto, que esto sea importante para la salud y que a la vez mantengan unos estándares de vida excelentes (Lim et al., 2016). Además, la forma de referenciar el dato, como diferencia respecto de otro valor más o menos prestigioso, impide conocer cuánto duermen los españoles diariamente según Arhoe. Tampoco hay ninguna referencia al instituto, tipo de estudio, metodología, tamaño de muestra o fecha del análisis que produzcan el dato. Téngase en cuenta que para llegar a él un hipotético estudio debió analizar los hábitos de sueño de los espańoles y, también, los del resto de europeos.

El único estudio comparativo de hábitos sociales que conozco es la Encuesta de Uso del Tiempo Armonizada en Europa (Hetus), que es una compilación de encuestas de uso del tiempo. Sus datos son públicos (Hetus 2005) y los relativos a los hábitos de sueño aparecen en el cuadro II. El dato español (08 h 34 m) está en el promedio de los datos europeos.

El cuadro muestra también el tiempo medio diario de sueño de los trabajadores. Este dato ha sido obtenido por mí a partir de los microdatos de encuestas de uso del tiempo. El dato español está en el segmento bajo pero ni es el peor ni es tan diferente del promedio como publicita Arhoe. En cualquier caso, está dentro de las recomendaciones diarias de la Asociación Americana del Sueño. 


\begin{tabular}{|c|c|c|c|c|c|c|}
\hline \multirow[t]{3}{*}{ País } & \multirow{3}{*}{$\begin{array}{c}\text { Hetus } \\
\text { Horas de sueño }\end{array}$} & \multicolumn{5}{|c|}{ Encuestas de uso del tiempo } \\
\hline & & \multirow[t]{2}{*}{ Horas de sueño } & \multicolumn{2}{|c|}{ Despertar } & \multicolumn{2}{|c|}{ Acostar } \\
\hline & & & $t$ & $t^{*}$ & $t$ & $t^{*}$ \\
\hline Alemania & $08 \mathrm{~h} 12 \mathrm{~m}$ & & & & & \\
\hline Bulgaria & $09 \mathrm{~h} 07 \mathrm{~m}$ & & & & & \\
\hline Bélgica & $08 \mathrm{~h} 25 \mathrm{~m}$ & & & & & \\
\hline Canadá & & $07 \mathrm{~h} 45 \mathrm{~m}$ & $6: 19$ & $6: 19$ & $22: 41$ & $22: 41$ \\
\hline Dinamarca & & $07 \mathrm{~h} 23 \mathrm{~m}$ & $6: 33$ & $6: 33$ & $23: 17$ & $23: 17$ \\
\hline Eslovenia & $08 \mathrm{~h} 21 \mathrm{~m}$ & & & & & \\
\hline España & $08 \mathrm{~h} 34 \mathrm{~m}$ & $07 \mathrm{~h} 28 \mathrm{~m}$ & 7:00 & $6: 00$ & $23: 48$ & $22: 48$ \\
\hline Estados Unidos & & $07 \mathrm{~h} 43 \mathrm{~m}$ & $5: 59$ & $5: 59$ & $22: 25$ & $22: 25$ \\
\hline Estonia & $08 \mathrm{~h} 25 \mathrm{~m}$ & & & & & \\
\hline Finlandia & $08 \mathrm{~h} 27 \mathrm{~m}$ & & & & & \\
\hline Francia & $08 \mathrm{~h} 50 \mathrm{~m}$ & $07 \mathrm{~h} 35 \mathrm{~m}$ & $6: 39$ & $5: 39$ & $22: 57$ & $21: 57$ \\
\hline Irlanda & & $07 \mathrm{~h} 26 \mathrm{~m}$ & $7: 12$ & $7: 12$ & $23: 38$ & $23: 38$ \\
\hline Italia & $08 \mathrm{~h} 18 \mathrm{~m}$ & $07 \mathrm{~h} 41 \mathrm{~m}$ & $6: 47$ & $6: 47$ & 23:02 & $23: 02$ \\
\hline Letonia & $08 \mathrm{~h} 40 \mathrm{~m}$ & & & & & \\
\hline Lituania & $08 \mathrm{~h} 32 \mathrm{~m}$ & & & & & \\
\hline Noruega & $08 \mathrm{~h} 03 \mathrm{~m}$ & & & & & \\
\hline Polonia & $08 \mathrm{~h} 28 \mathrm{~m}$ & & & & & \\
\hline Reino Unido & $08 \mathrm{~h} 23 \mathrm{~m}$ & $07 \mathrm{~h} 44 \mathrm{~m}$ & $6: 49$ & $6: 49$ & 23:01 & $23: 01$ \\
\hline Suecia & $08 \mathrm{~h} 06 \mathrm{~m}$ & & & & & \\
\hline
\end{tabular}

Cuadro II: El consumo diario de sueño según la Encuesta de Uso del Tiempo Armonizada en Europa (Hetus 2005) y los datos referidos a trabajadores en día laborable obtenidos a partir de las encuestas de uso del tiempo nacionales. En este último caso se muestra también la hora de despertar y de acostarse expresada en hora local $(t)$ y en hora estándar $\left(t^{*}\right)$, la apropiada para comparaciones. Estos datos se determinan como el momento cuando el $50 \%$ de los trabajadores deja de dormir por la mañana o empieza a dormir por la noche. Observe que el tiempo que transcurre desde la hora de acostarse hasta la hora de levantarse no coincide generalmente con el promedio de las horas de sueño.

Sin tener más información es difícil trazar el origen de la discrepancia. Sospecho que alguien ha deducido los datos de sueño de la diferencia entre la hora promedio de acostarse y la hora promedio de levantarse. Esta fácil operación matemática no 
es correcta si los ritmos de acostarse y levantarse difieren entre países. Lo correcto es determinar el área subtendida por el ritmo diario de sueño tal y como se observa en la figura 1. Así se computa correctamente el ritmo al que las personas se acuestan y se levantan y entra en consideración la siesta. Este tipo de sueńo es despreciado por Collin y Chinchilla (2012: 1) pero es relevante en los datos españoles como se observa en la figura. Aproximadamente un $20 \%$ de los trabajadores espańoles practican la siesta, cinco veces más que en Francia o Reino Unido y, en conjunto, representa un consumo diario de entre diez y quince minutos por trabajador (Martín Olalla, 2014 y 2015).

\section{Reloj (huso) adelantado}

$13141516171819202122 \quad 230001020304050607080910111213$

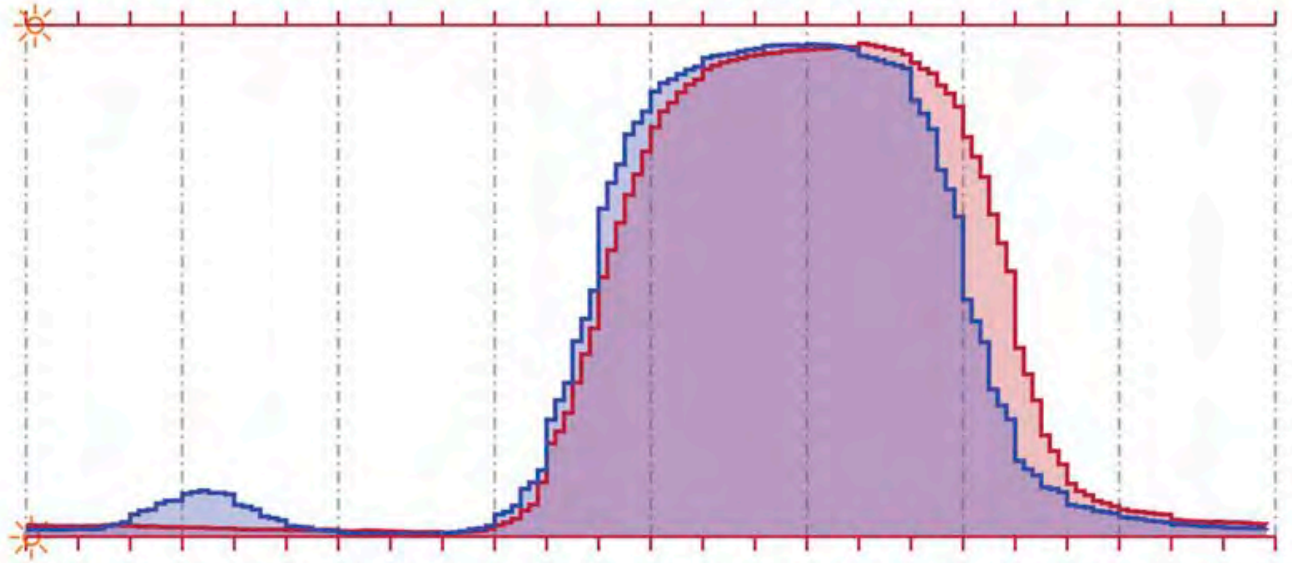

$1213141516171819202122 \quad 2300010203040506 \quad 070809101112$ Reloj (huso) estándar

Figura 1: Comparativa del ritmo diario de sueño de los trabajadores españoles (azul) y británicos (rojo) de lunes a viernes. El reloj estándar representa la hora de Londres; el reloj adelantado, la hora de Berlín. Verticalmente el límite inferior sería «ningún trabajador durmiendo» y el límite superior, «todos los trabajadores durmiendo». El área sombreada representa el consumo promedio diario de sueńo. La hora de despertarse y acostarse puede estimarse por el instante en que el $50 \%$ de los trabajadores deja de dormir o está durmiendo. El área que se observa para los datos españoles entorno a las cuatro de la tarde muestra la siesta.

En general es bueno que durmamos más pero entendamos varios aspectos de este problema: primero, que el problema del déficit de sueño y efecto en la 
actividad diaria no es específicamente español sino global (véase Hope 2016), aunque hay estudios que sugieren que el ritmo de sueño no se ha alterado gravemente por el modo de vida de finales del siglo xx y principios del xxi (véase Mediavilla 2015). Finalmente, debo recordar la obviedad de que las horas de sueño expresan una duración de tiempo y estas son independientes del huso horario: para dormir más hay que acostarse antes o levantarse más tarde, no cambiar el huso.

\section{LA LEYENDA DE LA FUGA DE GREENWICH}

La latitud es desconocida por el reloj moderno pero ha de tenerse en cuenta al comparar los hábitos horarios españoles con los del resto de Europa (que normalmente quiere decir Reino Unido y Alemania). Su influencia es despreciada por Collin y Chinchilla, como muestra el hecho de usar una imagen del anochecer equinoccial como supuesta pistola humeante del problema horario español (Chinchilla 2012: 6). La imagen no proporciona ninguna información adicional a la que ofrece un mapa normal con paralelos y meridianos. Peor aún, la imagen es irrelevante porque los hábitos sociales no están determinados por el amanecer y el anochecer de un día que dura $12 \mathrm{~h}$ en cualquier lugar de la Tierra, sino por los correspondientes al día más corto del año: el del solsticio de invierno, donde la latitud sí desempeña un papel determinante (Martín Olalla 2016a: 85-88).

La latitud de Londres, Berlín o Bruselas es de unos 50 grados y el día invernal dura menos que una jornada laboral típica. En la península ibérica la latitud es de unos 40 grados y ese día dura casi dos horas más (una hora más por la mañana y otra por la tarde), con lo que excede la duración de una jornada laboral.

Una gráfica basta para exponer esta influencia. La figura 2 muestra el ritmo diario de trabajo en España y Reino Unido: la gráfica está construida teniendo en cuenta que el reloj en España está adelantado (se lee en el eje superior) y en Reino Unido es estándar (se lee en el eje inferior). El símbolo del Sol indica en cada eje el mediodía. 
Reloj (huso) adelantado

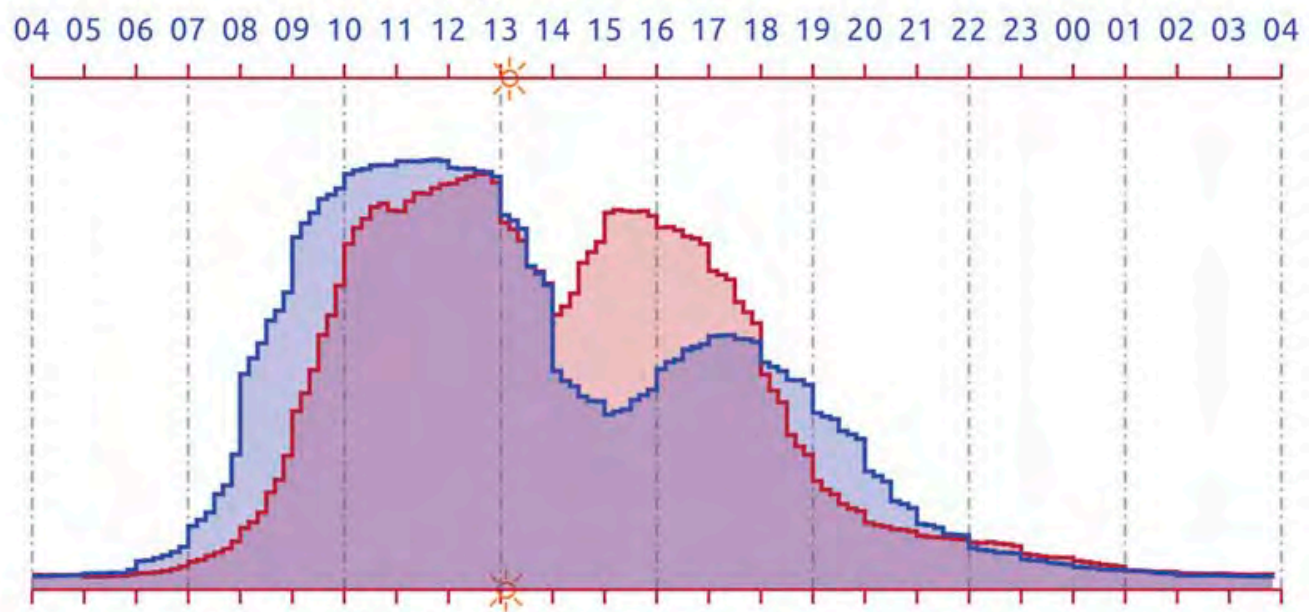

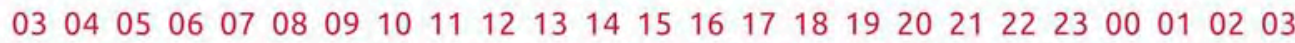
Reloj (huso) estándar

Figura 2: Comparativa del ritmo de trabajo en España (azul) y Reino Unido (rojo). La situación geográfica de los países representados implica que el reloj estándar es la hora de Londres y el reloj adelantado es la hora de Berlín. Verticalmente, el límite inferior sería «ningún empleado trabajando» y el límite superior, "todos los empleados trabajando». El símbolo del Sol marca el mediodía: en el eje superior, el español; en el inferior, el británico.

El ritmo diario de trabajo es el porcentaje de empleados que están trabajando a una hora del día. Por tanto, la gráfica no muestra la jornada laboral de ningún trabajador, sino el estado global de la sociedad respecto de la actividad laboral.

La gráfica muestra una coincidencia notable a mitad de día, cuando la actividad laboral decae. Esta coincidencia es contemporánea con el único fenómeno astronómico relevante que comparten ambos países: el mediodía solar. Es solo circunstancial que el reloj marque la 1 pm en España y las 12pm en Reino Unido cuando ocurre este fenómeno: su influencia es idéntica. También influye de la misma forma en Italia (Martín Olalla 2016a: 22), donde el mediodía ocurre una hora antes que en España y Reino Unido.

Hay dos diferencias significativas: (1) la actividad laboral se inicia antes en España y (2) la actividad laboral termina después en España. El día invernal proporciona una explicación natural convincente para ambas. 
En España amanece en invierno (Martín Olalla 2016a: 84-86) una hora antes que en Reino Unido, aunque nominalmente parece la misma hora: 8am-9am de husos diferentes. El inicio anterior de nuestra actividad laboral solo indica que racionalmente no esperamos a que amanezca en Reino Unido para empezar a desarrollarla.

Igualmente en España anochece en invierno una hora después que en Reino Unido (Martín Olalla 2016a: 87-90), aunque nominalmente parece que ocurre dos horas después. El final postrero de nuestra actividad laboral indica que racionalmente seguimos desarrollando actividad económica aunque ya haya anochecido en Reino Unido. Esta diferencia del anochecer se traslada al resto de eventos vespertinos: en España se cena una hora después que en Reino Unido, dos horas nominales si miramos el reloj.

La coincidencia general del ritmo diario de trabajo en España y Reino Unido con fenómenos naturales es una muestra de que no nos fuimos de Greenwich. Dejen el huso en paz.

\section{EL MEDIODÍA NO ES DETERMINANTE}

La hora legal española no ha estado históricamente ligada con la alemana, ni siquiera durante el nazismo; lo ha estado con la francesa (Martín Olalla 2016b). Ambos países tienen hoy un reloj adelantado. Comparten frontera, lo que hace que comparar hábitos a uno y otro lado de ella sea fácil. Y esa comparación muestra que los hábitos horarios en Francia son diferentes a los de España.

Las diferencias hispanofrancesas en los hábitos horarios son antiguas (Kron 1901, Bonilla 1907), valga como ejemplo esta cita de 1886 referida a las costumbres barcelonesas: «Las horas de comer a la francesa impiden la asistencia á las funciones de iglesia de mañana y noche, á estas funciones tan oportunamente establecidas por la piedad de nuestros mayores para el fin del día, con el objeto de no disminuir las horas del trabajo y de recoger el espíritu al concluir las tareas de la jornada» (Llauder 1886: 2).

La figura 3 muestra los ritmos diarios de trabajo en España y Francia. La semejanza por la mañana proviene del único hito astronómico que comparten completamente ambos países: el amanecer invernal es simultáneo en ambos (Martín Olalla 2016a: 84-86). La diferencia vespertina se debe a que el anoche- 
cer invernal ocurre en Francia a la vez que en las islas británicas y una hora antes que en la península ibérica (Martín Olalla 2016a: 87-90).

\section{Reloj (huso) adelantado}

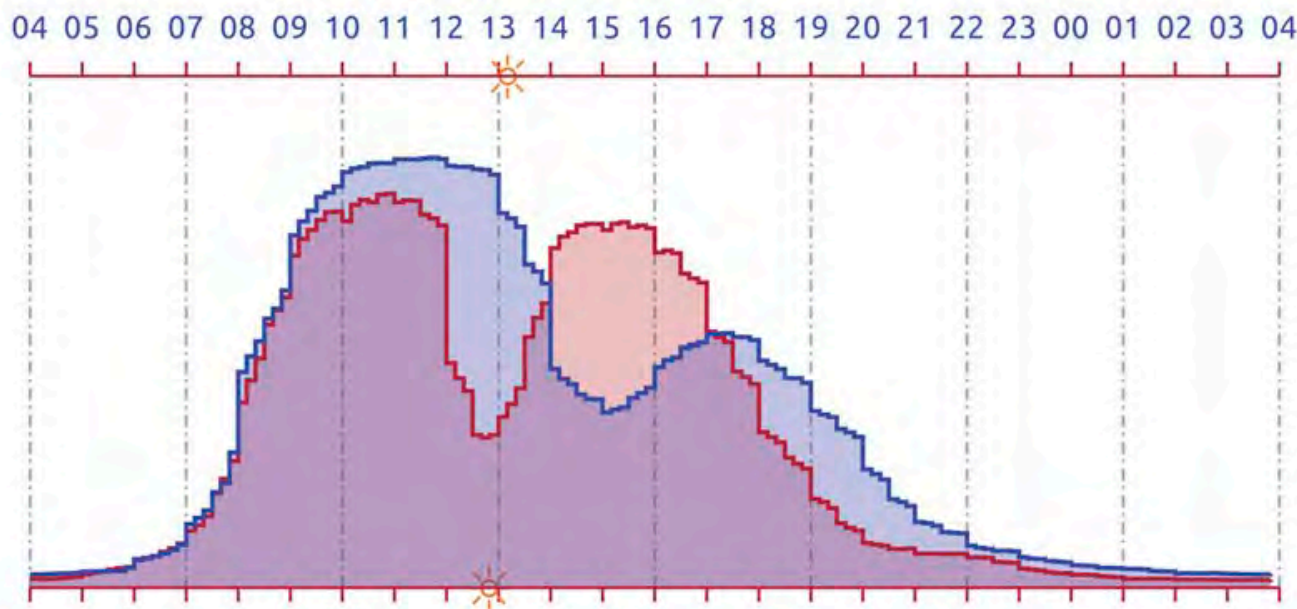

03040506070809101112131415161718192021222300010203 Reloj (huso) estándar

Figura 3: Comparativa del ritmo de trabajo en España (azul) y Francia (rojo). En esta gráfica el reloj adelantado es la hora de Berlín, oficial en ambos países. El reloj estándar es la hora de Londres. El símbolo del Sol marca el mediodía: en el eje superior, el español, y en el interior, el francés.

El mediodía solar es aproximadamente coincidente en ambos países y en Reino Unido, pero la caída de la actividad es muy anterior en Francia: en torno al mediodía civil, antes que el solar. Comparando con la figura 2 se deduce que también es anterior a la caída de la actividad británica. A consecuencia de ello, la hora de la comida en Francia (12:30pm en hora adelantada, 11:30am en hora estándar) es comparativamente más temprana en relación al resto de valores europeos (véase el cuadro I). Ocurre antes del mediodía solar, antes que en Italia o Eslovenia, países que están más al este que Francia, y casi una hora y media antes que la hora de la comida en Reino Unido y en España (países con los que comparte meridianos). Bélgica (véase cuadro I) replica el comportamiento francés.

Yo no dudo que la forma de comportarse de franceses y belgas sea racional. Solo pido un poco de reciprocidad, porque resulta un poco sorprendente que un 
ciudadano de origen belga, Jos Collin, haga fortuna vendiendo la idea de que en Espańa comemos muy tarde (Barbería 2014 y Collin 2016) cuando tal vez su problema sea que comía demasiado temprano en Bélgica.

De las figuras 2 y 3 se puede intuir que el amanecer y el anochecer determinan más fuertemente los hábitos humanos que el mediodía. La huella de los dos primeros en la actividad laboral es similar en los tres países que he mostrado. En cambio la huella del mediodía es variable, con Francia comportándose de forma diferente.

Una razón es que al amanecer y al anochecer la luz ambiental cambia drásticamente en poco tiempo. En el mediodía ocurre lo contrario: hay estabilidad. Las sociedades pueden comportarse de forma diferente en esta parte del día y tienden a comportarse más parecidamente en la otra. Así, el mediodía no es el fenómeno astronómico más relevante para la actividad humana, lo son el amanecer y el anochecer, para los cuales el reloj moderno es ciego. Por eso el meridiano y el huso geográfico no son tan importantes como suele creerse.

\section{LA LEYENDA DE CREAR OCIO VESPERTINO}

Tratar de arreglar los problemas de conciliación modificando el huso horario es tan irracional como tratar de arreglar la siniestralidad del tráfico o su congestión situando en la Puerta del Sol el punto kilométrico $100^{\circ}$ de las carreteras radiales. Pretender que el cambio de huso de 1945 alteró necesariamente nuestros hábitos es tanto como pretender que si en 1945 se hubiera alterado el punto kilométrico de la Puerta del Sol hoy la siniestralidad del tráfico o su congestión serían diferentes.

El cambio de huso es una forma de tratar de forzar a la población para que haga lo que no quiere hacer, y así lo emplea Arhoe. La técnica consiste en mantener la ilusión de que se hacen las cosas a la misma hora camuflando sus cambios en el huso.

La reforma de Arhoe (Informe de la Subcomisión, p. 26) consta de tres puntos: (1), retrasar el huso una hora (situarlo en la hora de Londres); (2), adelantar los horarios vespertinos una hora; (3), recortar la pausa para la comida en una hora. Según Arhoe, tiene un coste económico cero. La realidad es distinta.

Recurriendo al cambio de huso, Collin, Chinchilla y Arhoe crean la ilusión de que la hora de entrada al trabajo no cambia aunque se retrase: las 9am hora de Londres son una hora más tarde que las 9am hora de Berlín. Y crean la ilusión de 
que la hora de salida se adelanta («salir a las 6 pm sería lo más normal del mundo", Posilio 2010a), aunque solo cambie el nombre de la hora: cuando dicen las $6 \mathrm{pm}$ (de Londres) se están refiriendo a las actuales $7 \mathrm{pm}$.

Así, el cambio de huso distorsiona los efectos de una propuesta que puede describirse sin él. Lo que Collin, Chinchilla y Arhoe piden realmente es: (1) retrasar la hora de entrada al trabajo por la mañana y (2) compensar el retraso con una pausa menor para comer. El punto (1) solo afecta a quienes trabajan por la mañana, la gran mayoría de la población trabajadora. El punto (2) solo pueden aplicarlo quienes tengan una pausa para comer de dos horas o mayor; quienes tengan ya una jornada continua (una hora de pausa) o intensiva (sin pausa) compensarían el retraso inicial retrasando también la salida del trabajo (véase la figura 4).

\section{Reloj (huso) adelantado/Hora de Berlín}

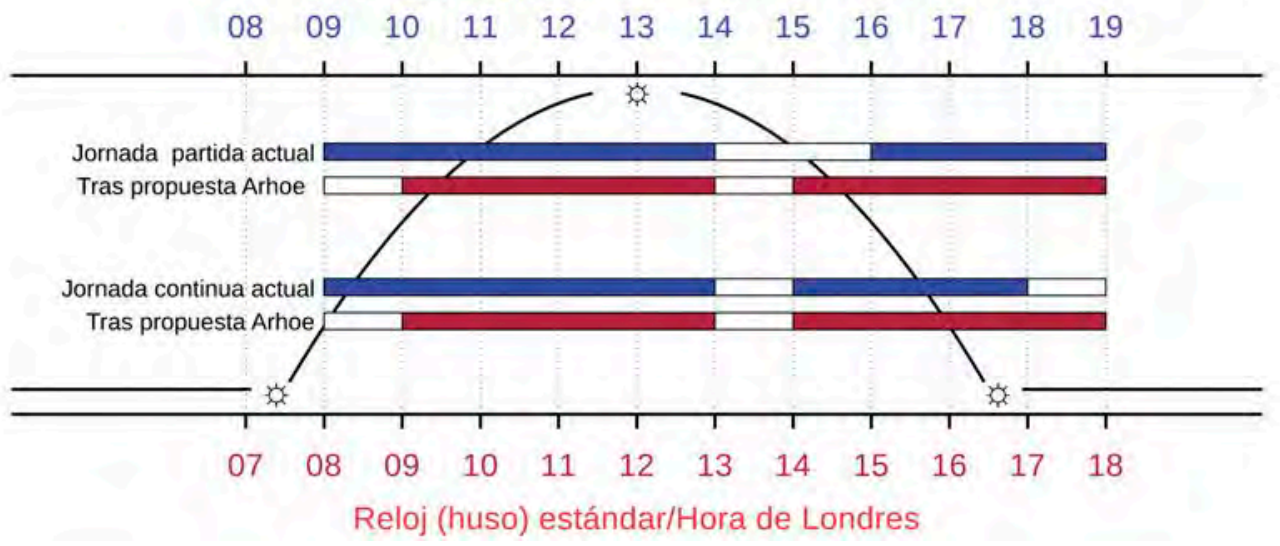

Figura 4: Afectación de los cambios propuestos por Arhoe a una jornada laboral partida con dos horas de pausa (arriba) y una jornada continua con una hora de pausa (abajo); en color, la jornada laboral; en blanco, el descanso u ocio. En el primer caso el efecto neto es intercambiar ocio a mediodía por ocio matinal, o trabajo matinal por trabajo a mediodía. En el segundo caso la jornada se retrasa; se intercambia ocio vespertino por ocio matinal, o trabajo matinal por trabajo vespertino. En ningún caso se aumenta el ocio vespertino.

Es complicado vender una propuesta conciliadora cuya idea principal sea retrasar la entrada al trabajo y, en muchos casos, retrasar también la salida. Por eso toda la 
argumentación del proyecto pivota en torno al huso, a sus imaginarios problemas (alteración del ritmo circadiano, jet-lag permanente, falta de sueño) y a su imaginaria génesis (nazismo). Hasta tal punto es así que cabe dudar de cuál es el objetivo principal de Collin y Chinchilla, o qué sacrificarían antes. Es decir, si su empeño es conciliar y el cambio de huso una herramienta accesoria e innecesaria, o si, debido a un naturismo mal entendido, se han empeñado en regresar a "la hora que nos corresponde» (sic) y la conciliación es una herramienta para vender tan banal deseo.

El cambio de huso tiene otro papel bastardo en la propuesta: hacer creer que su jornada continua propuesta solo es posible con ese cambio. Pero nada impide hoy que una empresa retrase la entrada al trabajo o adelante la salida del trabajo y lo compense con una pausa menor. Es más, la sociedad española ha estado haciendo esto en las últimas décadas sin el concurso de Arhoe: un $46 \%$ de los trabajadores encuestados en la Encuesta de Empleo del Tiempo tiene una jorna$\mathrm{da}$ intensiva matinal o una jornada partida con una pausa breve y las 6pm (¡de Berlín!) es la hora mediana de salida del trabajo de los trabajadores encuestados (véase Martín Olalla 2016c).

Arhoe sostiene también que el cambio mejoraría las relaciones comerciales con nuestros vecinos del continente porque habría más coincidencia en el segmento del mediodía. Y es cierto, pero silencia que solo a costa de empeorar esas mismas relaciones en el segmento matinal: los españoles entrarían a trabajar una hora más tarde que franceses, alemanes, suizos, belgas y holandeses. Aquellos con los que hoy coordina perfectamente ese segmento horario.

El plan no mejora la conciliación vespertina porque solo traslada ocio vespertino o de mediodía a la mañana, en ningún caso lo aumenta por la tarde. Algunos trabajadores experimentarían la ilusión de salir una hora antes pero las actividades extraescolares de los hijos, el cierre de los comercios, la hora de la cena y el inicio del programa de televisión favorito también llegarían una hora antes. Para estos trabajadores la tarde-noche sería exactamente igual a la actual: solo habría cambiado la manecilla del reloj. En cambio aquellos trabajadores con jornada continua o intensiva acarrearían una hora de retraso y tendrían que dejar de hacer algo por la tarde-noche. Solo al terminar la última actividad o antes de volver al trabajo al día siguiente encontrarían unos y otros esa hora perdida: conciliar por la mañana, a última hora de la noche o dormir más. Para eso Arhoe ha creado antes la ilusión de un gran déficit de sueño. 
Es fascinante analizar el porqué de este diseño, cómo Arhoe critica nuestra jornada vespertina en sus apariciones mediáticas pero actúa contra la jornada matinal en sus propuestas. Proviene de una interpretación sui géneris de nuestros hábitos que realiza el señor Collin.

Según él, tras el cambio de huso de 1945 la sociedad española adaptó bien el horario de comidas retrasándolas. Lo coherente entonces habría sido que la hora de entrada al trabajo hubiese sido las 10am-11am (Chinchilla 2012: 11), es decir, solo unas tres horas y media antes del mediodía solar. Esta increíble afirmación, que merece la pena releer antes de continuar, solo puede tener una explicación asociada a un imaginario muy concreto: en ese caso los trabajadores españoles habrían empezado su jornada laboral unas siete horas antes del anochecer invernal, como ocurre a 50 grados de latitud, en Bruselas, y se habrían visto obligados «naturalmente» a llevar una jornada laboral frenética, como a 50 grados de latitud, con una pausa breve al mediodía. El señor Collin tal vez añora en España el corto día invernal de su Bélgica natal.

Los trabajadores españoles se comportaron de otra forma ya que ellos nunca han conocido un día de siete horas: retrasaron racionalmente la entrada al trabajo para compensar el adelanto de la hora pero solo hasta el amanecer invernal (8am-9am de Berlín). Hoy hemos perdido de referencia que en España no era extraño trabajar a las $7 \mathrm{am}$ (hora de Londres) o que se considerara trabajo diurno el realizado entre las 5 am y las 7pm (hora de Madrid) (véase el Reglamento de Aplicación de la Ley de 13 de marzo de 1900), valores muy ajustados al día estival sin horario de verano.

Así, los trabajadores españoles prefirieron, como habían hecho siempre, consumir trabajo en las primeras horas del día en vez de consumirlo en las horas centrales del día. Es un intercambio que se puede hacer a nuestra latitud, incluso en invierno. Se necesita torcer mucho la argumentación para asociar este comportamiento racional al compendio de casi todos los males del siglo anterior. Además, hacerlo es un ejercicio profundamente injusto con nuestros antepasados.

Collin concluye por eso que madrugamos mucho y que nuestras jornadas matinales son muy largas. Y de ahí la idea de retrasar artificialmente la entrada al trabajo mediante el cambio de huso, para que cuando lleguemos al trabajo quede una hora menos de luz y nos parezcamos más al mundo a 50 grados de latitud.

En el pensamiento del señor Collin no entra que los europeos se levanten tarde o que sus jornadas matinales sean cortas. Olvida que, aunque el reloj esté 
ligado al mediodía, la actividad humana está ligada al amanecer, fenómeno desconocido por el reloj moderno. Dicho de otra forma, nadie decide cuándo acudir al trabajo en función de cuánto queda para el mediodía; lo hace en función del amanecer. Así, madrugamos lo mismo que en el resto de Europa o en Estados Unidos. Es solo que, en la península ibérica y en Estados Unidos o en Japón, cuando amanece en invierno el mediodía está una hora más lejos que cuando amanece hace a 50 grados de latitud.

Un análisis detallado de la Encuesta de Empleo del Tiempo permite desglosar las jornadas de los trabajadores encuestados en diferentes modelos: jornada intensiva, sin pausa; continua, con pausa breve de una hora; y partida, con pausa larga de dos horas o más (véase el cuadro III).

\section{Tipo de jornada}

Jornada intensiva matinal

Jornada continua (pausa menor a $1 \mathrm{~h} 30 \mathrm{~m})$

Jornada partida (pausa mayor de $1 \mathrm{~h} 30 \mathrm{~m}$ y menor de $2 \mathrm{~h} 30 \mathrm{~m}$ ) Jornada partida (pausa mayor a $2 \mathrm{~h} 30 \mathrm{~m})$

Jornada intensiva vespertina Múltiples pausas

\section{Fracción de Afectación de la propuesta de Arhoe} trabajadores

$\begin{array}{ll}34 \% & \text { Retraso de la entrada y salida del trabajo } \\ 22 \% & \text { Retraso de la entrada y salida del trabajo }\end{array}$

$14 \%$ Pasa a jornada continua: retraso de la entrada al trabajo

$12 \% \quad$ Retraso de la entrada al trabajo, pausa menor

$10 \% \quad$ Sin cambios

$8 \%$

Cuadro III: Desglose del tipo de jornada laboral en España según el análisis de los microdatos de la Encuesta de Empleo del Tiempo. En los primeros tipos de jornada la propuesta de Arhoe cambia ocio vespertino por ocio matutino. En los dos siguientes tipos cambia ocio al mediodía por ocio matutino.

La propuesta de Arhoe parece pensada para trabajadores con una jornada partida tipo 5-2-3 (cinco horas matinales de trabajo, dos horas de pausa y tres horas vespertinas, por ejemplo, de 9am a 2pm y de 4pm a 7pm; véase Posilio 2010a) porque con ella se convierte en una jornada continua 4-1-4 (véase la figura 4). Pero solo un $14 \%$ de los trabajadores entrevistados dan este perfil de jornada. Es un plan pensado para uno de cada siete trabajadores. 
Por el contrario, el $46 \%$ de los entrevistados tienen una jornada continua (22\%) o jornada intensiva matinal de más de seis horas de duración $(24 \%)$. Estos dos grupos de trabajadores ven perjudicada su conciliación vespertina al retrasar su jornada laboral y cambiar ocio vespertino por matinal.

El $11 \%$ de encuestados realizan una jornada intensiva (7-0-0) vespertina y el $10 \%$ de los encuestados realizan una jornada intensiva matinal menor de seis horas: estos trabajadores no sufrirán una alteración significativa.

El $12 \%$ de encuestados presentan una jornada partida con una pausa mayor de dos horas (5-3-3, por ejemplo): estos seguirían teniendo una jornada partida, si bien con una pausa menor.

Para ningún grupo de trabajadores la propuesta de Collin, Chinchilla y Arhoe generará más ocio vespertino. Es lo que pasa cuando se retrasa el huso.

\section{UN PUNTO OLVIDADO}

Cuando se habla del adelanto del huso de 1945 se olvida la respuesta que induce en la sociedad y que describí antes. Este olvido es trasladable a la propuesta de Arhoe, que también sería respondida en la mañana, donde más perturbación produce.

El problema es que, igual que hay sectores económicos que no pueden adelantar la salida del trabajo todo lo que se quiera, hay sectores económicos que no pueden retrasar el inicio de la actividad todo lo que se quiera.

Uno de ellos es el sector de la construcción, que tendría que adelantar nominalmente sus horarios de entrada si se aprobase ese plan. Esto arrastraría a otros sectores para satisfacer las demandas que a esa hora se empiecen a generar. Habría personas que simplemente no esperarían a que amanezca en Londres para empezar a trabajar si ya ha salido el Sol en España.

En general, ante la perturbación del retraso matinal, la sociedad tendría que buscar, de nuevo, el ajuste actual, que ya es suficientemente racional (véase la figura 5 al final de este artículo). En tiempos de paz este sería un proceso incierto en lo social y en lo económico, y penoso. Dejen el huso en paz. 


\section{UN POCO DE CONCILIACIÓN}

Los problemas que se relacionan con la conciliación son muchos. Una lista no necesariamente exhaustiva incluiría: las horas extras, la economía sumergida, la inflexibilidad horaria, la insoslayable asimetría en la relación empleado/empleador, la duración de los desplazamientos hogar-centro de trabajo, la variabilidad de los turnos o la estructura económica, tanto en lo referido al peso relativo de los diferentes sectores (primario frente a terciario, por ejemplo) como el peso de empresas con gran número de empleados frente a empresas con pequeño número de empleados, incluido el caso límite del trabajador autónomo. Todos estos problemas reales son independientes del huso. Dejen el huso en paz.

Es actuando sectorialmente sobre ellos como se puede mejorar la conciliación, no con medidas que afectan, indiscriminadamente, a todos, como es un retraso de la hora oficial. No dudo que haya sectores económicos que aún pueden acortar la pausa para comer adelantando la salida del trabajo o retrasando la entrada. En estos tiempos vemos muchos ejemplos de ellos en los medios de comunicación, normalmente en el primer sentido; es decir, hacen lo contrario a lo que propone Arhoe. Todos queremos que sean más. Pero es irreal pensar que pueden ser todos. Es incluso posible que no puedan ser muchos, porque ya muchos sectores han transitado por este camino: casi la mitad de los encuestados realizan una jornada intensiva matinal o una jornada continua.

El ministro Jordi Sevilla, que puso en marcha un plan de conciliación en la Administración, cuenta una anécdota que describe inadvertidamente este problema: «No logramos arrastrar a la empresa privada y hubo funcionarios, varones, que me interpelaban en los pasillos: "Ministro, ¿y qué voy a hacer yo en casa a las seis de la tarde?”». El ministro respondía: «Vete al gimnasio, aprende un idioma, haz amistades» (véase Barbería 2014). Podía haber respondido con «ordena la casa» o «haz la comida de mańana», pero eligió tres propuestas que, casi inevitablemente, siguen generando actividad económica posterior a las $6 \mathrm{pm}$.

Debo insistir, de nuevo, en la ligazón entre las actividades económicas y el Sol. En la península cualquier día del año dura más que una jornada laboral media, lo que permite diversas opciones para desarrollar la jornada laboral. Estas opciones difieren, básicamente, en dónde situar el período de descanso. Esto es 
un privilegio del que no se dispone a 50 grados de latitud, no lo convirtamos en un problema.

La pausa del comercio, por ejemplo, responde a una práctica más antigua que el franquismo. La Ley de Jornada de la Dependencia Mercantil (véase la Gaceta de Madrid 1918 y ABC 1919) promulgó en 1918 un descanso de dos horas para comer. Se trata de la misma ley garantista que promulgó el descanso continuo diario de doce horas (aún practicado hoy por algunos grandes almacenes) y una jornada semanal de cuarenta y ocho horas. Parece razonable deducir que esa pausa de dos horas ya era practicada antes de la entrada en vigor de esta ley.

Desde hace cuarenta ańos no existen restricciones a la actividad comercial al mediodía, pero los comercios siguen observando el descanso de 1918. En la discusión moderna se suele atribuir a que los trabajadores salen muy tarde de trabajar. Sin embargo, a modo indicativo, el pequeño comercio tampoco tiene restricciones para abrir en festivo, cuando más trabajadores vacan, y generalmente no abre.

En cambio, se olvida un hecho más general: en España se puede retrasar la salida del hogar para ir a comprar hasta las $5 \mathrm{pm}$, aproximadamente, porque siempre es de día a esa hora. En el otro lado del problema, hay una resistencia a regresar al trabajo de noche; así, en Espańa, el comerciante puede retrasar su regreso hasta cerca de las cinco. Es decir, ni clientes ni comerciantes tienen la urgencia vital que sí existe a latitudes mayores. Quizá ambos se comporten racionalmente, aunque no sea al gusto de todos.

\section{EL GOBIERNO ANTE EL CAMBIO DE HUSO}

El Gobierno de España quiere reflexionar sobre el cambio de huso. Mis dos primeras reflexiones son excepcionales: (1) nunca en la historia de Europa occidental ha triunfado un cambio de hora en tiempos de paz porque el bien superior es la estabilidad, no ningún huso concreto; (2) nunca antes en tiempos de paz un gobierno de ningún país del mundo ha retrasado la hora oficial, salvo porque hubiera fracasado un adelanto inmediatamente anterior. Este no es nuestro caso, el adelanto ocurrió hace setenta años. Tampoco volveríamos a nuestro «huso natural» ni «a la hora que nos corresponde»: esos conceptos solo existen en un imaginario mitológico o poco después de otro cambio de hora. 
El 95 \% de la población española no ha conocido la vida en la España peninsular con el reloj ajustado a la hora de Londres. No le ha pasado nada. No se ha perdido nada. No ha ganado nada. Los días han sido exactamente iguales. Solo su reloj, iino su vida!!, ha sido diferente.

La economía es la razón principal de que nunca se haya retrasado un huso y el objeto de mi tercera reflexión. Arhoe dice, sin ningún tipo de análisis, que el plan tiene un coste cero creyendo, tal vez, que la menor actividad matinal se compensa con más actividad al mediodía. No es cierto. Casi la mitad de los trabajadores cambiarán ocio vespertino por ocio matinal, un ocio que genera muy poca actividad económica. La misma afectación tendrá el turismo, que, manteniendo sus horarios, vería anochecer una hora antes. Si siguiéramos el plan de Arhoe, la conversación del ministro Sevilla antes referida sería: «Ministro ¿qué voy a hacer en casa a las $8 \mathrm{am}$ [de Berlín]?». Y la respuesta no podría ser entonces económicamente productiva. Por eso los gobiernos, todos los gobiernos del mundo, en todas las circunstancias, han sido siempre refractarios a la idea de retrasar la hora oficial. Hacerlo sería temerario. Dejen el huso en paz.

En mi última reflexión quiero mostrar el único gráfico (figura 5) que el Gobierno debería considerar para discernir sobre la necesidad de un cambio de huso. La gráfica muestra cuándo se activa y desactiva una sociedad en relación con la actividad solar. En ella se distingue la parte del día en la que siempre es de día (en claro), la parte del día en la que es de noche o de día según la época del año (en gris) y la parte del día en la que siempre es de noche (en gris oscuro). Los datos de Espańa no destacan particularmente en nada: la actividad laboral se inicia antes del amanecer invernal y concluye después del anochecer invernal, como en la mayoría de casos (véase el cuadro IV). España está en el huso horario correcto para sus hábitos, y viceversa. Retrasar la hora oficial, es decir, regresar a Greenwich, desplazaría los datos de España una hora hacia la derecha y entonces sí quedaría en una posición extraña en comparación al resto. 


\begin{tabular}{|c|c|c|c|c|c|c|}
\hline \multirow[t]{4}{*}{ País } & \multicolumn{3}{|c|}{ Inicio actividad laboral } & \multicolumn{3}{|c|}{ Fin actividad laboral } \\
\hline & Hora & Hora & Distancia al & Hora & Hora & Distancia al \\
\hline & oficial & estándar & amanecer & oficial & estándar & anochecer \\
\hline & $\mathrm{t}$ & $t^{*}$ & $\Delta \mathrm{t}$ & $\mathrm{t}$ & $\mathrm{t}^{*}$ & $\Delta \mathrm{t}$ \\
\hline Alemania* & $07: 30$ & $07: 30$ & $-01 \mathrm{~h} 00 \mathrm{~m}$ & $16: 40$ & $16: 40$ & $+00 \mathrm{~h} 20 \mathrm{~m}$ \\
\hline Bulgaria* & 08:00 & 08:00 & $+00 \mathrm{~h} 10 \mathrm{~m}$ & $17: 00$ & $17: 00$ & $+00 \mathrm{~h} 10 \mathrm{~m}$ \\
\hline Bélgica* & 08:00 & 07:00 & $-00 \mathrm{~h} 40 \mathrm{~m}$ & $17: 00$ & $16: 00$ & $+00 \mathrm{~h} 20 \mathrm{~m}$ \\
\hline Canadá & $07: 50$ & $07: 50$ & $-00 \mathrm{~h} 10 \mathrm{~m}$ & $17: 00$ & $17: 00$ & $+00 \mathrm{~h} 20 \mathrm{~m}$ \\
\hline Dinamarca & $07: 50$ & $07: 50$ & $-00 \mathrm{~h} 50 \mathrm{~m}$ & $16: 00$ & $16: 00$ & $+00 \mathrm{~h} 20 \mathrm{~m}$ \\
\hline Eslovenia* & 07:00 & 07:00 & $-00 \mathrm{~h} 40 \mathrm{~m}$ & $16: 00$ & $16: 00$ & $-00 \mathrm{~h} 20 \mathrm{~m}$ \\
\hline España & $08: 10$ & $07: 10$ & $-00 \mathrm{~h} 30 \mathrm{~m}$ & $18: 20$ & $17: 20$ & $+00 \mathrm{~h} 30 \mathrm{~m}$ \\
\hline Estados Unidos & $07: 30$ & $07: 30$ & $+00 \mathrm{~h} 00 \mathrm{~m}$ & $16: 50$ & $16: 50$ & $+00 \mathrm{~h} 00 \mathrm{~m}$ \\
\hline Estonia* & 08:00 & 08:00 & $-01 \mathrm{~h} 20 \mathrm{~m}$ & $17: 10$ & $17: 10$ & $+01 \mathrm{~h} 50 \mathrm{~m}$ \\
\hline Finlandia* & $07: 40$ & $07: 40$ & $-02 \mathrm{~h} 00 \mathrm{~m}$ & $16: 20$ & $16: 20$ & $+01 \mathrm{~h} 20 \mathrm{~m}$ \\
\hline Francia & $08: 10$ & $07: 10$ & $-00 \mathrm{~h} 30 \mathrm{~m}$ & $17: 40$ & $16: 40$ & $+00 \mathrm{~h} 40 \mathrm{~m}$ \\
\hline Irlanda & $08: 45$ & $08: 45$ & $+00 \mathrm{~h} 00 \mathrm{~m}$ & $17: 15$ & $17: 15$ & $+01 \mathrm{~h} 00 \mathrm{~m}$ \\
\hline Italia & 08:00 & 08:00 & $+00 \mathrm{~h} 10 \mathrm{~m}$ & $17: 50$ & $17: 50$ & $+01 \mathrm{~h} 10 \mathrm{~m}$ \\
\hline Letonia* & 08:00 & 08:00 & $-01 \mathrm{~h} 00 \mathrm{~m}$ & $18: 00$ & $18: 00$ & $+02 \mathrm{~h} 20 \mathrm{~m}$ \\
\hline Lituania* & $07: 40$ & $07: 40$ & $-01 \mathrm{~h} 10 \mathrm{~m}$ & $18: 00$ & $18: 00$ & $+02 \mathrm{~h} 00 \mathrm{~m}$ \\
\hline Noruega* & $07: 50$ & $07: 50$ & $-01 \mathrm{~h} 30 \mathrm{~m}$ & $16: 00$ & $16: 00$ & $+00 \mathrm{~h} 50 \mathrm{~m}$ \\
\hline Polonia* & 07:00 & 07:00 & $-00 \mathrm{~h} 50 \mathrm{~m}$ & $17: 00$ & $17: 00$ & $+01 \mathrm{~h} 20 \mathrm{~m}$ \\
\hline Reino Unido & $08: 20$ & $08: 20$ & $+00 \mathrm{~h} 00 \mathrm{~m}$ & $17: 00$ & $17: 00$ & $+01 \mathrm{~h} 00 \mathrm{~m}$ \\
\hline Suecia* & $07: 50$ & $07: 50$ & $-01 \mathrm{~h} 00 \mathrm{~m}$ & $16: 40$ & $16: 40$ & $+01 \mathrm{~h} 40 \mathrm{~m}$ \\
\hline
\end{tabular}

Cuadro IV: El inicio y final de la actividad laboral se determinan cuando el ritmo diario de trabajo sobrepasa hacia arriba (inicio) o hacia abajo (final) el umbral del $50 \%$ del máximo del ritmo diario de actividad laboral. En este cuadro, expresados de tres formas diferentes: $\mathrm{t}$ es la hora oficial, $\mathrm{t}^{*}$ es la hora estándar equivalente válida para comparar unos datos con otros (en el caso de Francia, Bélgica y Espańa, la hora del meridiano de Londres) y la columna $\Delta \mathrm{t}$ es la distancia al amanecer invernal (inicio) o al anochecer invernal (fin). Los datos se muestran en la figura 4 y en este cuadro están redondeados a la decena del minuto más cercano, excepto el irlandés, que lo está al cuarto de hora. Los datos de los países señalados con una estrella se obtuvieron de la Encuesta de Uso del Tiempo Armonizada en Europa (Hetus 2005). 


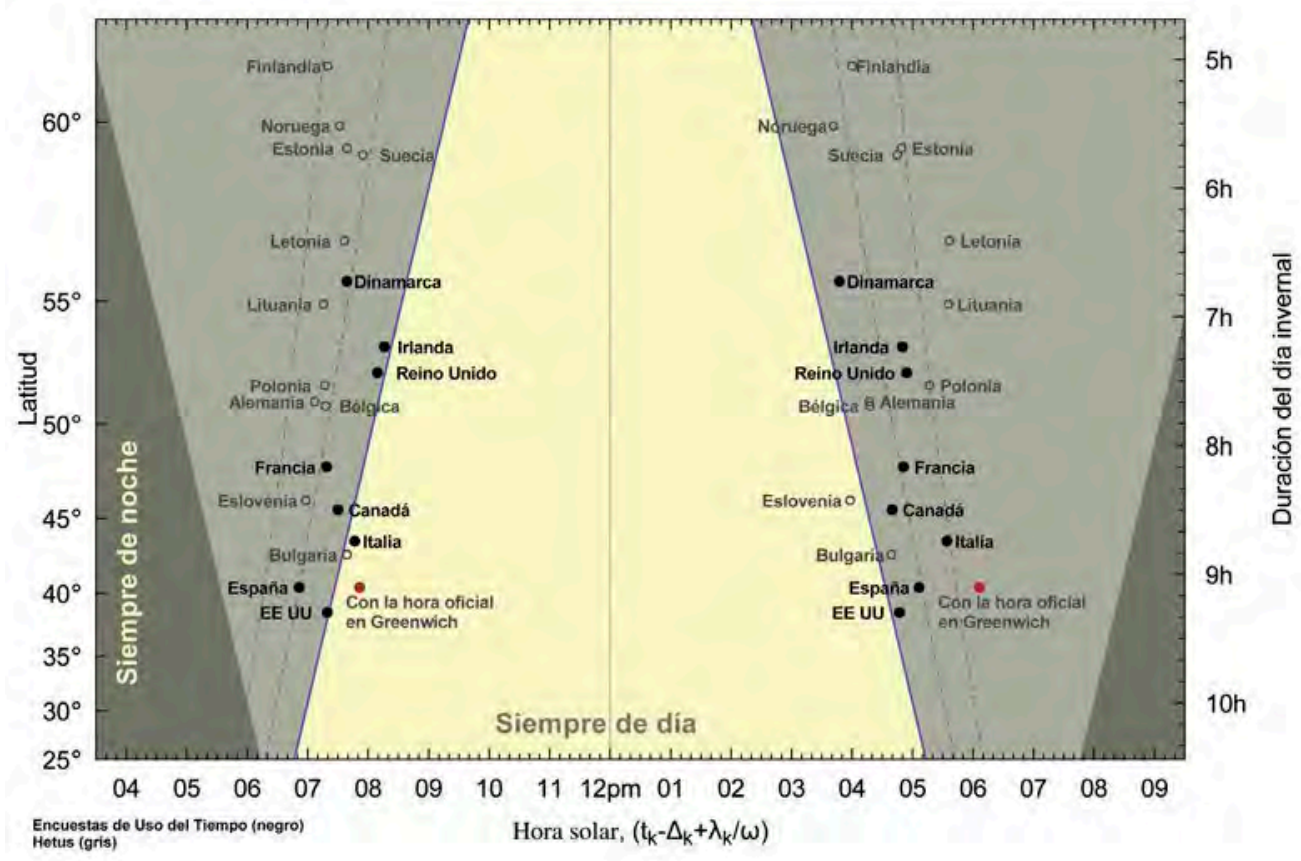

Figura 5: Inicio (izquierda) y fin (derecha) de la actividad laboral en países de Europa y América. El inicio se determina cuando la actividad laboral supera por la mańana la mitad de su máximo diario. El final cuando, por la tarde, la actividad decae por debajo de este nivel. Las líneas azules marcan el amanecer y anochecer invernales mientras que las discontinuas muestran el crepúsculo civil y náutico de ese día. Los puntos en rojo marcan los datos de Espańa si se adoptase la hora de Greenwich. En el eje $\mathrm{x}, \mathrm{t}$ es la hora oficial, $\Delta$ es el desfase del huso oficial con el Tiempo Universal, $\lambda$ es el desfase de longitud geográfica con el meridiano del Tiempo Universal y $\omega$ es la velocidad angular de rotación de la Tierra. Los datos temporales mostrados en el gráfico pueden observarse en el cuadro IV.

La figura muestra inequívocamente que España no tiene ningún problema con el huso y le dice al Gobierno que no juegue con aprendices de brujo. Dejen el huso en paz. 


\section{ALEGATO FINAL}

El asunto del cambio del huso ha permitido un discurso oportunista, históricamente falso, artificialmente naturista, acientífico, y casi con seguridad equivocado en lo económico. Es atractivo desde un punto de vista sociopolítico porque conmina a los agentes sociales, y en último término al Gobierno, a enfrentarse ante una medida concreta: un bálsamo para los males actuales. Y también es meridianamente estéril desde un punto de vista científico porque se trata de un cambio de referencia. Este cambio no altera ninguna ley o fenómeno natural, solo altera un aparato: el reloj.

La sensación de ser esclavos de este aparato nos hace olvidar que mantenemos una relación de dominio sobre él. Las personas, en todas partes, eligen sensatamente cuándo despertar, comer, cenar o descansar y lo hacen en relación con la actividad del Sol. Por eso cuando comparamos correctamente los hábitos sociales encontramos patrones regulares de comportamiento en Europa que muestran la racionalidad y naturalidad de estas decisiones. Estos patrones regulares desaparecen si solo comparamos relojes. Si alteramos la hora oficial, esos patrones regulares se pierden y esas decisiones racionales, que ya se han tomado, dejan de ser racionales.

Los horarios sociales responden a una amalgama de factores con origen diverso y donde la libertad individual desempeña también un papel importante. Los consejos morales, casi paternales, que acompañan esta discusión no son criticables: podemos dormir más, comer antes, pausar menos al mediodía y cenar antes. En general podemos administrar el tiempo de forma diferente... o podemos seguir haciéndolo como hasta ahora. Tan amplia es esta capacidad que podemos tomar todas estas decisiones sin cambiar de huso porque, en realidad, ninguno de estos consejos dependen de la hora oficial ni se coartan actualmente. Dependen, estadísticamente, del gusto por comer antes, por tardar menos en comer, por acostarse antes y por levantarse más tarde.

Voy a poner un ejemplo un tanto peculiar: el pasado 28 de febrero el presidente de Estados Unidos cenó a las 6:30pm (como es costumbre allí y equivalente a nuestras 7:30pm) y pronunció un discurso ante las cámaras legislativas a las 9pm (a nuestras 10pm). ¿Es más racional que pronunciar un discurso a las 7:30pm y cenar a las $10 \mathrm{pm}$ ? La pregunta nos lleva a una discusión vacua, relacionada con gustos personales y no con certezas. 
Con frecuencia se establecen nexos causales entre indicadores sociales y nuestro «huso incorrecto", por ejemplo, recientemente, relacionando el huso con la baja tasa de fecundidad en España (1.27 según el último dato del Banco Mundial). Sin embargo no solo el último dato de fecundidad en Portugal es aún más bajo, 1.21, sino que en los últimos 50 años ambas series siguen exactamente la misma tendencia, a pesar de que España estaba en el «huso incorrecto» y Portugal en el «correcto».

Además hay una selección interesada de indicadores: se critica la tasa de fecundidad y se oculta el buen dato de la esperanza de vida al nacer. Cuanto más apocalíptico es este discurso más refulge una contradicción: si el «huso incorrecto» es tan pernicioso, cómo es posible que tras setenta ańos con él España esté en el séptimo puesto mundial en estándar de vida (véase Lim et al. 2016), un puesto inimaginable hace setenta años. No hay mejor forma de señalar lo absurdo que es asociar huso horario a los males de vida.

Algunas personas señalan que el cambio del huso es solo una medida más de las muchas necesarias para mejorar las condiciones de vida, particularmente la conciliación laboral y familiar. Precisamente son esas otras medidas, sin duda de carácter social, las que merecen un análisis y donde debe centrarse la discusión académica, el debate público y la acción política. Es la clase de medidas que permitió la evolución de los estándares de vida en los últimos setenta años. $\mathrm{Ni}$ nuestros males provienen del huso horario ni en su cambio está nuestra redención. Dejen el huso en paz.

\section{Agradecimientos:}

Quiero agradecer y reconocer el buen criterio de Instituto Nacional de Estadística, Istat, UK Data archive, Statistics Canada/Statistique Canada, Bureau of Labor Statistics, Det Nationale Forkskningscenter for Velfærd, Economic and Social Research Institute y L'Institut National de la Statisque et des Études Économiques por facilitar en diversas formas el acceso a los microdatos de las respectivas encuestas de uso del tiempo; acceder a este tipo de datos es fundamental para el avance del conocimiento. También a Statistics Sweden y Statistics Finland por compilar y hacer públicos los datos de la Harmonised European Time Use Survey. 
También doy las gracias al think-tank Politikon, especialmente, a Octavio Medina, por las facilidades que han dado para publicar mis ideas y análisis. A la profesora Carmen Núñez Lozano, catedrática del área de Derecho Administrativo de la Universidad de Huelva, por su ayuda con las referencias legales de este texto. Y a Ana Vega (@biscayenne) por proporcionarme las referencias históricas sobre hábitos de comida.

\section{REFERENCIAS BIBLIOGRÁFICAS}

$A B C$ : «Desde el 1 o de octubre será obligatoria la jornada de ocho horas», $A B C(24 / 09 / 1919)$, pág. 7. (http://bit.ly/2jaJETn).

Banco Mundial: Indicadores, 2016. (http://bit.ly/2mKH2kZ).

BARBERía, José Luis: «España, ¿̇buena para vivir, mala para trabajar?», El País (14/12/2014). (http://bit.ly/135yDtv).

Boletín Oficial de las Cortes Generales: Informe de la Subcomisión creada en el seno de la Comisión de Igualdad para el Estudio de la Racionalización de Horarios, la Conciliación de la Vida Personal, Familiar y Laboral y la Corresponsabilidad, X Legislatura, Serie D, número 330, (28/09/2013). (http://bit.ly/1 mk5OxE).

Bonilla, Rodrigo H.: Spanish daily life, Newson \& Company, 1907. (http://bit.ly/2mocm4H).

Bureau of Labor Statistics: American Time Use Survey, (archivo electrónico), (serie plurianual), 2012.

Chinchilla, Nuria: "Conciliar presupone regresar a Greenwich», en VII Congreso nacional para racionalizar los horarios españoles, Madrid, Arhoe, 2012. (http://bit.ly/1zcPtnW).

Collin, Joseph: «Me pregunté por qué tengo que esperar a las 14 para comer», La Sexta Columna, La Sexta TV, diciembre de 2016. (http://bit.ly/2iGlza1).

Det Nationale Forkskningscenter for Velferd: Danske Tidsanvendelseundersøgelsen, Center for Survey and Survey/Register Data (distribuidor), 2001.

Economic and Social Research Institute: The Irish National Time-Use Survey, (archivo electrónico), Irish Social Science Data Archive (distribuidor).

Fernández-Crehuet, José María: La conciliación de la vida profesional, familiar y personal, Pirámide, 2016.

Hetus (Harmonised European Time Use Survey): Statistics Finland y Statistics Sweden, 2005-2007. (http://www.tus.scb.se).

Hope, Katie: «Sleep deprivation costs UK £40bn a year», BBC News (30/11/2016). (http://bbc.in/2i51T0e).

Institut National de la Statistique et des Études Économiques (INSEE): Enquête Emploi du Temps et Décisions dans les Couples, (archivo electrónico), 2010. 
Instituto Nacional de Estadística: Encuesta de Empleo del Tiempo, (archivo electrónico), 2010.

Ipsos-RSL y Office of National Statistics: United Kingdom Time Use Survey 2000, (archivo electrónico), 3a ed., Colchester, Essex, UK Data Archive (distribuidor), 2003.

Istituto Nazionale di Statistica (ISTAT): Uso del tempo, (archivo electrónico), 2009.

Kelley, Paul: «Spaniards' lack of sleep isn't a cultural thing - they're in the wrong time zone», The Guardian (22/02/2017). (http://bit.ly/2mltLf4).

Kron, Richard: French daily life, Newson \& Company, 1901. (http://bit.ly/2lzIG5d).

Lim, Stephen S. y GDB2015SDB Collaborators: «Measuring the health-related Sustainable Development Goals in 188 countries: a baseline analysis from the Global Burden of Disease Study 2015», The Lancet, 388 (2016), págs. 1831-50.

Llauder, Luis María de: "Una excursión á Andalucía», La Hormiga de Oro (10/07/1886). (http://bit.ly/2950lx4).

Martín Olalla, José María: «¿De verdad duermen poco los españoles (que trabajan)?», Politikon (17/07/2014). (http://bit.ly/ZQ7bOQ).

Martín Olalla, José María: «Así transcurre un día cualquiera en España, Italia, Reino Unido y Estados Unidos», Politikon (29/01/2015). (http://bit.ly/2j8KWOm).

Martín Olalla, José María: «Husos horarios españoles: racionalidad frente a leyenda», en Xornada: É o noso fuso horario un problema?, Santiago de Compostela, Consello da Cultura Galega, 2016a. (http://bit.ly/2jjuht1).

Martín Olalla, José María: «Historia del reloj adelantado en Europa occidental», Politikon (23/11/2016b). (http://bit.ly/2gK1j7N).

Martín Olalla, José María: «Informe de urgencia sobre la salida del trabajo en España», Politikon (14/12/2016c). (http://bit.ly/2likVKO).

Mediavilla, David: «Los humanos modernos no duermen menos que los primitivos», El Pais (15/10/2015). (http://bit.ly/1NeGWWA).

Ministerio de la Gobernación: "Reglamento para la aplicación de la ley de 13 de marzo de 1900 acerca del trabajo de mujeres y niños», Gaceta de Madrid, 319 (15/11/1900), pág. 562. (http://bit.ly/2jnH2oK).

Ministerio de la Gobernación: «Ley referente a la jornada mercantil», Gaceta de Madrid, 186 (05/07/1918), págs. 30-31. (http://bit.ly/2hX9ptV).

Posılıo, Alejandro: «Entrevista a Joseph Collin: El cambio horario afecta más a Galicia que a Cataluña", La Voz de Galicia (21/03/2010a). (http://bit.ly/2jg2wBq).

Posılıo, Alejandro: «Los españoles duermen 53 minutos menos al día que la media europea», La Voz de Galicia (28/09/2010b). (http://bit.ly/2m2GVjT).

SÁnchez SÁnchez, María: «El gráfico que muestra que en España tenemos horarios muy raros», Verne-El Pais (24/03/2016). (http://bit.ly/2hheNTJ).

Statistics Canada/Statistique Canada: General Social Survey, Time Use, Cycle 19, (archivo electrónico), 2005.

Vidales, Raquel: «En España siempre con “Jet Lag”», El País (26/09/2013).

(http://bit.ly/1 nubhVr). 


\section{HUSO HORARIO Y HÁBITOS SOCIALES}

José Fernández-Albertos

CSIC

Doi: 10.17075/enhhp.2017.004 

Todos los intentos de reforma del huso horario, así como los cuestionamientos de la conveniencia de modificar o eliminar el cambio de hora estacional, parten de una premisa fundamental: nuestros hábitos sociales son sensibles a la relación entre hora legal y hora solar. A su vez, buena parte de los argumentos contra estas reformas o al menos escépticos respecto a sus efectos se basan precisamente en el cuestionamiento de esta misma premisa: no, cambiando una convención (porque en eso consiste la reforma del huso horario: en cambiar la hora legal que es en cada momento del día) no se logra que la sociedad se comporte de forma diferente. Con toda la agitación mediática en torno a la petición del cambio de huso horario y el posicionamiento de unos y otros, resulta llamativo la poca atención que ha merecido la evaluación de la validez de este supuesto de partida.

En este trabajo trato de aportar un poco de luz sobre esta cuestión, aprovechando dos hechos: el primero, que disponemos de excelentes encuestas de usos del tiempo que nos permiten saber cómo los individuos distribuyen sus actividades durante el día. Y el segundo y fundamental, que dentro de España existe una considerable variación en la relación entre hora legal y hora solar, consecuencia de que la península y Baleares compartan el mismo huso horario, pese a que existen diferencias considerables en términos de longitud entre territorios: en Maó amanece y anochece aproximadamente una hora antes que en Vigo.

Existen dos hipótesis extremas a la hora de evaluar el efecto de la relación entre hora legal y hora solar en los hábitos sociales. De acuerdo a la hipótesis que podríamos llamar «reglamentista» (en el sentido que confía en la capacidad de las decisiones gubernamentales para cambiar los patrones de vida de los individuos), los comportamientos sociales son perfectamente moldeables mediante el cambio en las convenciones horarias. De acuerdo a la hipótesis «solarista» (en el sentido que da la primacía a la hora solar), los individuos organizan sus actividades únicamente en función de la disponibilidad o no de luz natural en diferentes momentos del día, siendo irrelevante cómo llamemos en términos legales a esos 
momentos. Para los defensores de la primera hipótesis, decidiendo por ejemplo que a las 18 horas sea de noche y a las 7 sea de día, y no al revés, es posible lograr que los individuos cambien sus hábitos: duerman más o menos, tengan jornadas laborales más o menos comprimidas, hagan comidas más o menos frugales, o dediquen más o menos tiempo al cuidado de sus hijos. Para los segundos, que los gobiernos impongan que una hora solar concreta se denomine «las 18 horas» o «las 19 horas» solo hará que al momento en el que realicen determinadas actividades se le asigne un número diferente, pero no afectará a sus hábitos, que seguirán siendo regidos no por esa convención sino por los ritmos marcados por los horarios solares.

Como trataré de mostrar, la evidencia apunta a que la realidad se sitúa en algún punto intermedio entre estas dos hipótesis extremas: por culpa de mecanismos que aquí no podremos entrar a analizar —endencias a la coordinación de actividades en horas focales, peso de la tradiciones y dependencia del pasado (path-dependency)... - , la relación entre hora legal y hora solar sí podría influir algo en cómo los individuos distribuyen las actividades a lo largo del día, y no solo en cómo los individuos llaman al momento en el cual realizan cada actividad. Dicho de otra forma, la relación entre hora legal y hora solar podría tener efectos no solo nominales, sino también reales. Sin embargo, como veremos, la magnitud de estos efectos es muy pequeña, lo que apunta a que la capacidad de los decisores políticos de incidir en las actividades humanas mediante manipulaciones estratégicas de la hora legal es enormemente limitada.

¿Qué implicaciones tiene esto para el debate en torno a la propuesta de que la península y Baleares adopten el huso horario GMT (el que ahora usan Gran Bretaña, Portugal o las Islas Canarias)? Es evidentemente presuntuoso pretender que un análisis como este aspirara a cerrar esta cuestión, pero en la sección final trato de hacer una lectura de los principales resultados y vincularlos a este debate, haciendo explícitos todos los supuestos que se tendrían que cumplir para que fuera recomendable tomar la decisión de alterar nuestro huso horario.

El resto del capítulo se estructura de la siguiente forma. Primero presento muy brevemente la naturaleza de los datos y la estrategia de investigación que uso para extraer conclusiones sobre el efecto de la relación entre hora solar y legal en los hábitos sociales. A continuación, se muestran una serie de resultados sobre los efectos de la posición geográfica en dos aspectos: las horas de sueño y el 
tiempo de calidad dedicado por las familias a los hijos en edad escolar. La última sección ofrece una reflexión general sobre las implicaciones de estos resultados para el debate sobre el cambio de huso horario.

\section{DESCRIPCIÓN DE LOS DATOS Y ESTRATEGIA DE INVESTIGACIÓN}

Los datos de distribución de hábitos sociales durante el día proceden de la mejor fuente que tenemos a nuestra disposición: la Encuesta de Empleo del Tiempo llevada a cabo por el Instituto Nacional de Estadística entre octubre de 2009 y septiembre de 2010. Es una encuesta diseñada de forma coordinada con otros países europeos, que se realiza siguiendo las directrices publicadas por Eurostat (2008) en Harmonised European Time Use Surveys, y que, tanto por su tamaño (se entrevistan a los residentes en 11538 viviendas) como por el diseño del cuestionario y sobre todo el delicado procedimiento de recogida de datos, permite acceder a una información incomparable a cualquier otra fuente estadística.

La encuesta codifica, usando una tipología que incluye 116 tipos de actividades diferentes, lo que está haciendo cada miembro del hogar de más de 10 años en cada uno de los 144 intervalos de 10 minutos en los que se divide un día de 24 horas. Aquí mostraré solo información respecto a algunos tipos de actividades, que son centrales en los debates sobre la supuestamente «anormal» distribución del tiempo que se hace en España: el tiempo dedicado al sueño (se argumenta con insistencia, aunque con pocos datos comparados, que los españoles dormimos poco por culpa de nuestro huso horario), la jornada laboral y el tiempo de calidad dedicado a los niños del hogar (se repite también que las largas jornadas laborales asociadas a tener un huso horario «adelantado» provocan que padres y madres tengan poco tiempo para atender a los menores).

Como se mencionaba más arriba, para examinar si la relación entre la hora legal y la hora solar tiene efectos en la distribución de tiempo en esos dos tipos de actividades, exploto la notable variación de longitud que hay dentro de España. A pesar de que la cantidad de horas de sol en un determinado momento del año es prácticamente la misma entre los territorios situados más al este y más al oeste, es posible analizar si aquellos individuos que residen más al este, donde amanece y anochece «antes» en términos de hora legal, hacen 
las cosas de forma diferente: ¿duermen más o menos horas?, ¿atienden más o menos tiempo a sus hijos? Recuérdese que, para que el argumento de los que defienden que el cambio de huso sea válido, es condición necesaria (aunque no suficiente) que los hogares no solo hagan las cosas en diferentes momentos de acuerdo a la hora legal, sino que la distribución de actividades a lo largo del día sea en términos agregados diferente. Dicho de otra forma, si todo lo que revelan los datos es que los individuos que residen en el este se levantan antes, comen antes, salen del trabajo antes y se van a dormir antes (siempre en términos de «hora legal») que los que viven en el oeste, sería la postura "solarista» extrema la que quedaría validada. Para avalar la premisa de los defensores del cambio de huso, es necesario mostrar, además, que los hogares más penalizados por nuestro huso (según su argumento, los que viven en regiones más al oeste) distribuyen peor las actividades que los hogares que viven en zonas donde nuestro huso no está tan adelantado, y sería por lo tanto menos problemático (los residentes en las zonas más al este).

En la sección siguiente se presentan dos tipos de análisis. Por un lado, de manera eminentemente descriptiva, se muestran una serie de gráficos bivariados que ponen en relación la posición geográfica de la comunidad autónoma (la unidad de análisis en estos gráficos) en términos de longitud ${ }^{1}$ (nuestra variable-indicador del «desfase» entre hora legal y hora solar) y la hora «legal» media a la que se realizan determinadas actividades. Evidentemente estas correlaciones solo sirven para sugerir algunas posibles tendencias. Más relevantes son los resultados de una serie de modelos de regresión multinivel en los que la cantidad de tiempo que los individuos dedican a ciertas actividades, medidas en unidades de 10 minutos, es explicada por un conjunto de características del entrevistado (sexo, edad, ingresos del hogar, tipo de municipio en el que reside...), pero también por una variable que toma un valor determinado para todos los entrevistados de la misma comunidad autónoma, y que es la variable central para nuestro análisis: la posición geográfica del lugar de residencia del

${ }^{1}$ Idealmente, los datos de longitud se deberían referir a la posición media, ponderada por población, de cada comunidad autónoma. Sin embargo, estos datos no están disponibles y no resulta fácil calcularlos, por lo que se han usado las coordenadas de longitud de la capital de cada comunidad autónoma. Esto no es muy problemático porque, quizá con la excepción de Andalucía, las capitales suelen ubicarse en una posición central dentro de su comunidad autónoma en el eje este-oeste y porque en las capitales reside una parte desproporcionalmente grande de la población de cada comunidad. 
entrevistado ${ }^{2}$. La inclusión de variables «de control» en los modelos nos permite descartar el hecho de que la razón por la cual la posición geográfica esté relacionada con la distribución de actividades se deba a la diferente composición social de los grupos de encuestados de cada comunidad autónoma. La interpretación de los modelos es relativamente sencilla: si el coeficiente asociado a una variable es estadísticamente significativo, un cambio de una unidad en esa variable (en el caso de nuestra variable principal de interés, un cambio de un grado hacia el este ${ }^{3}$ ) está asociado a un cambio de la magnitud indicada por el coeficiente en la variable dependiente que, recordemos, está medida en bloques de tiempo de diez minutos de duración.

\section{RESULTADOS}

Antes de analizar la distribución de tareas durante el día, empecemos analizando si existen diferencias entre la hora de levantarse y de acostarse de los españoles en función de su lugar de residencia. Los gráficos 1 y 2 muestran la hora media a la que se realizan estas dos actividades, representadas en los ejes verticales de cada gráfico, así como la posición geográfica de cada comunidad autónoma (nuestro indicador de la distancia entre hora solar y hora legal), representada en el eje horizontal.

\footnotetext{
${ }^{2}$ Estos modelos, conocidos como modelos con efectos aleatorios (asumen que cada comunidad autónoma tiene un nivel medio a partir del cual oscilan sus propios individuos, y este nivel medio depende de variables que cambian solo entre comunidades autónomas -en este caso, la posición geográfica), se estiman por máxima verosimilitud. Los errores típicos de las estimaciones se calculan teniendo en cuenta esta estructura multinivel de los datos (son «clustered» por comunidad autónoma).

${ }^{3}$ Esta variable está medida en grados respecto al meridiano de Greenwich, con lo que oscila entre el valor mínimo de Galicia $(-8,57)$ y el máximo de lslas Baleares $(2,65)$. Para que en todas las observaciones este valor refleje la distancia entre la hora legal y la hora solar, el valor de Canarias ha sido ajustado 15 grados para reflejar el hecho de que tiene otro huso horario.
} 
Gráfico 1. Hora media de levantarse y posición geográfica

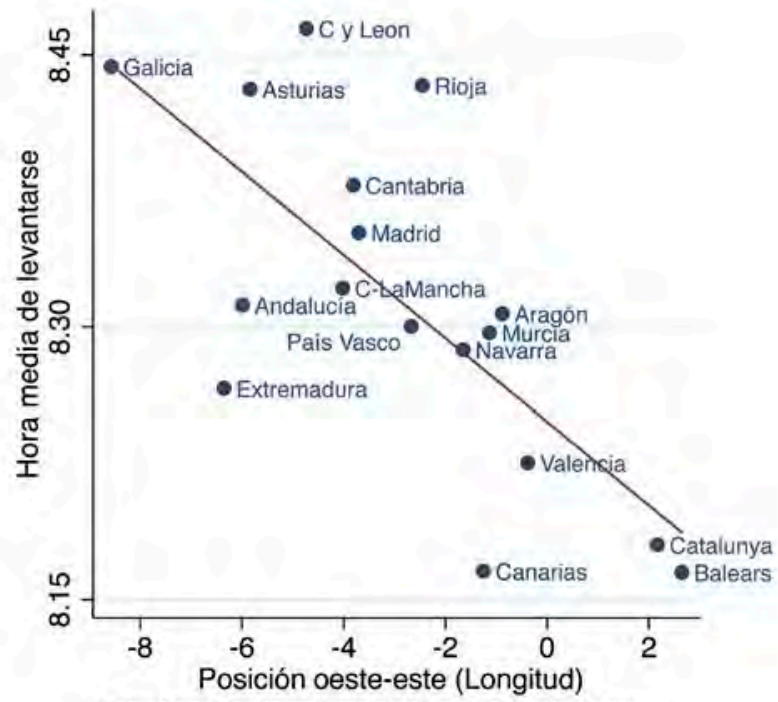

Nota: Canarias ha sido resituada en $15^{\circ}$ hacia el este porque está en otro huso horario.

Se toma como referencia la capital de cada CCAA.

Gráfico 2. Hora media de acostarse y posición geográfica

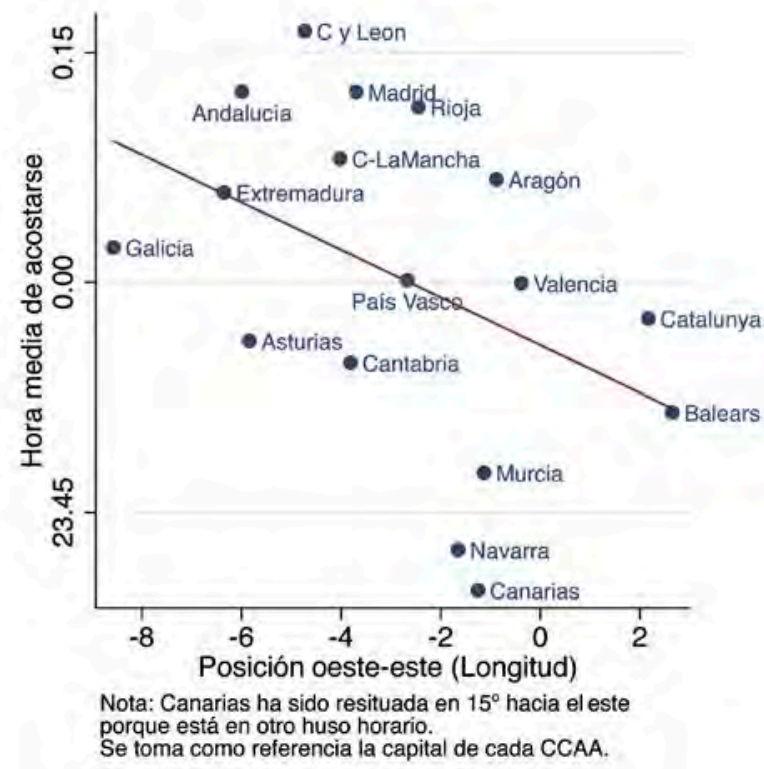


Como es esperable, los dos gráficos muestran una cierta correlación entre la posición geográfica de los entrevistados y la hora media a la que se levantan y acuestan. En términos de hora oficial, los catalanes y baleares se levantan por la mañana casi media hora antes que los gallegos, y se van a dormir por la noche aproximadamente un cuarto de hora antes. Los gráficos reflejan tres cosas más: primero, que lejos de ser una relación perfecta, parece que existe una considerable variación en la hora media de levantarse y acostarse entre territorios no asociada, al menos aparentemente, a la posición geográfica de cada uno de ellos. La segunda, que la relación es más fuerte en el primer caso que en el segundo: la salida del sol parece determinar más la hora de levantarse de los individuos que la puesta de sol la hora de irse a dormir. Y la tercera, que la magnitud de estas diferencias en hábitos sociales es significativamente menor a las diferencias en términos de exposición a la luz solar marcadas por la geografía (mientras que el amanecer en Baleares ocurre aproximadamente una hora antes que en Galicia, los gallegos se levantan solo media hora después que los baleares). Esto parece consistente parcialmente con las dos hipótesis delineadas anteriormente: ni los individuos se fijan solo en la hora legal a la hora de organizar sus actividades (si así fuera, no deberíamos observar diferencia alguna en la hora de levantarse y de acostarse entre comunidades autónomas), ni la exposición a la luz solar parece determinar completamente los hábitos sociales (parece existir una tendencia a coordinar la hora a la que realizamos ciertas actividades, lo que hace que nos levantemos y acostemos de forma más coordinada a lo que marca la rotación de la tierra).

Fijémonos a continuación en otro indicador, quizá más interesante para medir la calidad de la distribución del tiempo por los individuos y que se ha relacionado con nuestro huso horario: las horas de entrada y salida del trabajo de las personas con menores en el hogar. Si, como se dice, nuestro huso horario dificulta la conciliación, deberíamos esperar que aquellos individuos que viven en lugares donde el desfase de nuestro huso es mayor dispongan de menos tiempo después de trabajar para atender sus obligaciones familiares. El panel izquierdo del gráfico 3 muestra la hora de entrada media (aunque la moda de la distribución está en las 8 de la mañana, el hecho de que una parte pequeña pero no despreciable de la población tenga jornadas vespertinas hace que la hora media de entrada sea muy alta) y el de la derecha, la hora de salida, siempre en relación con la posición geográfica de la comunidad autónoma. 
Gráfico 3. Hora media de entrada y salida del trabajo por comunidad autónoma para personas con un menor en el hogar, en días laborables
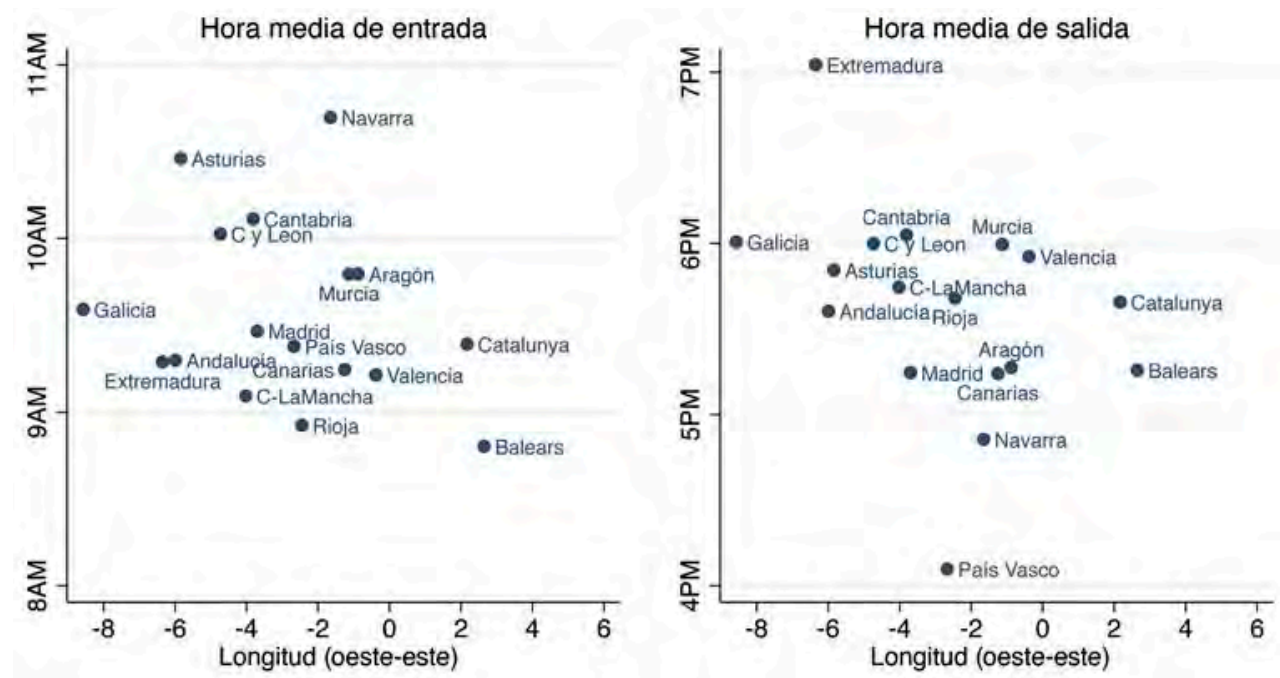

A diferencia de lo que ocurría con la hora de levantarse y acostarse, ahora la posición geográfica parece estar más relacionada con la hora (legal) de salir del trabajo que con la hora de entrada. Los trabajadores que tienen que atender a niños en el hogar acaban antes su jornada laboral cuanto más al este está su comunidad autónoma de residencia. La magnitud de la diferencia es aproximadamente de una hora entre la comunidad autónoma más al este y la más al oeste (aproximadamente la misma diferencia que hay en tiempo de salida y puesta del sol entre ellas). La tabla 1 presenta una forma más rigurosa de examinar la relación entre longitud y las horas de entrada y salida: dos modelos de regresión como los descritos en la sección anterior, en los que las variables dependientes son el momento (medido en intervalos de 10 minutos) de entrada al trabajo de los encuestados con empleo y con menores en el hogar durante un día de lunes a viernes. Los modelos controlan por el nivel de ingresos del hogar, el sexo del entrevistado, la edad, la edad al cuadrado (esta variable es previsible que tenga un efecto no lineal en la jornada de trabajo), si nació en España o no, el nivel educativo, el tamaño del municipio y el trimestre del año en el que se realizó la entrevista. Más allá del efecto individual de estas variables en cada modelo, lo 
relevante para nuestros propósitos es comprobar si el efecto de la longitud sobrevive tras tener en cuenta todos estos factores. Para la hora de entrada al trabajo, la longitud no tiene efecto significativo alguno (el coeficiente es indistinguible de cero). Para la hora de salida, en cambio, sí hay un cierto efecto y en la dirección esperada: por cada grado de longitud más al este, la hora de salida del trabajo se reduce en torno a 6 minutos. De nuevo, esto corresponde, aproximadamente, al tiempo que tarda el sol en ponerse por cada grado que nos movemos hacia el oeste, lo que indica que, a la hora de salir del trabajo, las madres y padres con hijos responden, en media, a una lógica casi exclusivamente «solarista».

Tabla 1. Determinantes de la hora de entrada y salida del trabajo de individuos que conviven con menores, entre lunes y viernes

\begin{tabular}{|l|c|c|} 
& $(1)$ & $(2)$ \\
Longitud & Hora de entrada & Hora de salida \\
Ingresos del hogar & -0.30 & $-0.62^{* *}$ \\
& $(0.27)$ & $(0.30)$ \\
Mujer & -1.02 & 0.29 \\
& $(1.03)$ & $(0.99)$ \\
Edad & $3.27^{* *}$ & $-8.58^{* *}$ \\
& $(1.44)$ & $(1.36)$ \\
Edad^2 & -1.24 & $-1.75^{* *}$ \\
& $(0.82)$ & $(0.79)$ \\
Nativo & 0.016 & $0.022^{* *}$ \\
Educación secundaria & $(0.010)$ & $(0.010)$ \\
Educación terciaria & -2.41 & -2.81 \\
N & $(2.09)$ & $(1.96)$ \\
& $4.25^{* *}$ & 1.88 \\
& $(2.16)$ & $(2.05)$ \\
& -0.71 & 2.97 \\
& $(2.59)$ & $(2.50)$ \\
& 955 & 976 \\
& &
\end{tabular}

Los modelos incluyen controles también por tamaño de municipio y trimestre del año en el que se realizó la entrevista. Errores típicos entre paréntesis. ${ }^{*} \mathrm{p}<0.10,{ }^{* *} \mathrm{p}<0.05$. 
¿En qué medida se traduce este adelanto en la salida del trabajo en diferentes empleos del tiempo durante la tarde? Si uno de los caballos de batalla de los defensores del cambio de huso horario es la mayor facilidad que tendrían los individuos de conciliar sus obligaciones laborales con las familiares, una posible hipótesis sería que aquellos individuos más negativamente afectados por el huso adelantado (aquellos que residen en lugares más al oeste), al tener jornadas laborales que se extienden algo más por la tarde, disponen de menos tiempo para dedicarlo de forma intensa a los menores que residen con ellos. Nótese que, para que la propuesta de cambio de huso tenga sentido, es preciso que el desplazamiento de actividades producido por la diferente hora solar entre territorios no sea homogénea, es decir, que no provoque un desplazamiento de todas las actividades en la misma magnitud. En los datos que hemos presentado hay algo de evidencia que apunta en esta dirección: la relación entre hora legal y hora solar parece cambiar el momento en el cual los padres y madres salen del trabajo, pero no la hora a la que entran, y no tanto la hora a la que se van a dormir.

En el siguiente análisis nos fijamos en la cantidad total de tiempo, siempre medido en intervalos de 10 minutos, que los individuos que trabajan y que conviven con menores ${ }^{4}$ dedican a diferentes tipos de actividades. La extraordinariamente rica codificación de los diferentes usos posibles del tiempo que ofrece la encuesta permite hacer este análisis. En la primera columna se presenta un modelo explicativo del tiempo total dedicado a cuidado de niños. En la segunda columna de la tabla se usa otra variable dependiente más precisa, el tiempo dedicado a «enseñar, leer, jugar, hablar o conversar con los niños». Es por tanto un indicador mejor del tiempo de calidad dedicado a los niños. Los modelos presentados en la tercera y cuarta columna de la tabla tratan de explicar, respectivamente, el tiempo dedicado a actividades de ocio (que incluye los epígrafes de «vida social y diversión» $\mathrm{y}$ «deportes y actividades al aire libre») y tiempo dedicado a actividades sociales participativas.

4 De nuevo, nos centramos en esta submuestra de entrevistados porque son ellos, de acuerdo a defensores del cambio a la hora de Greenwich, los más supuestamente penalizados por nuestro huso adelantado actual. 
Tabla 2. Determinantes del tiempo dedicado por individuos que conviven con menores y que trabajan a diferentes actividades

\begin{tabular}{|c|c|c|c|c|}
\hline & (1) & (2) & (3) & (4) \\
\hline & Tiempo & Tiempo & Tiempo & Tiempo \\
\hline & con niños & educando & de ocio & participac. \\
\hline \multirow[t]{2}{*}{ Longitud } & 0.078 & $0.086^{* *}$ & -0.11 & $-0.044^{*}$ \\
\hline & $(0.088)$ & $(0.043)$ & $(0.079)$ & $(0.023)$ \\
\hline \multirow[t]{2}{*}{ Ingresos del hogar } & $0.59^{*}$ & $0.31^{*}$ & 0.19 & $-0.20^{* *}$ \\
\hline & $(0.31)$ & $(0.16)$ & $(0.25)$ & $(0.10)$ \\
\hline \multirow[t]{2}{*}{ Mujer } & $3.11^{* *}$ & 0.050 & -0.023 & -0.078 \\
\hline & $(0.44)$ & $(0.23)$ & $(0.35)$ & $(0.14)$ \\
\hline \multirow[t]{2}{*}{ Edad } & $0.64^{* *}$ & $0.42^{* *}$ & -0.080 & $-0.28^{* *}$ \\
\hline & $(0.24)$ & $(0.12)$ & $(0.19)$ & $(0.077)$ \\
\hline \multirow[t]{2}{*}{$\operatorname{Edad}^{\wedge} 2$} & $-0.011^{* *}$ & $-0.0058^{* *}$ & 0.0010 & $0.0035^{* *}$ \\
\hline & $(0.0030)$ & $(0.0016)$ & $(0.0024)$ & $(0.00098)$ \\
\hline \multirow[t]{2}{*}{ Nativo } & $1.45^{* *}$ & 0.058 & 0.57 & $0.36^{*}$ \\
\hline & $(0.63)$ & $(0.33)$ & $(0.51)$ & $(0.21)$ \\
\hline \multirow[t]{2}{*}{ Educación secundaria } & 0.85 & 0.090 & -0.0056 & -0.17 \\
\hline & $(0.66)$ & $(0.35)$ & $(0.53)$ & $(0.22)$ \\
\hline \multirow[t]{2}{*}{ Educación terciaria } & $2.93^{* *}$ & 0.49 & -0.070 & 0.0067 \\
\hline & $(0.79)$ & $(0.41)$ & $(0.63)$ & $(0.26)$ \\
\hline \multirow[t]{2}{*}{ Fin de Semana } & $1.95^{* *}$ & $1.33^{* *}$ & $3.90^{* *}$ & $0.29^{* *}$ \\
\hline & $(0.43)$ & $(0.23)$ & $(0.35)$ & $(0.14)$ \\
\hline$N$ & 1795 & 1795 & 1795 & 1795 \\
\hline
\end{tabular}

Los modelos incluyen controles también por tamaño de municipio y trimestre del año en el que se realizó la entrevista. Errores típicos entre paréntesis. ${ }^{*} \mathrm{p}<0.10,{ }^{* *} \mathrm{p}<0.05$.

Después de descontar el efecto de las variables individuales incluidas en los modelos (edad, sexo, nivel de ingresos del hogar, nivel educativo, tipo de municipio y el trimestre del año en que se realizó la entrevista), la variación en el desfase entre hora legal y hora solar medido por la posición geográfica parece afectar al tiempo total dedicado a educar a los niños (cuanto más al este, más tiempo) y a las actividades participativas (cuanto más al este, menos tiempo). En principio, 
esto podría dar argumentos a los defensores del cambio de hora: de acuerdo al valor del coeficiente mostrado en la segunda columna, vivir en comunidades autónomas donde el sol se pone en términos de hora legal una hora antes hace que los padres y madres dediquen en media unos nueve minutos más de calidad al día a los niños que viven con ellos. Curiosamente, el efecto de la longitud en el total de tiempo pasado con los niños (primera columna) no es estadísticamente significativo, como tampoco lo es en el tiempo dedicado al ocio.

¿Tiene que ver esta mayor dedicación en tiempo de calidad dedicado a los niños con el hecho de que, como vimos antes, en las comunidades autónomas situadas más al este, las madres y padres salen algo antes del trabajo? En la tabla 2 se puede comprobar cómo un poderoso determinante de la cantidad de tiempo dedicado a todas las actividades analizadas es, evidentemente, si se trata de un día de fin de semana o no. Si el argumento de los que defienden el cambio de huso horario fuera cierto (el cambio supuestamente fomentaría una mayor concentración de las jornadas laborales, lo que permitiría disponer de más tiempo por la tarde para dedicarlo a la familia), deberíamos esperar que las leves «ventajas» detectadas en el segundo modelo de la tabla 2 se concentraran en los días laborables. Esto es precisamente lo que se pone a prueba en los análisis de la tabla 3, donde se presentan las mismas estimaciones que en los modelos segundo y cuarto de la tabla anterior (los únicos en los que la longitud de la comunidad autónoma de residencia tiene un efecto estadísticamente significativo), pero diferenciando entre aquellos entrevistados que reportan la distribución de actividades de un día entre lunes y viernes, y aquellos que reportan la de un día de fin de semana.

Quizás sorprendentemente, lo que muestran las dos primeras columnas es que el efecto de la posición geográfica en la distribución del tiempo de calidad dedicado a los niños se produce exclusivamente durante los fines de semana, mientras que es totalmente inexistente entre lunes y viernes. El gráfico 4 toma los resultados de estas dos estimaciones y representa el tiempo predicho de dedicación media a los niños en función del día de la semana y de la posición geográfica del entrevistado. Como se puede apreciar, mientras que en los fines de semana la posición geográfica sí parece asociada a una mayor cantidad de tiempo dedicada a leer y educar a los niños (como de un cuarto de hora más en las comunidades más orientales respecto a las más occidentales), de lunes a viernes no existe diferencia alguna. No parece, por tanto, que sea el diferente horario laboral causado por el 
Tabla 3. Determinantes del tiempo dedicado por individuos que conviven con menores y que trabajan a leer y educar a los niños y al ocio por día de la semana

\begin{tabular}{|c|c|c|c|c|}
\hline & (1) & (2) & (3) & (4) \\
\hline & Tiempo & Tiempo & Tiempo de & Tiempo de \\
\hline & educando & educando & act. part. & act. part. \\
\hline & Fin de semana & Día laborable & Fin de semana & Día laborable \\
\hline \multirow[t]{2}{*}{ Longitud } & $0.19^{*}$ & 0.0060 & $-0.077^{*}$ & -0.025 \\
\hline & $(0.10)$ & $(0.037)$ & $(0.041)$ & $(0.029)$ \\
\hline \multirow[t]{2}{*}{ Ingresos del hogar } & 0.49 & 0.23 & -0.16 & $-0.24^{* *}$ \\
\hline & $(0.33)$ & $(0.16)$ & $(0.18)$ & $(0.12)$ \\
\hline \multirow[t]{2}{*}{ Mujer } & -0.40 & 0.34 & -0.091 & -0.059 \\
\hline & $(0.46)$ & $(0.23)$ & $(0.26)$ & $(0.17)$ \\
\hline \multirow[t]{2}{*}{ Edad } & $0.46^{*}$ & $0.37^{* *}$ & $-0.31^{* *}$ & $-0.23^{* *}$ \\
\hline & $(0.23)$ & $(0.13)$ & $(0.13)$ & $(0.094)$ \\
\hline \multirow[t]{2}{*}{$\operatorname{Edad}^{\wedge} 2$} & $-0.0062^{* *}$ & $-0.0052^{* *}$ & $0.0044^{* *}$ & $0.0026^{* *}$ \\
\hline & $(0.0029)$ & $(0.0016)$ & $(0.0016)$ & $(0.0012)$ \\
\hline \multirow[t]{2}{*}{ Nativo } & -0.36 & 0.31 & -0.20 & $0.68^{* *}$ \\
\hline & $(0.69)$ & $(0.33)$ & $(0.38)$ & $(0.24)$ \\
\hline \multirow[t]{2}{*}{ Educación secundaria } & -0.21 & 0.18 & 0.15 & -0.37 \\
\hline & $(0.73)$ & $(0.34)$ & $(0.40)$ & $(0.25)$ \\
\hline \multirow[t]{2}{*}{ Educación terciaria } & 0.35 & 0.48 & 0.34 & -0.16 \\
\hline & $(0.84)$ & $(0.41)$ & $(0.47)$ & $(0.30)$ \\
\hline$N$ & 687 & 1108 & 687 & 1108 \\
\hline
\end{tabular}

Los modelos incluyen controles también por tamaño de municipio y trimestre del año en el que se realizó la entrevista. Errores típicos entre paréntesis. ${ }^{*} \mathrm{p}<0.10,{ }^{* *} \mathrm{p}<0.05$.

menor desfase entre hora legal y hora solar lo que explique esta pequeña diferencia detectada en el uso del tiempo con los menores. Por su parte, la variación (aún menor, y estimada con menor precisión) en el tiempo dedicado a las actividades participativas también parece solo deberse a los diferentes hábitos en los fines de semana. 
Gráfico 4. Tiempo estimado dedicado a leer y educar a los niños en individuos que trabajan y que conviven con menores, con intervalos de confianza al $95 \%$. Estimaciones realizadas a partir de los coeficientes de los modelos presentados en la tabla 3

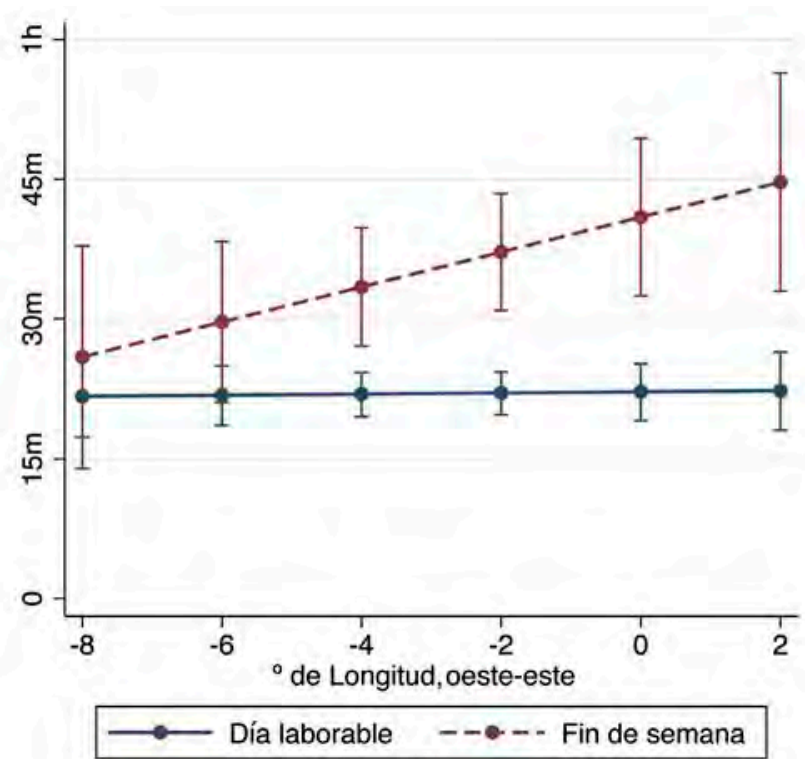

\section{REFLEXIONES FINALES}

¿Qué conclusiones podemos sacar de este análisis sobre cómo varía el uso del tiempo en función de la magnitud del desfase entre hora solar y legal? ¿Los individuos que sufren un desfase mayor al estar situados más al oeste, distribuyen su tiempo peor? Nótese que cualquier hipótesis sobre la deseabilidad del cambio de huso horario ha de estar fundamentada en esto: no en que pasemos a despertarnos, comer o cenar a una hora legal determinada (eso en sí no es ni bueno ni malo), sino en que la distribución total de actividades durante el día sea mejor.

Los resultados apuntan a que, cuando analizamos las diferencias entre individuos que viven más al este y más al oeste, sí existen algunos cambios en cómo se distribuyen las actividades. Los individuos más al oeste no solo «desplazan» actividades en función de la disponibilidad de luz solar. Así, por ejemplo, salen más 
tarde del trabajo, aunque no entran significativamente más tarde. Sin embargo, cuando analizamos diferentes dimensiones de la conciliación entre vida laboral y personal, solo encontramos una leve diferencia en la cantidad de tiempo dedicada a educar y leer a los nińos: en aquellos lugares donde el desfase entre hora solar y hora legal es mayor, los individuos que residen con niños emplean menos tiempo en estas actividades. Pero un análisis más refinado de los datos revela que esta diferencia no es consecuencia de los diferentes horarios laborales, puesto que se produce exclusivamente durante los fines de semana.

¿Qué lectura podemos extraer de estos datos de cara al debate sobre el cambio de huso horario? En primer lugar, el hecho de que haya algo de evidencia que muestre que los individuos no solo desplazan automáticamente actividades en función de la disponibilidad de luz solar permite hipotetizar que gracias a ciertas manipulaciones de la hora legal se podrían alcanzar distintos equilibrios sociales respecto a cómo los individuos y los hogares usan el tiempo. Sin embargo, explotando la notable diferencia de desfase entre hora legal y hora solar entre territorios dentro de España, vemos que las diferencias en hábitos sociales son muy pequeńas y que no parecen deberse a algunos de los mecanismos sugeridos por los defensores del cambio (en concreto, el mayor tiempo de calidad dedicado a los niños en las comunidades autónomas más al este no parece estar conectado a una mejor conciliación de los horarios laborales con las obligaciones familiares en estos lugares). En definitiva, los datos presentados aquí se antojan muy insuficientes para avalar la necesidad de un cambio de huso horario. A mi juicio, para justificar tal cambio, sería necesario disponer de evidencia mucho más contundente que de la que disponemos hasta ahora respecto a dos cuestiones fundamentales. En primer lugar, ¿es saludable siempre forzar la compactación de la jornada laboral asimilándonos a países septentrionales donde el día invernal es mucho más corto y por consiguiente están obligados a ello?, ¿es mejor que sean frugales las cenas y no los almuerzos? En segundo lugar y quizá más importante, ¿es posible hacerlo en un país tan septentrional como el nuestro? Podemos intuir, a partir de la evidencia presentada aquí, que un primer efecto del cambio de huso sería el adelantamiento de la hora legal de salida en algunos trabajos. Pero también sabemos que el inicio de la jornada es muy sensible a la disponibilidad de luz solar, por lo que cabría preguntarse cómo esos individuos ocuparían ese tiempo adicional ganado por 
la mañana (previsiblemente, desearían entrar a trabajar antes, cancelando los supuestamente efectos saludables en términos de compactación de la jornada de trabajo). En ausencia de respuestas claras a estas preguntas y a la vista de la revisión de la evidencia presentada aquí, existen pocos motivos para hoy estar convencido de que un cambio de huso horario tendría consecuencias beneficiosas para nuestra sociedad. 
CURRÍCULOS 



\section{José Fernández-Albertos (j.f.albertos@csic.es)}

Científico Titular en el Instituto de Políticas y Bienes Públicos del Consejo Superior de Investigaciones Científicas (CSIC). Es licenciado por la Universidad Complutense, doctor en Ciencia Política por la Universidad de Harvard y doctor-miembro del Instituto Juan March. Desarrolla su investigación en la intersección de las áreas de la sociología política, la política comparada y la economía política internacional. Algunos de sus temas de interés son el estudio de las actitudes de los actores políticos y de la opinión pública hacia la integración económica y política, las instituciones macroeconómicas, las preferencias por la redistribución y el estado del bienestar, y los efectos políticos y electorales de las crisis económicas en las sociedades contemporáneas. Ha impartido docencia en el Institut Barcelona d'Estudis Internacionals (IBEI), la Universitat Pompeu Fabra y el Instituto de Empresa. Sus trabajos han sido publicados en Annual Review of Political Science, Comparative Political Studies, International Studies Quarterly, Party Politics, Economics Letters, entre otros. Escribe de manera regular en el blog Piedras de Papel, en www.eldiario.es.

Más información sobre su trabajo se puede encontrar en www.sites.google. com/site/jfalbertos/.

José María Fernández-Crehuet (josemaria.fernandez-crehuet@upm.es)

Profesor de Economía e Innovación en la Universidad Politécnica de Madrid. Doctor internacional por la Universidad Rey Juan Carlos en Economía y Empresa. También es profesor visitante en la Universidad de Oxford y London School of Economics, PDD Management Development Program IESE Business School, delegado internacional de la Comisión Nacional para la Racionalización de los Horarios Españoles (ARHOE), consultor científico y académico del Instituto 
Internacional de Ciencias Políticas (IICP), miembro de la International Association for Time Use Research (IATUR) y del consejo asesor del Instituto Español de Resiliencia (IER). Experto en conciliación y corresponsabilidad. Autor del libro La conciliación de la vida profesional, familiar y personal: España en el contexto europeo (Ediciones Pirámide) y de numerosas publicaciones científicas. Premio Nacional Alares. Modalidad Profesores e Investigadores. Divulgador científico en prensa, radio y televisión.

\section{José María Martín Olalla (olalla@us.es)}

Doctor en Ciencias Físicas por la Universidad de Sevilla (1997) y profesor titular de Universidad del Área de Física de la Materia Condensada (2002) de la misma Universidad. Ha estudiado el comportamiento de trabajadores de algunos países de Europa y América a través de Encuestas de Uso del Tiempo, haciendo especial énfasis en relacionar los usos sociales con las condiciones de luz ambiental. Sus análisis pueden leerse en http://www.politikon.es/horarios y en arXiv.org.

\section{Jorge Mira Pérez (jorge.mira@usc.es)}

Físico, catedrático del Departamento de Física Aplicada de la Universidade de Santiago de Compostela (USC).

Autor de más de un centenar de publicaciones en física de materiales, nanotecnología, imagen médica y modelización matemática de sistemas sociales. Entre otros reconocimientos ha sido finalista del Premio 'Investigador Novel' de la Real Sociedad Española de Física, Premio de la Real Academia Galega de Ciencias, del Colegio Oficial de Físicos de España y Premio de la Crítica Galicia Investigación.

Director del Departamento de Física Aplicada de la USC (2006-2014), director del Programa ConCiencia (visitas de Premios Nobel a Galicia) y director de la colección de divulgación científica de la editorial de la USC. Miembro del Consello da Cultura Galega y académico correspondiente de la Real Academia Galega. 
Colaborador de programas de la Televisión y la Radio Autonómica de Galicia, de TVE-Galicia, RNE-Radio Clásica, Onda Regional Murcia y del diario La Voz de Galicia. Por su actividad divulgativa ha sido reconocido, entre otros, con el Premio 'Física en Acción', la Medalla de Honor 'Ciencia en Acción', el Premio 'José María Savirón' y el Premio de la Real Sociedad Española de Física - modalidad de Enseńanza y Divulgación de la Física. 

